Portland State University

PDXScholar

$11-18-1981$

\title{
Chemistry of Chromium Oxyfluorides and Group VIB Perfluoroglutarates
}

Bruce Michael Johnson

Portland State University

Follow this and additional works at: https://pdxscholar.library.pdx.edu/open_access_etds

Part of the Inorganic Chemistry Commons, and the Polymer Chemistry Commons Let us know how access to this document benefits you.

\section{Recommended Citation}

Johnson, Bruce Michael, "Chemistry of Chromium Oxyfluorides and Group VIB Perfluoroglutarates" (1981). Dissertations and Theses. Paper 3096.

https://doi.org/10.15760/etd.3091

This Thesis is brought to you for free and open access. It has been accepted for inclusion in Dissertations and Theses by an authorized administrator of PDXScholar. Please contact us if we can make this document more accessible: pdxscholar@pdx.edu. 
AN ABSTRACT OF THE THESIS OF Bruce Michael Johnson for the Master of Science in Chemistry presented November 18, 1981.

Title: Chemistry of Chromium Oxyfluorides and Group VIB Perfluoroglutarates.

APPROVED BY MEMBERS OF THE THESIS COMMITTEE:
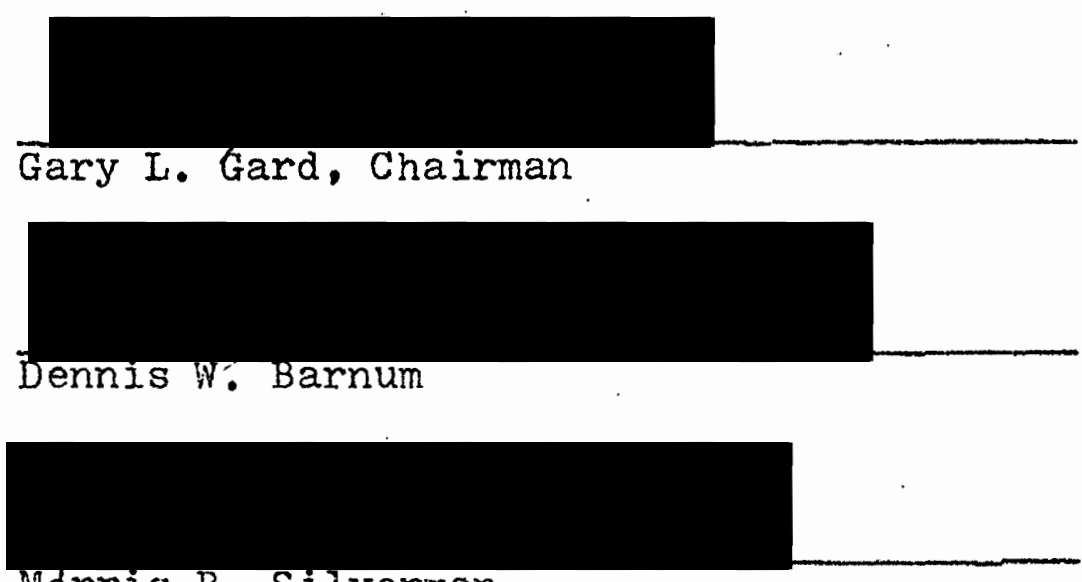

Morris B. Silverman

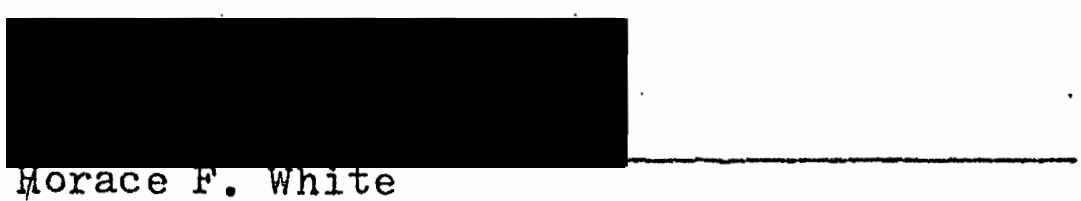

Pure chromium oxide trifluoride was prepared for the first time by reaction of $\mathrm{CrO}_{3}$ and $\mathrm{ClF}$, with subsequent multiple fluorine treatments at $120^{\circ} \mathrm{C}$. On the basis of. its infrared spectrum, the purple $\mathrm{CrOF}_{3}$ was assigned as a fluorinebridged polymer with terminal oxygen groups. Chromium oxide trifluoride was found to be stable to $300^{\circ} \mathrm{C}$, where it decomposes with the loss of oxygen to $\mathrm{CrF}_{3}$. 
A limited study of the reaction chemistry of $\mathrm{CrOF}_{3}$ was carried out. With the Lewis bases, $\mathrm{KF}$ and $\mathrm{NO}_{2} \mathrm{~F}, \mathrm{CrOF}_{3}$ was found to form $1: 1$ adducts. The $x$-ray powder pattern of the $\mathrm{KF}$ adduct matched literature values for $\mathrm{KCrOF}_{4}$. Infrared spectral data for $\mathrm{KCrOF}_{4}$ indicates a square pyramidal structure ( $\mathrm{C}_{4 \mathrm{v}}$ symmetry) for the $\mathrm{CrOF}_{4}^{-}$anion. Infrared spectral data for $\mathrm{NO}_{2} \mathrm{CrOF}_{4}$ shows that the tan solid has linear ONO cations and $\mathrm{CrOF}_{4}^{-}$anions, with $\mathrm{C}_{4 \mathrm{v}}$ symmetry.

Reaction of $\mathrm{CrOF}_{3}$ with the strong Lewis acid, $\mathrm{SbF}_{5}$, resulted in the loss of oxygen and formation of $\mathrm{CrF}_{2} \mathrm{Sb}_{2} \mathrm{~F}_{11}$. The ultraviolet spectrum of this compound in DMSO proved that chromium was present in the trivalent state and infrared spectral data supported the presence of the $\mathrm{Sb}_{2} \mathrm{~F}_{11}$ - anion.

Chromium oxide trifluoride is insoluble and unreactive with $W_{6}$ at $110^{\circ} \mathrm{C}$, but reacts with fluorine at $190^{\circ} \mathrm{C}$ to form $\mathrm{CrF}_{5}$

The anhydride $\left(\mathrm{CF}_{2}\right)_{3}(\mathrm{CO})_{2} \mathrm{O}$, (perfluoroglutaric anhydride), was reacted with chromium trioxide, producing the new compound $\mathrm{CrO}_{2}\left(\left(\mathrm{O}_{2} \mathrm{C}\right)_{2}\left(\mathrm{CF}_{2}\right)_{3}\right)$, (chromyl perfluoroglutarate). The chromyl compound was also prepared by reaction of the anhydride with $\mathrm{CrO}_{2} \mathrm{~F}_{2}$, and by the acid fluoride, (FOOC $\left.\left(\mathrm{CF}_{2}\right)_{3} \mathrm{COOF}\right)$, with $\mathrm{CrO}_{3}$. The ultraviolet spectrum of chromyl perfluoroglutarate was found to be consistent with other chromyl compounds. Reaction of perfluoroglutáric anhydride with the other group VIB metal trioxides. $\mathrm{MOO}_{3}$ and $\mathrm{WO}_{3}$, resulted in $90 \%$ to 95\% formation of $1: 1$ adducts. These new compounds were form- 
ulated, by analogy with chromyl perfluoroglutarate, as the corresponding molybdenyl and tungstenyl compounds, $\mathrm{MOO}_{2}\left(\left(\mathrm{O}_{2} \mathrm{C}\right)_{2}\left(\mathrm{CF}_{2}\right)_{3}\right.$ and $\mathrm{WO}_{2}\left(\left(\mathrm{O}_{2} \mathrm{C}\right)_{2}\left(\mathrm{CF}_{2}\right)_{3}\right)$.

Perfluoroglutaric anhydride was also reacted with group VIB metal salts; with $\mathrm{K}_{2} \mathrm{CrO}_{4}$, addition occurred across both metal-oxygen double bonds to produce $\mathrm{K}_{2} \mathrm{CrO}_{2}\left(\left(\mathrm{O}_{2} \mathrm{C}\right)_{2}\left(\mathrm{CF}_{2}\right)_{3}\right)_{2}$, with $\mathrm{Na}_{2} \mathrm{MOO}_{4}$ and $\mathrm{Na}_{2} \mathrm{WO}_{4}$, addition across only one metaloxygen double bond occurred, producing $\mathrm{Na}_{2} \mathrm{MoO}_{3}\left(\left(\mathrm{O}_{2} \mathrm{C}\right)_{2}\left(\mathrm{CF}_{2}\right)_{3}\right)$ and $\mathrm{Na}_{2} \mathrm{WO}_{3}\left(\left(\mathrm{O}_{2} \mathrm{C}\right)_{2}\left(\mathrm{CF}_{2}\right)_{3}\right)$.

Infrared spectra of all the perfluoroglutarate compounds indicated unidentate carboxylate linkage to the metal. $X$-ray data and the results of elemental analysis are also reported.

New preparative routes to chromium oxide tetrafluoride were sought; all new methods failed to produce $\mathrm{CrOF}_{4}$. Chromium oxide tetrafluoride was prepared by the previously reported method, and found to have terminal chromium-oxygen double bonds in the gas phase by infrared spectroscopy.

In the course of the preparation of $\mathrm{CrOF}_{4}$, the little known oxyfluoride, $\mathrm{CrOF}_{2}$, was prepared. Chromium oxide difluoride was assigned as a fluorine and oxygen-bridged polymer from infrared spectral data. The surface area of Crof 2 was measured and reaction with $\mathrm{F}_{2}$ at $250^{\circ} \mathrm{C}$ was found to produce $\mathrm{CrF}_{5} \cdot$ 


\title{
CHEMISTRY OF CHROMIUM OXYFLUORIDES AND GROUP VIB PERFLUOROGIUTARATES
}

BRUCE MICHAEI JOHNSON

A thesis submitted in partial fulfillment of the requirements for the degree of

\author{
MASTER OF SCIENCE \\ in
}

CHEMISTRY

Portland State University

1981 
TO THE OFFICE OF GRADUATE STUDIES AND RESEARCH:

The members of the Committee approve the thesis of Bruce Michael Johnson presented November 18, 1981.

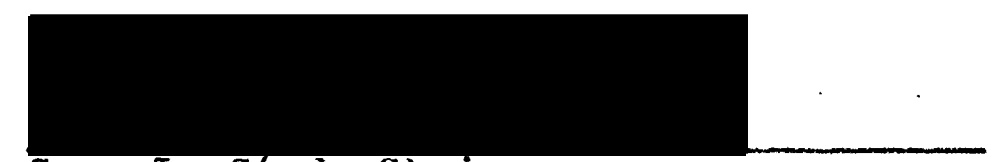

Gary I. Gkard, Chairman

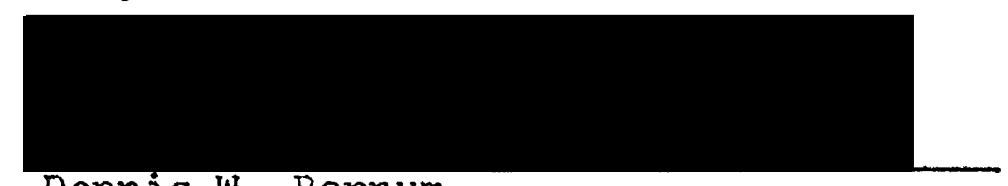

Dennis W. Barnum

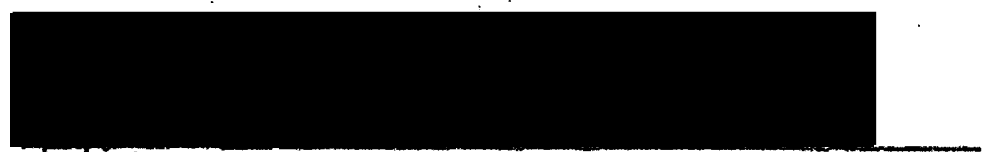

Morris $B$. Silverman

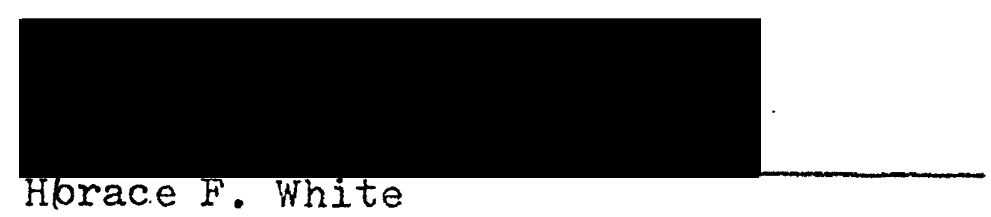

APPROVED :

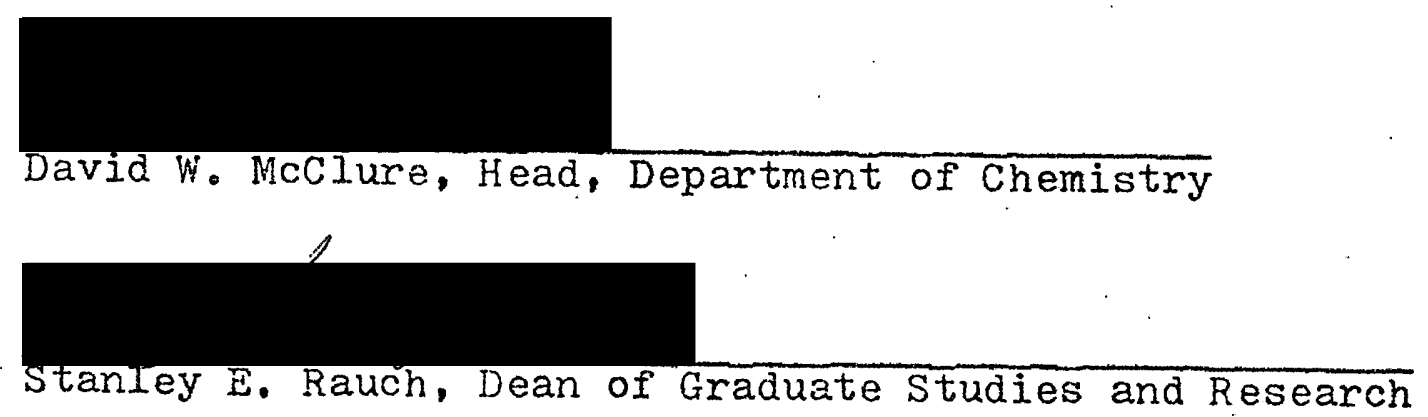




\section{ACKNOWLEDGEMENTS}

The author wishes to thank Mrs. Joann I. Johnson for her drawings of experimental apparatus, Mrs. Wendy JohnsonKent for typing a difficult manuscript, Ms. Virginia Volpe Thurston for the preparation and physical data of the group VIB perfluoroglutarate salts, Dr. Gary I. Gard for his enthusiasm and advice, and his family, especially Mr. Frank R. Johnson and Mrs. Ferne W. Gamble, for their support. 
TABIE OF CONTENTS

PAGE

ACKNOWLEDGEMENTS ....................... iii

IIST OF TABIES $\ldots \ldots \ldots \ldots \ldots \ldots \ldots \ldots \ldots \ldots \ldots \ldots \ldots$ v

IIST OF FIGURES $\ldots \ldots \ldots \ldots \ldots \ldots \ldots \ldots \ldots \ldots \ldots \ldots \ldots$ vi

CHAPTER

I INTRODUCTION $\ldots \ldots \ldots \ldots \ldots \ldots \ldots \ldots \ldots \ldots \ldots \ldots \ldots$

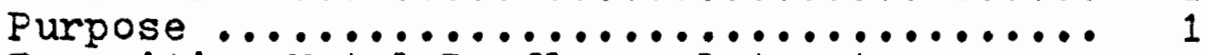

Transition Metal Perfluoroglutarate Complexes ......................... 1

Chromium oxide Fiuorides ................. 8

II EXFERIMENTAL METHODS .................... 13

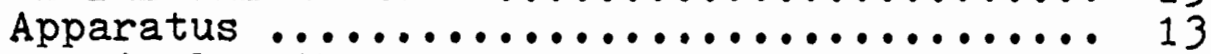

Physical Methods .................... 20

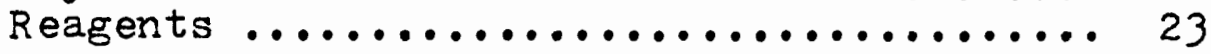

III SYNTHESIS OF GROUF VIB PERFLUOROGIUTARATES .. 28

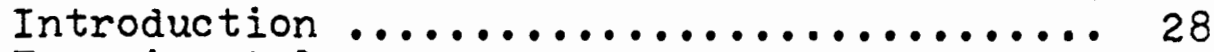

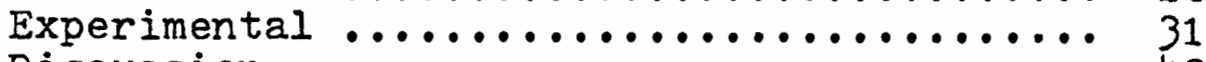

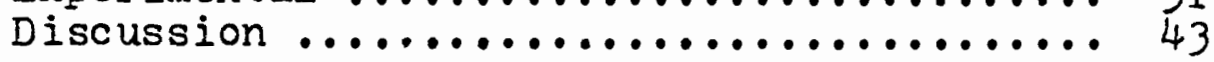

IV . CHEMISTRY OF CHROMIUM OXIDE FLUORIDES ...... 52

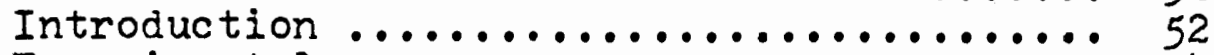

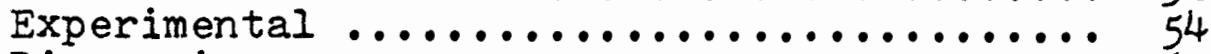

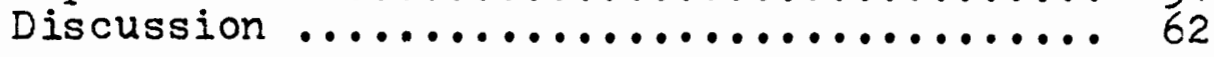

$\mathrm{V}$ SYNTHESIS OF CHROMIUM OXIDE TRIFLUORIDE

AND SOME REACTION CHEMISTRY ............ 66

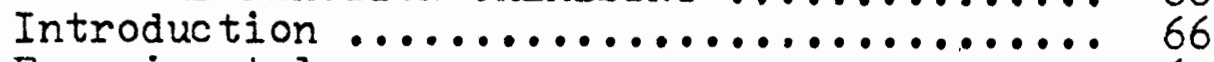

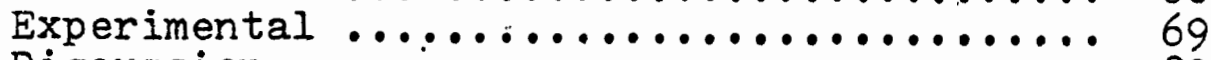

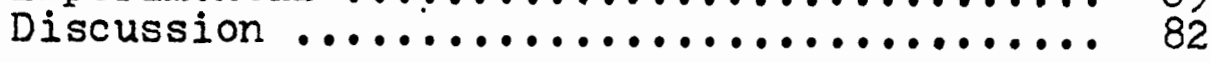

BIBLIOGRAPHY $\ldots \ldots \ldots \ldots \ldots \ldots \ldots \ldots \ldots \ldots \ldots \ldots \ldots \ldots \ldots$

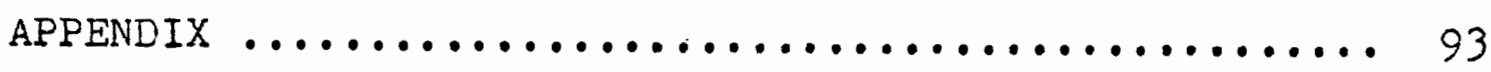




\section{IIST OF TABLES}

TABLE

PAGE

I X-Ray Powder Pattern of Chromyl

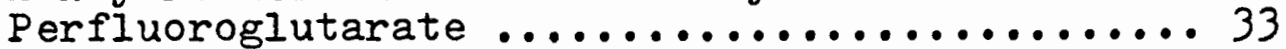

II Infrared Spectra of Chromyl Perfluoroglutarate. 34

III Infrared spectra of $\mathrm{MOO}_{2}\left(\left(\mathrm{O}_{2} \mathrm{C}\right)_{2}\left(\mathrm{CF}_{2}\right)_{3}\right)$ and

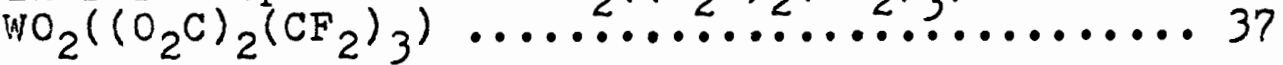

IV X-Ray Powder Pattern of $\mathrm{K}_{2} \mathrm{CrO}_{2}\left(\left(\mathrm{O}_{2} \mathrm{C}\right)_{2}\left(\mathrm{CF}_{2}\right)_{3}\right)_{2} \cdot 39$

$\mathrm{V}$ Infrared spectrum of $\mathrm{K}_{2} \mathrm{CrO}_{2}\left(\left(\mathrm{O}_{2} \mathrm{C}\right)_{2}\left(\mathrm{CF}_{2}\right)_{3}\right)_{2} \ldots 40$

VI Infrared Spectra of $\mathrm{Na}_{2} \mathrm{MOO}_{3}\left(\left(\mathrm{O}_{2} \mathrm{C}\right)_{2}\left(\mathrm{CF}_{2}\right)_{3}\right)$ and $\mathrm{Na}_{2} \mathrm{WO}_{3}\left(\left(\mathrm{O}_{2} \mathrm{C}\right)_{2}\left(\mathrm{CF}_{2}\right)_{3}\right) \ldots \ldots \ldots \ldots \ldots \ldots . \ldots \ldots$

VII. X-Ray Powder Pattern of $\mathrm{Na}_{2} \mathrm{WO}_{3}\left(\left(\mathrm{O}_{2} \mathrm{C}\right)_{2}\left(\mathrm{CF}_{2}\right)_{3}\right) \ldots 44$

VIII Ultraviolet Spectra of Chromyl Compounds

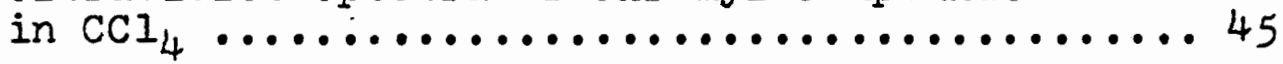

IX Experimental and Literature Values of the $\mathrm{X}$-Ray Powder Pattern for $\mathrm{CrOF}_{2}$............6 60

X Infrared spectrum of $\mathrm{CrOF}_{2} \ldots \ldots \ldots \ldots . . \ldots 61$

XI X-Ray Powder Pattern of $\mathrm{CrOF}_{3} \ldots \ldots \ldots \ldots . \ldots 2$

XII Vibrational Frequencies of Solid $\mathrm{CrOF}_{3}$, $\mathrm{VOF}_{3}$ and $\mathrm{MOOF}_{3}$

XIII X-Ray Powder Patterns of the $\mathrm{CrOF}_{3}$

Decomposition Product and $\mathrm{CrF}_{3} \ldots \ldots \ldots \ldots . \ldots 74$

XIV Observed and Calculated X-Ray Powder Fatterns

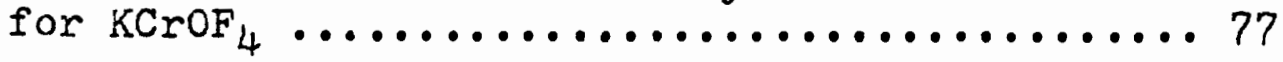

$\mathrm{XV}$ Infrared spectra of $\mathrm{KCrOF}_{4}$ and $\mathrm{CsVOF}_{4} \ldots \ldots \ldots 78$

XVI $\quad X$-Ray Powder Pattern of $\mathrm{NO}_{2} \mathrm{CrOF}_{4} \ldots \ldots \ldots . \ldots 79$

XVII Infrared spectrum of $\mathrm{NO}_{2} \mathrm{CrOF}_{4} \ldots \ldots \ldots \ldots . \ldots . \ldots 79$

XVIII Infrared Spectra of $\mathrm{CrF}_{2} \mathrm{Sb}_{2} \mathrm{~F}_{11}$ and $\mathrm{CrF}_{4} \mathrm{Sb}_{2} \mathrm{~F}_{11} \cdot 81$ 


\section{IIST OF FIGURES}

FIGURE

PAGE

1 Fluorine Inductive Effect on the Carbonyl

Groups of Perfluoroglutaric Anhydride

2 Iinkage Isomerism of Carboxylate Groups ..... 6

3 Glass Vacuum Manifold ................... 14

4 Metal Vacuum System ...................... 16

5 Fluorine Iine ...................... 17

6 Glass Trap for Condensation of Volatile Materials ........................... 19

$7 \quad$ Reaction Vessels ....................... 21

8 Proposed Mechanism for the Addition of Acid Anhydrides Across Metal-Oxygen Multiple Bonds. 28

9 Proposed Structure of Chromyl Perfluoroglutarate .................... 46

10 Structure of solid $\mathrm{VOF}_{3} \ldots \ldots \ldots \ldots \ldots \ldots$

11 Possible structures of the $\mathrm{CrOF}_{4}^{-}$. Anion ...... 84 
CHAPTER I

\section{INTRODUCTION}

\section{Purpose}

Hexavalent chromium compounds are strong oxidizing agents which have found use in preparative organic and inorganic chemistry. In addition, chromium compounds in higher oxidation states ( $V$ and $V I$ ) have important industrial uses, such as the preparation of polymerization catalysts and in chromium plating. Complexes of chromium with fluorinated carboxylic acids and alcohols have been used to waterproof fabrics and shrinkproof wool.

To expand the chemistry of chromium in high oxidation states, it is of interest to increase the number of available compounds. Work was extended on the stabilization of hexavalent chromium by preparing a new chromyl compound with a bidentate, fluorinated dicarboxylate ligand. Also new salts of the unusual pentavalent oxidation state of chromium were prepared.

Transition Metal Perfluoroglutarate Complexes

Despite well founded criticism (1), fluorine containing organic compounds are generally named after their hydrocarbon analogues by adding the prefix "fluoro". The prefix "perfluoro" is used with a compound's common name to indicate the substitution of all non-functional group hydrogens with fluorine. 
Hence, perfluoroglutaric acid is used as the common name for $2,2,3,3,4,4-$ hexafluoropentanedioic acid.

The substitution of fluorine for hydrogen in organic compounds markedly changes their properties. The large increase in molecular weight is not accompanied by increases in melting or boiling points, which indicates a decrease in intermolecular bonding forces. In fact, when the boiling points of fluorocarbons are plotted against their molecular weights, the resulting curve lies not far above the curve for the inert gases (2). Thus, glutaric acid ( $\mathrm{MW}=132 \mathrm{~g} / \mathrm{mole}$ ) melts at $97.5^{\circ} \mathrm{C}$ yet perfluoroglutaric acid ( $\mathrm{MW}=240 \mathrm{~g} / \mathrm{mole}$ ) melts at $88^{\circ} \mathrm{C}$. Even more striking is perfluoroglutaric anhydride which boils at $72^{\circ} \mathrm{C}, 208^{\circ} \mathrm{C}$ lower than the boiling point of glutaric anhydride, but this last example also reflects the result of the loss of hydrogen bonding.

Fiuorocarbon groups are more resistant to oxidation than the corresponding hydrocarbons. Chromyl acetate, $\mathrm{CrO}_{2}\left(\mathrm{O}_{2} \mathrm{CCH}_{3}\right)_{2}$, is explosive at room temperature (3) yet chromyl trifluoraacetate, $\mathrm{CrO}_{2}\left(\mathrm{O}_{2} \mathrm{CCF}_{3}\right)_{2}$, melts at $48.5^{ \pm_{1}}{ }^{\circ} \mathrm{C}$ (4). This stability results from the greater strength of the carbon-fluorine bond and the presence of the lone electron pairs on fluorine which extend far enough to shield the carbon backbone from electrophilic attack but not so far as to sterically hinder one another, which is the case in polychlorinated compounds.

Perfluorination of organic acids increases their acid strength by the inductive effect of fluorine stabilizing the 
conjugate base. This electronic effect also causes changes in infrared spectra. The highest frequency carbonyl stretching mode of perfluoroglutaric anhydride occurs at $1878 \mathrm{~cm}^{-1}$, which is blue shifted $50 \mathrm{~cm}^{-1}$ relative to the hydrogen analogue. This stretching frequency is at the extreme upper limit for this functional group. The fluorine inductive effect possibly increases the carbonyl bond force constant by encouraging the shift of electron density from the lone pairs on oxygen to the bonding system, causing triple bond-like behavior.

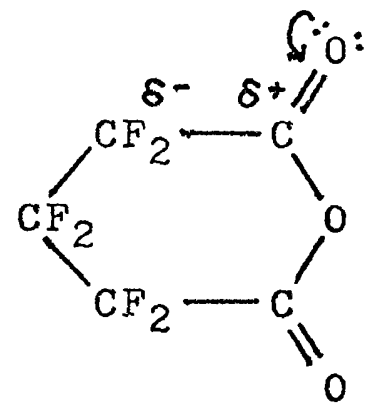

Figure 1. Fluorine inductive effect on the carbonyl groups of perfluoroglutaric anhydride.

A variety of metal-glutarate complexes have been prepared but not well characterized $(5,6)$. Very few perfluoroglutarate complexes have been reported. In a solubility study, Amaral and de Carvalho (?) prepared the glutarates and some perfluoroglutarates of the rare earth elements by refluxing the metal oxide and acid in aqueous solution, then crystallizing under vacuum. Using this method, the following perfluoroglutarate complexes were prepared: 
$\mathrm{I}-1 \quad \mathrm{La}_{2} \mathrm{O}_{3}+3 \mathrm{PFGA} \frac{100^{\circ} \mathrm{C}}{\mathrm{H}_{2} \mathrm{O}} \mathrm{La}_{2}(\mathrm{PFG})_{3} \cdot 7 \mathrm{H}_{2} \mathrm{O}$

$\mathrm{I}-2 \quad \mathrm{Nd}_{2} \mathrm{O}_{3}+3 \mathrm{PFGA} \longrightarrow \mathrm{Nd}_{2}(\mathrm{PFG})_{3} \cdot 4 \mathrm{H}_{2} \mathrm{O}$

I-3 $\mathrm{Gd}_{2} \mathrm{O}_{3}+3 \mathrm{PFGA} \longrightarrow \mathrm{Gd}_{2}(\mathrm{PFG})_{3} \cdot \mathrm{xH}_{2} \mathrm{O}$

$\mathrm{I}-4 \quad \mathrm{Dy}_{2} \mathrm{O}_{3}+3 \mathrm{PFGA} \longrightarrow \mathrm{Dy}_{2}(\mathrm{PFG})_{3} \cdot \mathrm{xH}_{2} \mathrm{O}$

$\mathrm{I}-5 \quad \mathrm{Er}_{2} \mathrm{O}_{3}+3 \mathrm{PFGA} \longrightarrow \mathrm{Er}_{2}(\mathrm{PFG})_{3} \cdot 8 \mathrm{H}_{2} \mathrm{O}$

I-6 $\mathrm{Tm}_{2} \mathrm{O}_{3}+3 \mathrm{PFGA} \longrightarrow \mathrm{Tm}_{2}(\mathrm{PFG})_{3} \cdot \mathrm{XH}_{2} \mathrm{O}$

$\mathrm{I}-7 \quad \mathrm{Yb}_{2} \mathrm{O}_{3}+3 \mathrm{PFGA} \longrightarrow \mathrm{Yb}_{2}(\mathrm{PFG})_{3} \cdot \mathrm{XH}_{2} \mathrm{O}$

( $P F G A=$ perfluoroglutaric acid)

( $P F G=$ perfluoroglutarate)

The perfluoroglutarate complexes were found to be very hygroscopic and had solubilities roughly three orders of magnitude greater than their hydrocarbon analogues. No other physical or structural data was given.

A mercury complex has also been prepared (8) by reacting mercuric oxide and perfluoroglutaryl chloride in aqueous solution:

I-8 $\mathrm{HgO}+\mathrm{PFGCl} \stackrel{\mathrm{H}_{2} \mathrm{O}}{\longrightarrow} \stackrel{\text { evac. }}{\longrightarrow} \mathrm{HgPFG} \cdot \mathrm{xH}_{2} \mathrm{O}$

Again, no structural data was given but the reported mass balance suggests some water of crystallization.

The only other report of a perfluoroglutarate complex is by Blake et al. (9) who carried out the reaction in a strictly anhydrous, closed system. Oxidative addition of perfluoroglutaric anhydride to an iridium (I) complex occurred with ring opening to produce a bifunctional ligand with acyl and unidentate carboxylate linkages: 


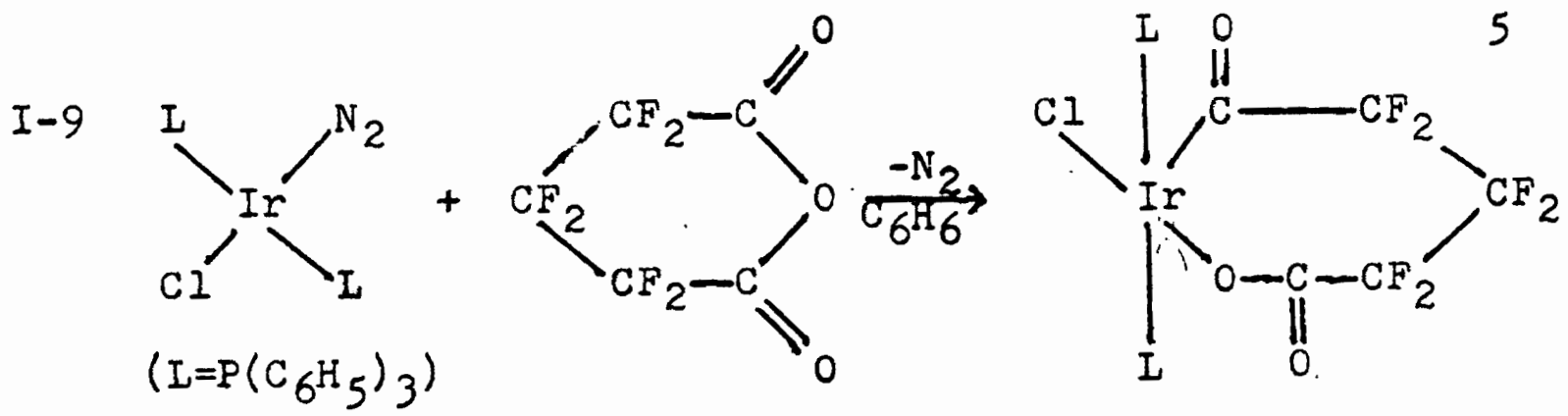

The structure was supported with infrared spectral data but the complex was presumed to contain a seven-membered chelate ring instead of polymeric chains.

Figure 2 illustrates the linkage isomerism of carboxylate groups. Because of low symmetry and vibrational coupling, along with differences in the metal's ionic radius, oxidation state, other bound groups, etc.. the number and position of infrared bands' do not provide a general distinction between the modes of carboxylate coordination.

Unidentate coordination leaves one of the carbon-oxygen bonds with enhanced double bond character (10) and the stretching frequencies correspond to approximately $\mathrm{C}=0$ and C-O (11). Despite the formal valence bond structures, investigators assign carbon-oxygen stretching frequencies in unidentate carboxylate complexes as asymmetric and symmetric $\mathrm{CO}_{2}(9-16)$. This reflects the strong electronic interaction that is believed to occur between the three atoms of the carboxylate group. The relatively large separation between the asymmetric and symmetric $\mathrm{CO}_{2}$ stretching frequencies is used to distinguish between unidentate carboxylate and the other various bidentate forms. In studies where the absolute. configurations were confirmed by $x$-ray data $(11,14), \Delta \omega$ 
<smiles>[M]OC([R])=O</smiles>

I. Unidentate<smiles></smiles><smiles>[R]C1[M]=NO1</smiles>

II. Bidentate - symmetrical chelate

III. Bidentate - unsymmetrical chelate<smiles>[M]OC([R])O[M]</smiles>

IV. Bidentate - bridging

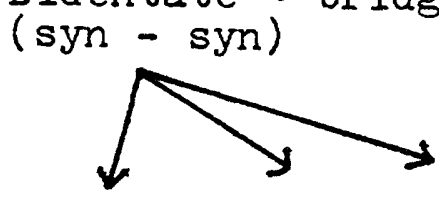<smiles>[M]OC([R])O[M]</smiles><smiles>[M]OC([R])O[M]</smiles>

(syn - syn) $(\operatorname{anti}-\operatorname{anti})$<smiles></smiles>

V. Ionic

$$
\begin{aligned}
& (R=\text { alkyl group }) \\
& (M=\text { metal })
\end{aligned}
$$

Figure 2. Linkage isomerism of carboxylate groups. 
$\left(\mathrm{CO}_{2}\right.$ asymmetric $-\mathrm{CO}_{2}$ symmetric $)$ was 80 to $200 \mathrm{~cm}^{-1}$ for bidentate carboxylates and 300 to $500 \mathrm{~cm}^{-1}$ for unidentate carboxylates. Robinson and Uttley (15) have proposed values of 175 to $215 \mathrm{~cm}^{-1}$ for bidentate, and 240 to $310 \mathrm{~cm}^{-1}$ for unidentate carboxylates in fluoroalkyl complexes.

Symmetrical bidentate coordination (chelating and bridging forms) leaves the two carbon-oxygen bonds somewhat equivalent and the effects on stretching frequencies are not easily predictable. Alcock et al. (11) found a slightly smaller $\Delta \boldsymbol{\omega}$ for bidentate chelating with respect to bidentate bridging groups.

Bidentate unsymmetrical chelating is an uncommon mode of coordination, but Catterick and Thornton (16) suggest that unidentate coordination is the upper limit in a range of unsymmetrical chelate structures and others (11) relate the size of the metal to this effect.

Ionic carboxylate occurs in solution and in alkali metal salts. The carbon-oxygen bonds are equivalent and are of intermediate bond order. The infrared spectra of ionic carboxylates show closely separated asymmetric and symmetric $\mathrm{CO}_{2}$ stretching frequencies about 150 to $250 \mathrm{~cm}^{-1}$ apart.

It should be noted that perfluoroglutaric acid is a bifunctional group ligand, therefore in addition to the various possible carboxylate linkages, the ligand as a whole can coordinate in chelating or bridging (polymeric) configurations. The preparation and properties of group VIB transition metal complexes of perfluoroglutaric acid are described in Chapter 
III. The perfluoroglutarate ligand is believed to act in the bidentate bridging mode with unidentate carboxylate linkages to the metal.

\section{Chromium oxide Fluorides}

oxyfluorides of chromium have been prepared in oxidation states from III to VI. Although $\mathrm{CrOCl}$ and $\mathrm{CrOBr}$ are known (17, 18), apparently CrOF has not been isolated as no physical data appears in the two brief reports of its preparation. Petit and Bourlange (19) obtained CrOF by mixing $\mathrm{Cr}_{2} \mathrm{O}_{3}$ and $\mathrm{CrF}_{3}$ in $\mathrm{KF}$. Chromium oxide fluoride was" also proposed to be formed in the catalytic fluorination of chlorinated hydrocarbons (20). A vaporized mixture of chlorinated hydrocarbon and aqueous HF was passed over a Cr-AI fluoride catalyst bed at 275 to $425^{\circ} \mathrm{C}$. Various fluorocarbons were obtained resulting from the replacement of chlorine.

Chromium oxide difluoride $\left(\mathrm{CrOF}_{2}\right)$ has been prepared by Rochat, "et al. (21) from the thermal decomposition of chromyl fluoride.

$\mathrm{I}-10 \quad \mathrm{CrO}_{2} \mathrm{~F}_{2} \stackrel{500^{\circ} \mathrm{C}}{\longrightarrow} \mathrm{CrOF}_{2}+\frac{1}{2} \mathrm{O}_{2}$

The compound is an inert brown-black solid that is insoluble in water and common acids, bases, and organic solvents. Crop 2 is stable at $1600^{\circ} \mathrm{C}$ in vacuo, but is converted to $\mathrm{Cr}_{2} \mathrm{O}_{3}$ when exposed to air at this temperature. The $\mathrm{x}$-ray powder pattern was also reported.

Chromium oxide trifluoride $\left(\mathrm{CrOF}_{3}\right)$ was first prepared in impure form by Sharpe and woolf (22) who reacted $\mathrm{CrO}_{3}$ with 
$\mathrm{BrF}_{3}$. After evaporation of the excess $\mathrm{BrF}_{3}$, the product retained some bromine which could not be removed, even after prolonged heating at $200^{\circ} \mathrm{C}$ in vacuo. It was proposed that a thermally unstable addition compound, $\left(\mathrm{BrF}_{2}\right)\left(\mathrm{CrOF}_{4}\right)$, was formed. Later, in an extension of this work, Clark and Sadana (23. 24) again prepared impure $\mathrm{CrOF}_{3}$.

$\mathrm{I}-11 \mathrm{CrF}_{4}+\mathrm{BrF}_{3} \stackrel{\text { reflux }}{\longrightarrow} \mathrm{CrOF}_{3} \cdot 25 \mathrm{BrF}_{3}$

$\mathrm{I}-12 \mathrm{CrO}_{3}+\mathrm{BrF}_{3} \stackrel{25^{\circ} \mathrm{C}}{\longrightarrow} \mathrm{CrOF}_{3} \cdot 25 \mathrm{BrF}_{3}$

$\mathrm{I}-13 \mathrm{CrO}_{3}+\mathrm{BrF}_{5} \stackrel{25^{\circ} \mathrm{C}}{\rightarrow} \mathrm{CrOF}_{3} \cdot .25 \mathrm{BrF}_{5}$

$\mathrm{I}-14 \mathrm{CrO}_{3}+\mathrm{ClF}_{3} \stackrel{12^{\circ} \mathrm{C}}{\longrightarrow} \mathrm{CrOF}_{3} \cdot 30 \mathrm{ClF}_{3}$

In the first reaction $(I-11) \mathrm{CrOF}_{3} \cdot 25 \mathrm{BrF}_{3}$ was a by-product, probably formed through attack of the quartz system by $\mathrm{BrF}_{3}$. Reactions I-12 to I-14 (also carried out in quartz) presumably proceed with the evolution of oxygen and either chlorine or bromine. As before, elemental analysis showed that the products were contaminated with the particular halogen fluoride and all attempts to purify them by heating in vacuum resulted in decomposition. The impure samples were dull red solids which fumed in air but had magnetic moments that demonstrated the presence of chromium $(V)$. Attempts to obtain $x$-ray powder patterns failed because the silica capillaries exploded shortly after loading. This lead the authors to believe that $\mathrm{CrOF}_{3}$ is unstable which is incorrect as Green (25) prepared a more pure form of $\mathrm{CrOF}_{3}$ and found it to be stable up to $200^{\circ} \mathrm{C}$ in Pyrex glass. The preparation, characterization, and some chemistry of $\mathrm{CrOF}_{3}$ is described in Chapter $\mathrm{V}$. 
Two oxyfluorides of chromium(VI) are known. Chromium dioxide difluoride (chromyl fluoride $-\mathrm{CrO}_{2} \mathrm{~F}_{2}$ ) and chromium oxide tetrafluoride $\left(\mathrm{CrOF}_{4}\right)$. Chromyl fluoride is the most well known of the chromium oxyfluorides and a fair amount of literature exists on its properties and reaction chemistry. Engelbrecht and Grosse (26) were first to prepare pure samples of $\mathrm{CrO}_{2} \mathrm{~F}_{2}$ and determine many of its physical properties. Chromium dioxide difluoride is a volatile dark violet-red solid which melts at $31.6^{\circ} \mathrm{C}$ to an orange-red.liquid and redbrown vapor. The thermal stability of $\mathrm{CrO}_{2} \mathrm{~F}_{2}$ has already been mentioned and although it is stable in the dark, it polymerizes to a white solid on exposure to ultraviolet light (21). There are many preparative routes to $\mathrm{CrO}_{2} \mathrm{~F}_{2}$ which have been summarized (27), two methods appear in Chapter IV. Chromyl fluoride is a strong oxidizer which attacks glass, therefore most organic oxidations are carried out with the milder chromyl chloride. Most of the chemistry of chromyl fluoride has been with inorganic systems. A few examples are the reaction with alkali and alkaline metal fluorides forming fluorochromate salts (28):

$$
\begin{aligned}
& \begin{aligned}
\mathrm{I}-15 \quad \mathrm{MF} & +\mathrm{CrO}_{2} \mathrm{~F}_{2}, \overrightarrow{\mathrm{M}}=\mathrm{M}_{2} \mathrm{CrO}_{2} \mathrm{~F}_{4} \\
& =\mathrm{Na}, \mathrm{Cs}
\end{aligned} \\
& \mathrm{I}-16 \quad \mathrm{MF}_{2}+\mathrm{CrO}_{2} \mathrm{~F}_{2} \longrightarrow \mathrm{MCrO}_{2} \mathrm{~F}_{4} \\
& \mathrm{M}=\mathrm{C} \mathrm{a}, \mathrm{Mg}
\end{aligned}
$$

Reaction with Lewis acids to produce new chromyl compounds:

I-17 $\mathrm{CrO}_{2} \mathrm{~F}_{2}+2 \mathrm{SO}_{3} \stackrel{25^{\circ} \mathrm{C}}{\longrightarrow} \mathrm{CrO}_{2}\left(\mathrm{SO}_{3} \mathrm{~F}\right)_{2}$

$\mathrm{I}-18 \mathrm{CrO}_{2} \mathrm{~F}_{2}+\mathrm{TaF}_{5} \stackrel{60^{\circ} \mathrm{C}}{\longrightarrow} \mathrm{CrO}_{2} \mathrm{~F}\left(\mathrm{TaF}_{6}\right)$ 
I-19 $\mathrm{CrO}_{2} \mathrm{~F}_{2}+\mathrm{SbF}_{5} \stackrel{25^{\circ} \mathrm{C}}{\longrightarrow} \mathrm{CrO}_{2} \mathrm{~F}\left(\mathrm{SbF}_{6}\right)$

$\mathrm{I}-20 \quad \mathrm{CrO}_{2} \mathrm{~F}_{2}+2 \mathrm{SbF}_{5} \stackrel{25^{\circ} \mathrm{C}}{\longrightarrow} \mathrm{CrO}_{2} \mathrm{~F}\left(\mathrm{Sb}_{2} \mathrm{~F}_{11}\right)$

and with Lewis bases (29):

$\mathrm{I}-21 \quad \mathrm{CrO}_{2} \mathrm{~F}_{2}+\mathrm{NO}_{2} \mathrm{~F} \stackrel{45^{\circ} \mathrm{C}}{\longrightarrow} \mathrm{NO}_{2} \mathrm{CrO}_{2} \mathrm{~F}_{3}$

$\mathrm{I}-22 \mathrm{CrO}_{2} \mathrm{~F}_{2}+\mathrm{NOF} \stackrel{25^{\circ} \mathrm{C}}{\longrightarrow} \mathrm{NOCrO}_{2} \mathrm{~F}_{3}$

By comparison with chromyl fluoride, chromium oxide tetrafluoride is relatively unknown and difficult to prepare. Edwards (30) first obtained $\mathrm{CrOF}_{4}$ as a by-product from the direct fluorination of chromium metal in a glass flow system. The separation of $\mathrm{CrOF}_{4}$ from the other major products of the reaction was difficult and required careful fractional distillation. Chromium oxide tetrafluoride is a dark red solid which melts at $55^{\circ} \mathrm{C}$ to a liquid of the same color. Despite its extreme moisture sensitivity, $x$-ray data was obtained for the compound and it was found to have a monoclinic unit cell. $a=12.3, b=5.4, c=7.3 \AA$, and $\beta=104^{\circ}$. Later Edwards et al. (31) prepared $\mathrm{CrOF}_{4}$ by fluorination of $\mathrm{CrO}_{3}$ in a water-cooled static system. The reaction is believed to be a stepwise replacement of fluorine for oxygen, controlled by temperature. $\mathrm{I}-23 \mathrm{CrO}_{3}+\mathrm{F}_{2} \stackrel{150^{\circ} \mathrm{C}}{\longrightarrow} \mathrm{CrO}_{2} \mathrm{~F}_{2}+\frac{1}{2} \mathrm{O}_{2}$ $\mathrm{I}-24 \mathrm{CrO}_{2} \mathrm{~F}_{2}+\mathrm{F}_{2} \stackrel{220^{\circ} \mathrm{C}}{\longrightarrow} \mathrm{CrOF}_{4}+\frac{1}{2} \mathrm{O}_{2}$ $\mathrm{I}-25 \mathrm{CrOF}_{4}+\mathrm{F}_{2} \stackrel{250^{\circ} \mathrm{C}}{\longrightarrow} \mathrm{CrF}_{6}+\frac{1}{2} \mathrm{O}_{2} \stackrel{-100^{\circ} \mathrm{C}}{\longrightarrow} \mathrm{CrF}_{5}+\frac{1}{2} \mathrm{~F}_{2}$ At $220^{\circ} \mathrm{C}$ only small amounts of $\mathrm{CrO}_{2} \mathrm{~F}_{2}$ were present which were pumped away from the $\mathrm{CrOF}_{4}$ at $-23^{\circ} \mathrm{C}$. The mass spectrometric cracking pattern of $\mathrm{CrOF}_{4}$ was determined and from vapor pressure measurements, thermodynamic constants were calculated. 
The boiling boint of $95^{\circ} \mathrm{C}$ was extrapolated from the vapor pressure data as $\mathrm{CrOF}_{4}$ reacts with glass, rapidly above $70^{\circ} \mathrm{C}$. to produce $\mathrm{CrO}_{2} \mathrm{~F}_{2}, \mathrm{CrO}_{3}$, and presumably $\mathrm{SiF}_{4}$. Iike $\mathrm{MOOF}_{4}$ and $\mathrm{ReOF}_{4}, \mathrm{CrOF}_{4}$ was assumed to be a cis fluorine bridged polymer with terminal oxygens.

Using the data of Edwards, and assuming $C_{2 v}$ symmetry, Russian workers calculated a theoretical infrared spectrum for $\mathrm{CrOF}_{4}$ (32). Twelve fundamentals were calculated with a value of $1080 \mathrm{~cm}^{-1}$ for the chromium-oxygen stretching frequency. These three reports represent all that is known about $\mathrm{CrOF}_{4}$ to date. Attempts to prepare $\mathrm{CrOF}_{4}$ by new methods are described in Chapter IV. 
EXPERIMENTAL METHODS

\section{Apparatus}

Glass Vacuum System. For most of the work that did not involve materials reactive towards glass, the glass vacuum system was used. This consisted of a manifold evacuated through a liquid nitrogen cooled trap by a Sargent-Welch, Duo-seal Model 1400 rotary vacuum pump. The manifold was constructed of $20 \mathrm{~mm}$ Pyrex glass tubing and fitted with four Eck and Krebs $2 \mathrm{~mm}$ high-vacuum stopcocks attached to outer 10/30 $\$$ ground glass joints. A two-leg mercury manometer, constructed of $10 \mathrm{~mm}$ Pyrex glass tubing was also attached to the manifold. Pressures below $1 \mathrm{~mm} \mathrm{Hg}$ were monitored with a Televac thermocouple gauge. The stopcocks and ground glass joints were lubricated with Apiezon type $M$ grease. The typical working vacuum was $5 \times 10^{-3}$ to $10 \times 10^{-3}$ torr. The glass vacuum manifold is illustrated in Figure 3. Metal Vacuum system. For the transfer of extremely reactive materials used in this work, a metal vacuum line was used. The manifold was constructed of $1 / 4$ inch 0.0 . copper tubing. Three taps were fitted to the manifold via swagelok fittings. The taps consisted of a metal 10/30 outer joint connected through a VWR stainless steel valve. The manifold was connected to a tank containing CIF and also featured a 


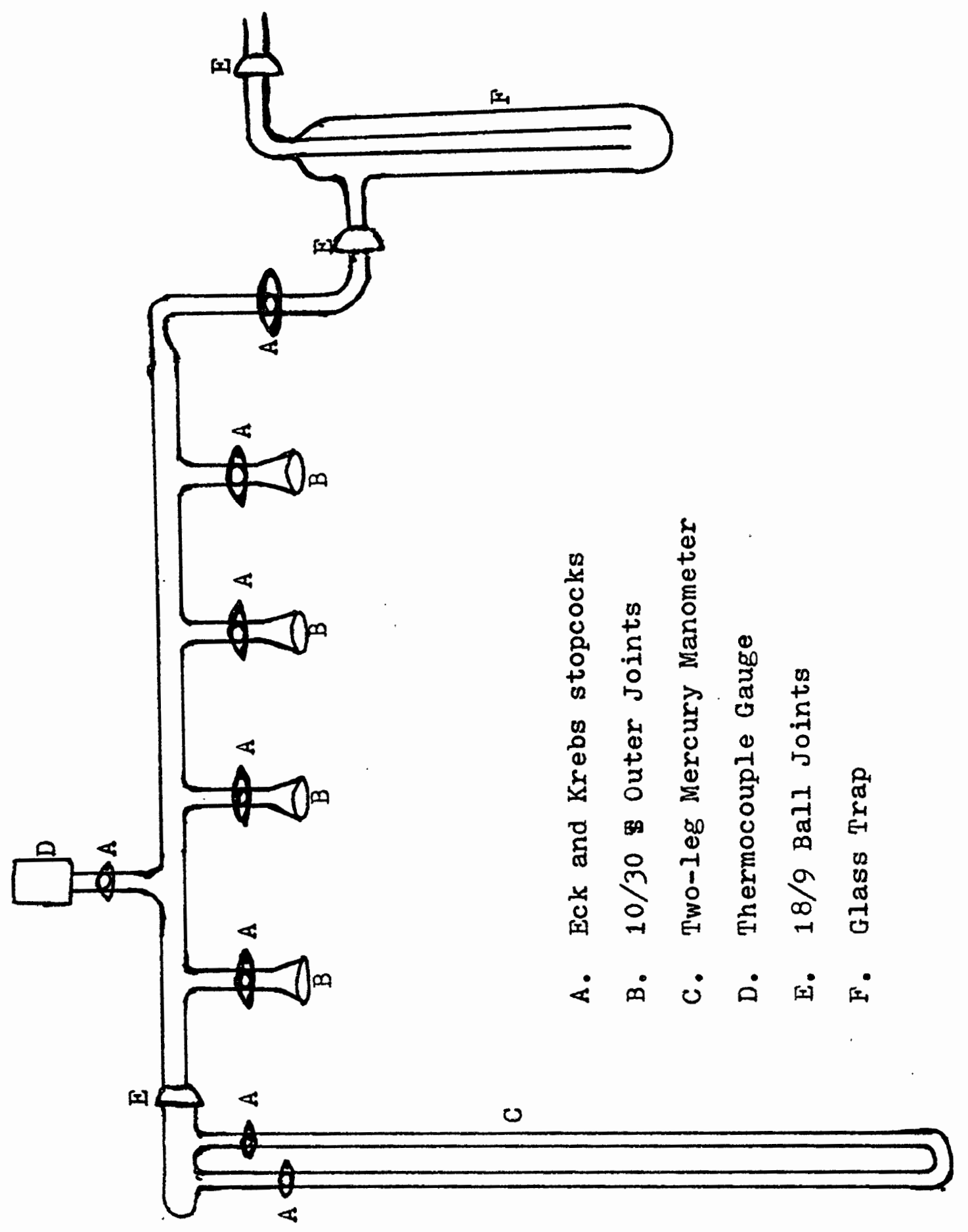

Figure 3. Glass vacuum manifold 
1.8 liter, copper surge vessel for the metering out of gaseous reagents. The fraction of the exterior system as described above was electroless nickel plated.

An Acco diaphram type vacuum gauge was used to monitor vacuum from $1 \mathrm{~mm}$ to $760 \mathrm{~mm}$ while high vacuum was measured with a Kontes thermocouple vacuum gauge. The manifold was evacuated through a liquid nitrogen cooled trap by a pump identical to the one already described, and was equipped via a bypass system, with a CVC model VMF-10 oil diffusion pump. All joints were lubricated with Halocarbon grease. The system was capable of achieving pressures less than 10-3 torr with the mechanical pump alone, and is illustrated in Figure 4.

Fluorine Line. Fluorine was dispensed in a manifold constructed of $1 / 4$ inch $0 . D$. copper tubing to which two taps were attached. The taps consisted of brass VWR valves, one ending with a metal 10/30 outer joint and the second ending in a copper tube for use as a manifold vent. Pressure was monitored on an Acco diaphram type vacuum/pressure gauge. The manifold was connected to the fluorine tank through a copper U trap filled with nickel helices and cooled to $-78^{\circ} \mathrm{C}$. Halocarbon grease was used on the metal joint. The line is illustrated in Figure 5.

Vacuum Traps. For the removal of volatile materials, a glass trap was attached between the reaction vessel and the vacuum manifold. A typical trap consisted of an outer 


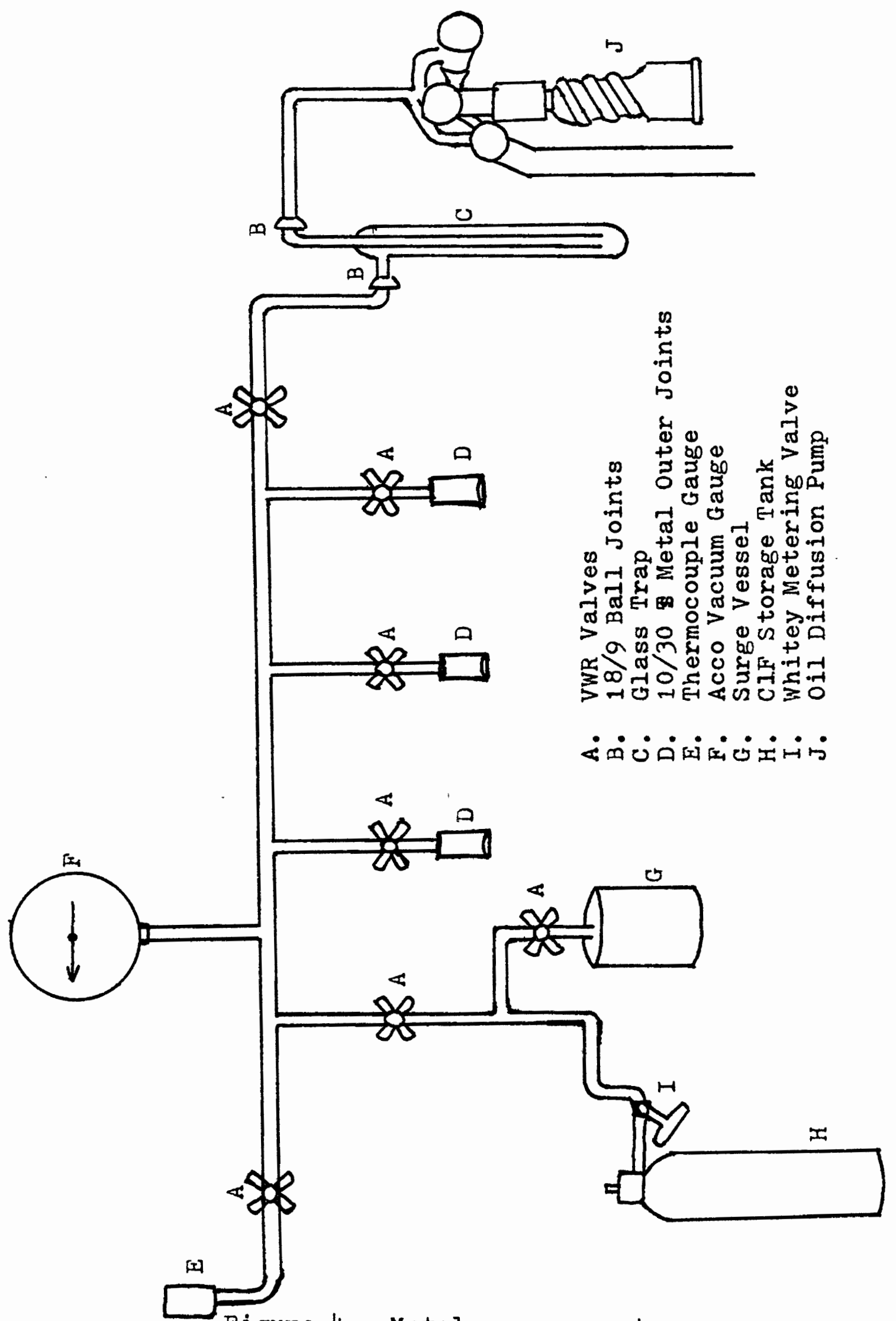

Figure 4. Metal vacuum system 


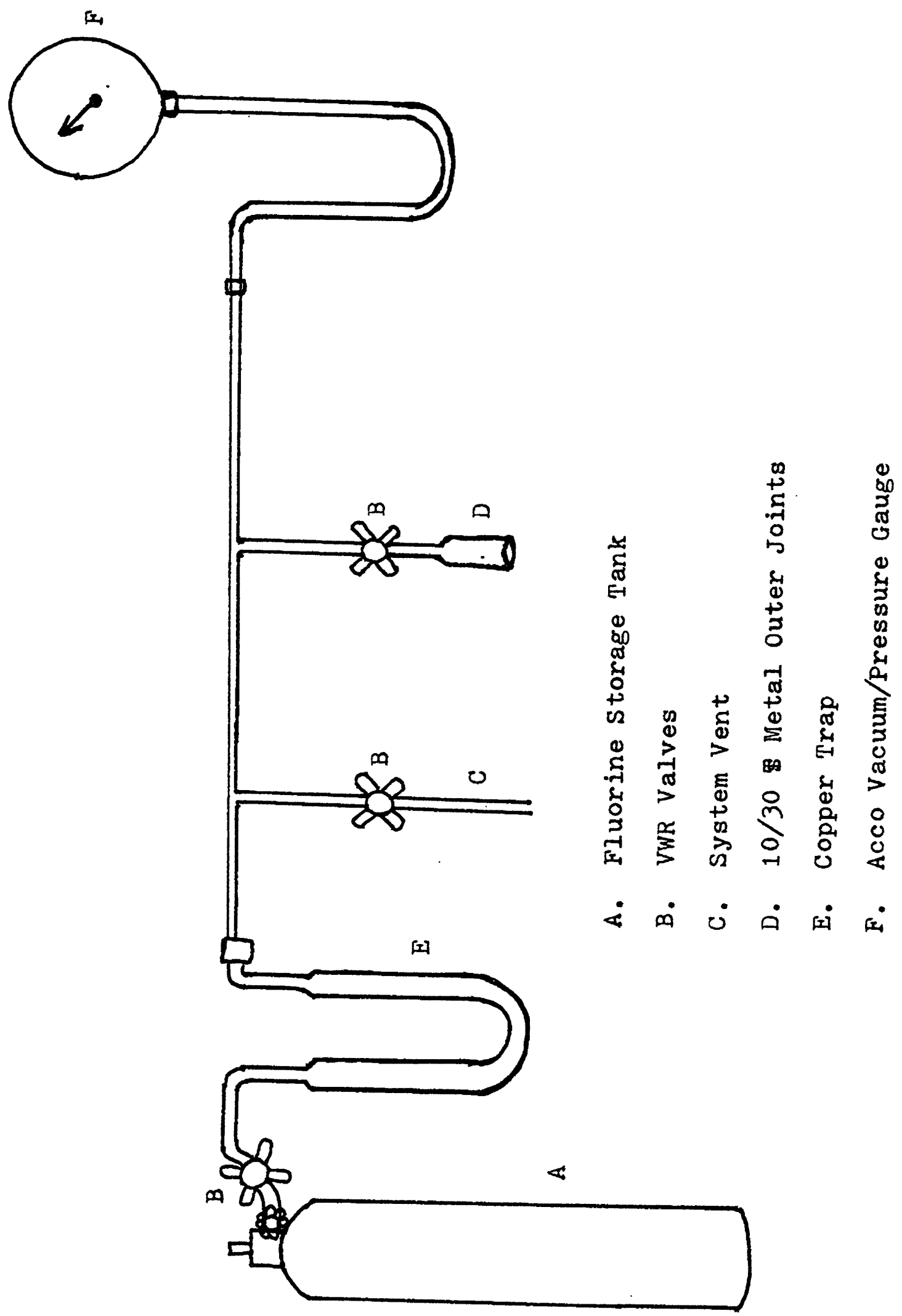

Figure 5. Fluorine line 
tube of $20 \mathrm{~mm}$ I.D. Pyrex glass, to which a Kontes high vacuum Tefion valve was attached by $8 \mathrm{~mm}$ Pyrex tubing, and an inner tube of $8 \mathrm{~mm}$ I.D. Pyrex glass ending in another Teflon valve. Both valves were tipped with 10/30 ground glass joints. A trap is illustrated in Figure 6.

Reaction Vessels. Reaction vessels were composed of either Pyrex glass, fused silica, stainless steel, Monel, or Inconel. The Pyrex glass vessels were constructed from a $100 \mathrm{ml}$ round bottom flask to which had been sealed a Kontes high vacuum Teflon valve fitted with an inner 10/30 ground glass joint. The fused silica vessels were similarly outfitted but the body of the vessel was cylindrical, being constructed of 22,40 , or $50 \mathrm{~mm}$ tubing resulting in a vessel volume of 30,70 , or $100 \mathrm{ml}$, respectively. The body of the vessel was attached to the valve through a graded seal. The Pyrex glass and fused silica vessels were equipped with Teflon coated stirring bars.

Hoke stainless steel cylinders were used for reactions involving pressures up to 100 atmospheres. The vessels had a volume of $75 \mathrm{ml}$ and were equipped with either Hoke, Whitey, or VWR stainless steel valves attached to metal 10/30 $\mathrm{s}$ inner joints.

High pressure reactions up to 300 atmospheres were run in a $100 \mathrm{ml}$ Hoke Monel cylinder equipped with a Hoke high pressure stainless steel metering valve attached to a metal $10 / 30$ inner joint. 


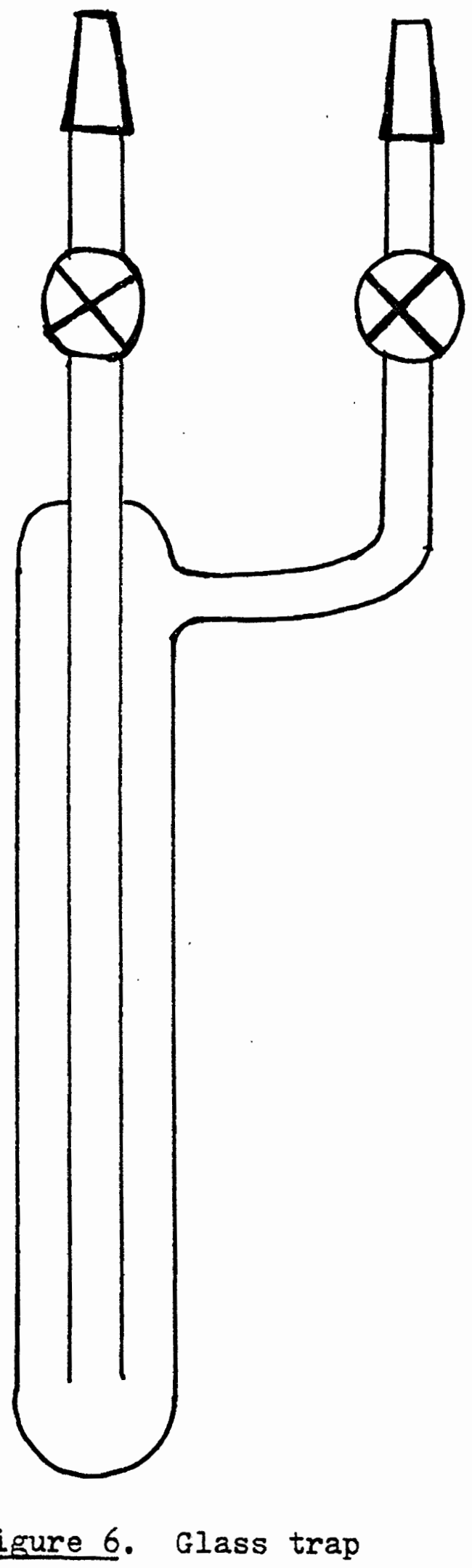


The reaction of chromium trioxide with elemental fluorine was carried out in a $200 \mathrm{ml}$ top loading Inconel vessel. The lid was secured with a lead gasket and twelve $3 / 8$ inch bolts. The vessel was equipped with a Whitey stainless steel metering valve fitted to an inner 10/30 metal joint.

Metal vessels were passivated before reactions were run by heating them while they contained either chlorine monofluoride $(C I F)$ or fluorine $\left(F_{2}\right)$. Frequently nickel bushings $6 \mathrm{~mm}$ in diameter were added to the vessels to facilitate mixing of reactants. Selected reaction vessels are illustrated in Figure 7.

Dry Box. All air sensitive materials were handled in a KSE dry box. Nitrogen, used as the atmosphere, was passed through a calcium sulfate tube. A dry environment was maintained by leaving a container of phosphorous pentoxide exposed in the chamber.

Physical Methods

Infrared Spectra. Infrared spectra were recorded over the range 4000 to $250 \mathrm{~cm}^{-1}$ on a Perkin-Elmer 467 spectrophotometer. Gaseous samples were contained in a Monel cell with a path length of $8.25 \mathrm{~cm}$. Sodium chloride or silver chloride windows were used. All surfaces that were to contact silver chloride were silver plated. The cell was equipped with a Whitey stainless steel metering valve connected to a metal 10/30 inner joint. The spectra of solids were obtained either neat or as Nujol mulls between barium fluoride or 

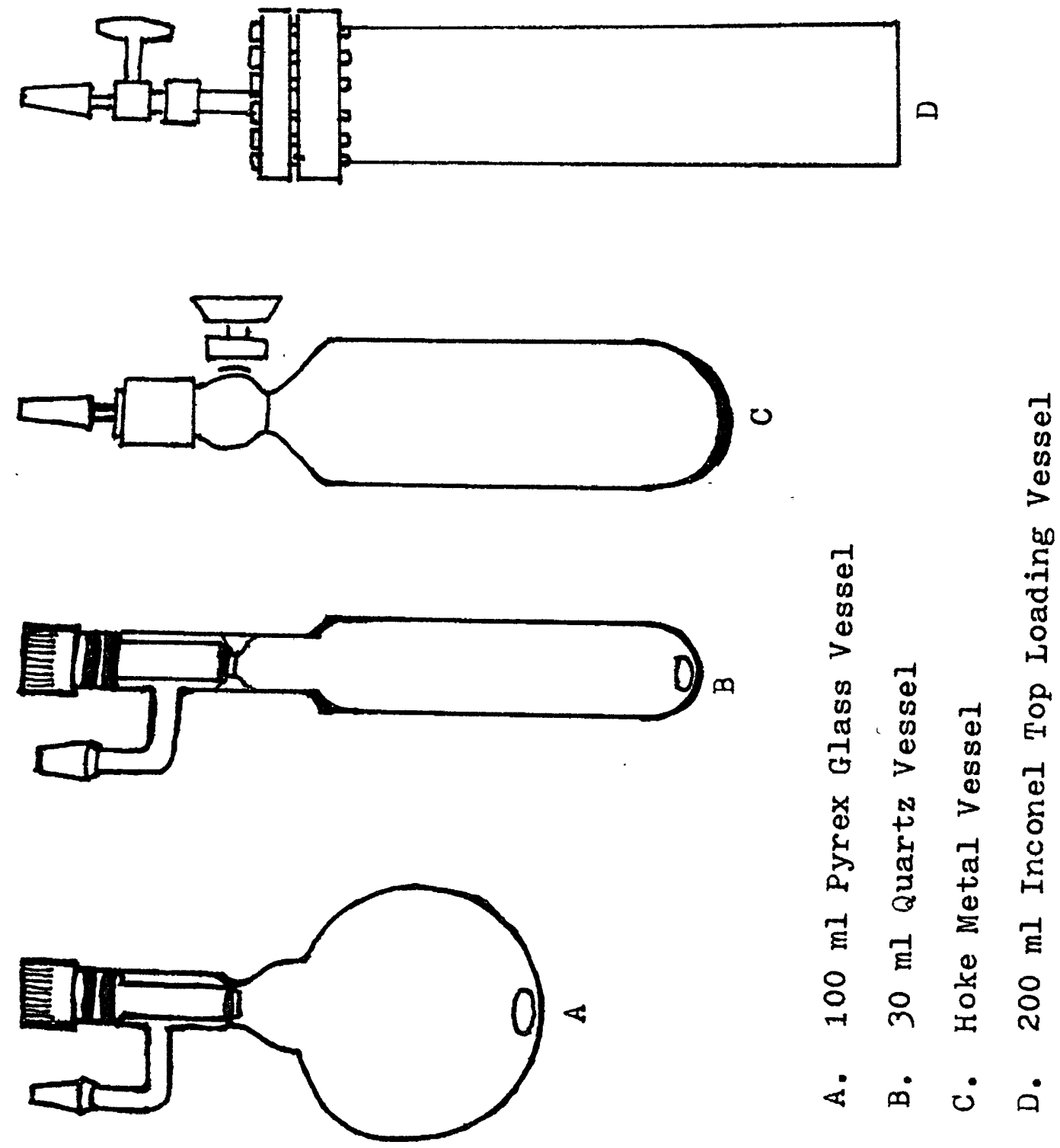

Figure 2. Reaction vessels 
KRS -5 plates, or as potassium bromide pellets. The pellet die and $\mathrm{KBr}$ (Mallinckrodt, Infrared Grade) were taken directly from a drying oven to the dry box, where the pellets were pressed. Infrared spectra were calibrated using polystyrene film.

Visible/Ultraviolet Spectra. Spectra were recorded in the region between 700 and $190 \mathrm{~nm}$ on a Cary 14 spectrometer. Cylindrical quartz sample cells with a path length of $1.0 \mathrm{~cm}$ were used.

X-ray Powder Spectra. Powder spectra were obtained with a General Electric XRD-5 camera, using nickel filtered copper radiation. Pyrex or quartz capillaries of $0.5 \mathrm{~mm}$ diameter were used to contain the samples, which were loaded in the dry box. Exposure time varied between two and four hours. The method was calibrated by measuring the patterns of $\mathrm{CrO}_{3}, \mathrm{~K}_{2} \mathrm{CrO}_{4}$, and $\mathrm{CrF}_{3} \cdot 3 \mathrm{H}_{2} \mathrm{O}$ which agreed with published ASTM values.

Molecular Weight Determinations. The molecular weights of vapors were determined by the vapor density method. A calibrated $200 \mathrm{ml}$ Pyrex glass bulb fitted with an Eck and Krebs high vacuum Teflon valve and a glass $10 / 30$ inner joint was used as the sample vessel.

Melting Points. Melting points were determined with a Mel-Temp apparatus which had a range from ambient conditions to $400^{\circ} \mathrm{C}$.

Elemental Analysis. Elemental analysis of products were 
performed by Beller Microanalytisches Laboratorium, Gottingen, West Germany. Samples for analysis were loaded into $6 \mathrm{~mm} \mathrm{O.D.}$ Pyrex glass tubes in the dry box, and flame sealed under vacuum. A sample container was fabricated out of stainless steel for the shipment of samples which were found to be reactive towards glass.

\section{Reagents}

Antimony Pentafluoride. Antimony pentafluoride $\left(\mathrm{SbF}_{5}\right)$, (Allied Chemical), was vacuum distilled from the commercial shipping cylinder to a trap containing $\mathrm{NaF}$, where it was again distilled into a quartz storage vessel containing NaF. The compound was subjected to dynamic vacuum at $0^{\circ} \mathrm{C}$ before distillation into the reaction vessel.

Bromine Trifluoride. Bromine trifluoride $\left(B r F_{3}\right)$, (Ozark-Mahoning), was condensed over $\mathrm{NaF}$ and then vacuum distilled into the reaction vessel.

Carbon Disulfide. Carbon disulfide $\left(\mathrm{CS}_{2}\right),(\mathrm{MC} / \mathrm{B}$, Spectroquality Reagent), was used as received.

Carbon Tetrachloride. Carbon tetrachloride $\left(\mathrm{CCl}_{4}\right)$, (Mallinckrodt, SpectrAR Grade), was used as received.

Carbonyl Fluoride. Carbonyl fluoride $\left(\mathrm{COF}_{2}\right),(\mathrm{PCR})$, was condensed over $\mathrm{NaF}$ and then vacuum transferred into the reaction vessel. The infrared spectrum agreed with the Iiterature (33).

Chlorine Monofluoride. Chlorine monofluoride (CIF). (Ozark-Mahoning), was transferred from the commercial shipping 
cylinder in a metal vacuum line described elsewhere. No purification was attempted. The infrared spectrum agreed with the Iiterature (34).

Chromium Oxide Difluoride. Chromium oxide difluoride ( $\mathrm{CrOF}_{2}$ ) was prepared by the method of Rochat et al. (21). as described in Chapter IV. The compound was subjected to dynamic vacuum at $150^{\circ} \mathrm{C}$ before use. The $\mathrm{x}$-ray powder spectrum agreed with the literature (21). An infrared spectrum appears in the Appendix.

Chromium Oxide Trifluoride. Chromium oxide trifluoride $\left(\mathrm{CrOF}_{3}\right)$ was prepared by a modified method from that of Green (25) as described in Chapter V. Freshly prepared CrOF 3 was directly transferred from the synthesis vessel to the reaction vessel in the dry box, then subjected to dynamic vacuum at $100^{\circ} \mathrm{C}$. Infrared spectra appear in the Appendix. Chromium Trioxide. Chromium trioxide $\left(\mathrm{CrO}_{3}\right)$, (Baker, Reagent Grade), was transferred to the reaction vessel in the dry box, then subjected to dynamic vacuum at $150^{\circ} \mathrm{C}$ before use. The $\mathrm{x}$-ray powder pattern matched ASTM values.

Chromyl Chloride. Chromyl chloride $\left(\mathrm{CrO}_{2} \mathrm{Cl}_{2}\right)$, (PfaltzBauer), was vacuum distilled from a vessel containing metallic mercury to the reaction vessel. The infrared spectrum agreed with the literature (35).

Chromyl Fluoride. Chromyl fluoride $\left(\mathrm{CrO}_{2} \mathrm{~F}_{2}\right)$ was prepared by two methods developed by Green and Gard (27) and is described in Chapter IV. The compound was subjected to 
dynamic vacuum at $-78^{\circ} \mathrm{C}$ before sublimation through the metal vacuum line to the reaction vessel. The infrared spectrum agreed with the literature (36) and appears in the Appendix. Dimethyl Sulfoxide. Dimethyl sulfoxide $\left(\left(\mathrm{CH}_{3}\right)_{2} \mathrm{SO}\right)$, (MC/B, Spectroquality Reagent), was used as received.

Fluorine. Fluorine $\left(\mathrm{F}_{2}\right)$, (Air Products, 98\%), was passed through a copper trap filled with nickel helices, cooled to $-78^{\circ} \mathrm{C}$, in a metal line described elsewhere.

Hydrogen Fluoride. Hydrogen fluoride (HF), (Matheson), was distilled into the reaction vessel through the metal vacuum line. The infrared spectrum agreed with the literature (37) with no extraneous bands present.

Molybdenum Trioxide. Molybdenum trioxide $\left(\mathrm{MoO}_{3}\right)$, ( $\mathrm{MC} / \mathrm{B}$, Reagent Grade), was transferred to the reaction vessel in the dry box, then subjected to dynamic vacuum at $150^{\circ} \mathrm{C}$ before use. The x-ray powder pattern matched ASTM values.

Nitryl Fluoride. Nitryl fluoride $\left(\mathrm{NO}_{2} \mathrm{~F}\right)$, (OzarkMahoning), was found to be highly contaminated with $\mathrm{NO}_{2}$ and $\mathrm{N}_{2} \mathrm{O}_{4}$. The commercial shipping cylinder was cooled to $-78^{\circ} \mathrm{C}$ and then crude $\mathrm{NO}_{2} \mathrm{~F}$ was distilled through the metal vacuum line to a metal vessel containing NaF. The metal vessel was now held at $-78^{\circ} \mathrm{C}$ and pure $\mathrm{NO}_{2} \mathrm{~F}$ was vacuum distilled directly into the reaction vessel. The infrared spectrum agreed with the literature (38).

Perfluoroglutaric Anhydride. Perfluoroglutaric anhydride $\left(\left(\mathrm{CF}_{2}\right)_{3}(\mathrm{CO})_{2} \mathrm{O}\right)$, ( $\left.\mathrm{PCR}\right)$, was vacuum distilled directly into 
the reaction vessel. The infrared spectrum agreed with the Iiterature (39).

Perfluoroglutaryl Fluoride. Perfluoroglutaryl fluoride $\left(\left(\mathrm{CF}_{2}\right)_{3}(\mathrm{COF})_{2}\right),(\mathrm{PCR})$, was handled in the same manner as the anhydride.

Potassium Chromate. Potassium chromate $\left(\mathrm{K}_{2} \mathrm{CrO}_{4}\right)$, (Mallinckrodt, Reagent Grade), was subjected to dynamic vacuum while heating at $150^{\circ} \mathrm{C}$ before use.

Potassium Fluoride. Potassium fluoride (KF), (Baker, Anhydrous Reagent), was transferred to the reaction vessel in the dry box, then subjected to dynamic vacuum.

Sodium Molybdate Dihydrate. Sodium molybdate dihydrate $\left(\mathrm{Na}_{2} \mathrm{MOO}_{4} \cdot 2 \mathrm{H}_{2} \mathrm{O}\right)$, ( $\mathrm{Mallinckrodt,} \mathrm{Reagent}$ Grade), was dehydrated by heating in vacuo at $140^{\circ} \mathrm{C}$ until a high vacuum was achieved. The $\mathrm{x}$-ray powder pattern matched ASTM values for $\mathrm{Na}_{2} \mathrm{MOO}_{4}$.

Sodium Perfluoroglutarate. Sodium perfluoroglutarate $\left(\mathrm{Na}_{2}\left(\mathrm{O}_{2} \mathrm{C}\right)_{2}\left(\mathrm{CF}_{2}\right)_{3}\right)$ was prepared by hydrolyzing the anhydride $(P C R)$ and titrating the resulting acid solution with sodium hydroxide (Mallinckrodt, Reagent Grade) to a $\mathrm{pH} 7$ endpoint. The salt solution was evaporated, then subjected to dynamic vacuum at $20^{\circ} \mathrm{C}$. The white crystals of sodium perfluoroglutarate were mildly hygroscopic and decomposed above $280^{\circ} \mathrm{C}$. An infrared spectrum appears in the Appendix.

Sodium Tungstate Dihydrate. Sodium tungstate dihydrate $\left(\mathrm{Na}_{2} \mathrm{WO}_{4} \cdot 2 \mathrm{H}_{2} \mathrm{O}\right)$, (Mallinckrodt, Reagent Grade), was treated in the same manner as the molybdenum salt. The $x$-ray powder pattern 
matched ASTM values for $\mathrm{Na}_{2} \mathrm{HO}_{4}$.

Trifluoroacetic Acid. Trifluoroacetic acid ( $\left.\mathrm{CF}_{3} \mathrm{COOH}\right)$. $(P C R)$, was contacted with $\mathrm{P}_{4} \mathrm{O}_{10}$ then vacuum distilled into the reaction vessel.

Tungsten Hexafluoride. Tungsten hexafluoride ( $\left.W F{ }_{6}\right)$, (Ozark-Mahoning), was vacuum distilled onto $\mathrm{NaF}$, then redistilled into the reaction vessel. The infrared spectrum agreed with the literature (40).

Tungsten Trioxide. Tungsten trioxide $\left(\mathrm{WO}_{3}\right),(\mathrm{MC} / \mathrm{B}$, Reagent Grade), was transferred to the reaction vessel in the dry box, then subjected to dynamic vacuum at $150^{\circ} \mathrm{C}$ before use. The $x$-ray powder pattern matched ASTM values. 


\section{CHAPTER III}

\section{SYNTHESIS OF GROUP VI B PERFLUOROGLUTARATES}

Introduction

Fluorinated acid anhydrides have been found to add across metal-oxygen multiple bonds, while the corresponding reaction with hydrocarbon anhydrides is ineffective. The proposed pathway (41) is illustrated in Figure 8. The fluoroalkyl group induces a partial positive charge on the carbonyl carbon which facilitates interaction with the $\pi$ electrons in the $M=0$ Iinkage. In hydrocarbon anhydrides the inductive effect is absent.
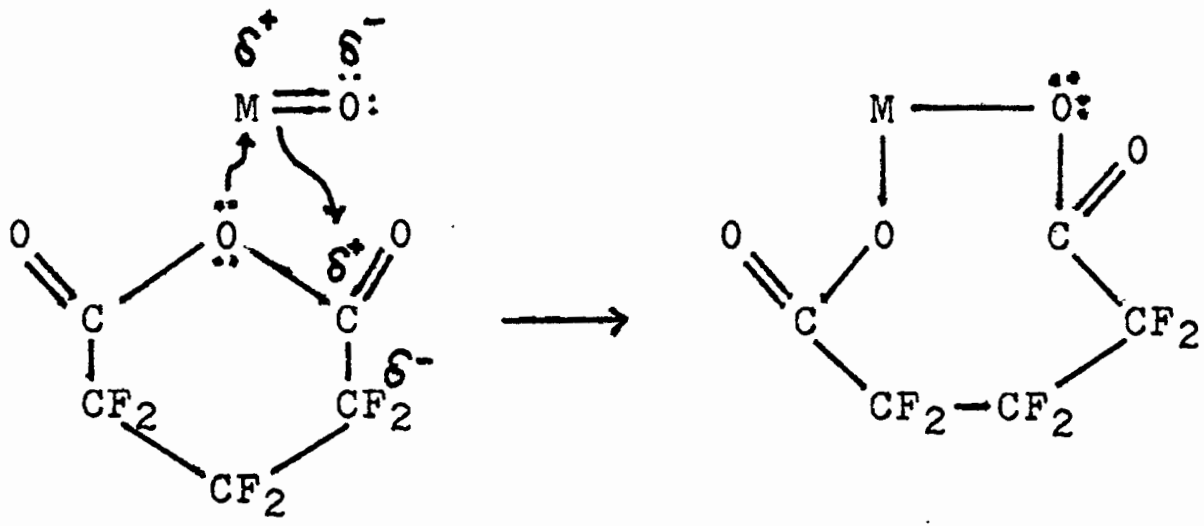

Figure 8. Proposed mechanism for the addition of acid anhydrides (perfluoroglutaric anhydride) across metal-oxygen multiple bonds.

For simplicity the figure shows a chelate structure, but a two-step mechanism would also allow a polymeric structure. In this manner, a series of chromyl compounds were prepared by reacting the appropriate acid anhydride with 
chromium trioxide at room temperature in the absence of light (4).

III-1 $\mathrm{CrO}_{3}+\left(\mathrm{CF}_{3} \mathrm{CO}\right)_{2} \mathrm{O} \longrightarrow \mathrm{CrO}_{2}\left(\mathrm{O}_{2} \mathrm{CCF}_{3}\right)_{2}$

III-2 $\mathrm{CrO}_{3}+\left(\mathrm{CICF}_{2} \mathrm{CO}\right)_{2} \mathrm{O} \longrightarrow \mathrm{CrO}_{2}\left(\mathrm{O}_{2} \mathrm{CCF}_{2} \mathrm{CI}\right)_{2}$

III-3 $\mathrm{CrO}_{3}+\left(\mathrm{C}_{3} \mathrm{~F}_{7} \mathrm{CO}\right)_{2} \mathrm{O} \longrightarrow \mathrm{CrO}_{2}\left(\mathrm{O}_{2} \mathrm{CC}_{3} \mathrm{~F}_{7}\right)_{2}$

The products were shown to have unidentate carboxylate linkages by their infrared spectra which is in accord with the four coordinate, tetrahedral structure of chromyl compounds. The products were also soluble in carbon tetrachloride, were moisture and light sensitive, and did not explode with handling or heating above room temperature.

In addition to covalent chromyl compounds, many transition metal salts were prepared (41). A few examples are relevant to the work reported in this chapter:

III-4 $\mathrm{K}_{2} \mathrm{CrO}_{4}+2\left(\mathrm{CF}_{3} \mathrm{CO}\right)_{2} \mathrm{O} \frac{25^{\circ} \mathrm{C}}{1 \mathrm{day}} \mathrm{K}_{2} \mathrm{CrO}_{2}\left(\mathrm{O}_{2} \mathrm{CCF}_{3}\right)_{4}$

III-5 $\mathrm{Na}_{2} \mathrm{MOO}_{4}+2\left(\mathrm{CF}_{3} \mathrm{CO}\right)_{2} \mathrm{O} \frac{50^{\circ} \mathrm{C}}{20 \text { days }} \mathrm{Na}_{2} \mathrm{MOO}_{2}\left(\mathrm{O}_{2} \mathrm{CCF}_{3}\right)_{4}$

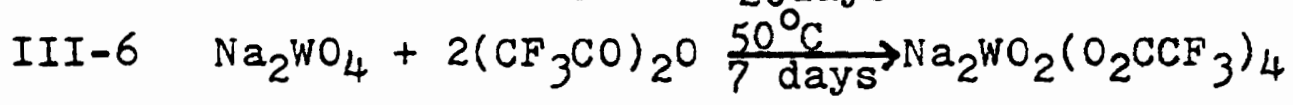

Based on the above work, it was thought that a chromyl compound containing a bivalent ligand in place of the customary two univalent ligands, might exhibit interesting properties such as increased stability. A new chromyl compound, chromyl perfluoroglutarate, was prepared by reacting chromium trioxide with perfluoroglutaric anhydride:

III-7 $\mathrm{CrO}_{3}+\left(\mathrm{CF}_{2}\right)_{3}(\mathrm{CO})_{2} \mathrm{O} \frac{35^{\circ} \mathrm{C}}{5 \text { days }} \mathrm{CrO}_{2}\left(\left(\mathrm{O}_{2} \mathrm{C}\right)_{2}\left(\mathrm{CF}_{2}\right)_{3}\right)$

Chromyl perfluoroglutarate was also prepared by two other methods: 
III- $82 \mathrm{CrO}_{3}+\mathrm{FOC}\left(\mathrm{CF}_{2}\right)_{3} \mathrm{COF} \frac{30^{\circ} \mathrm{C}}{2 \text { days }} \mathrm{CrO}_{2}\left(\left(\mathrm{O}_{2} \mathrm{C}\right)_{2}\left(\mathrm{CF}_{2}\right)_{3}\right)+\mathrm{CrO}_{2} \mathrm{~F}_{2}$

III-9 $\mathrm{FrOC}_{2} \mathrm{FCF}_{2}+2\left(\mathrm{CF}_{2}\right)_{3}(\mathrm{COF})_{2} \mathrm{O}_{1} \underset{1 \text { day }}{\stackrel{\mathrm{O}_{\mathrm{C}}}{\mathrm{CrO}_{2}}\left(\left(\mathrm{O}_{2} \mathrm{C}\right)_{2}\left(\mathrm{CF}_{2}\right)_{3}\right)+}$

In addition, the analogous molybdenyl and tungstenyl compounds were prepared:

III-10 $\mathrm{MOO}_{3}+\left(\mathrm{CF}_{2}\right)_{3}(\mathrm{CO})_{2} \mathrm{O} \frac{60^{\circ} \mathrm{C}}{13 \text { days }} \mathrm{MoO}_{2}\left(\left(\mathrm{O}_{2} \mathrm{C}\right)_{2}\left(\mathrm{CF}_{2}\right)_{3}\right)$

III-11 $\mathrm{WO}_{3}+\left(\mathrm{CF}_{2}\right)_{3}(\mathrm{CO})_{2} \mathrm{O} \cdot \frac{80^{\circ} \mathrm{C}}{50 \text { days }} \mathrm{WO}_{2}\left(\left(\mathrm{O}_{2} \mathrm{C}\right)_{2}\left(\mathrm{CF}_{2}\right)_{3}\right)$

Group VI B perfluoroglutarate salts were prepared in reactions similar to those already described (equations III-4, III-5, III-6) except that in the case of the molybdenum and tungsten salts, addition occurred across only one metaloxygen double bond:

III-12 $\mathrm{K}_{2} \mathrm{CrO}_{4}+2\left(\mathrm{CF}_{2}\right)_{3}(\mathrm{CO})_{2} \mathrm{O} \underset{24}{\stackrel{50^{\circ} \mathrm{C}}{2} \mathrm{days}_{2}} \mathrm{~K}_{2} \mathrm{CrO}_{2}\left(\left(\mathrm{O}_{2} \mathrm{C}\right)_{2}\left(\mathrm{CF}_{2}\right)_{3}\right)_{2}$

III-13 $\mathrm{Na}_{2} \mathrm{MOO}_{4}+\left(\mathrm{CF}_{2}\right)_{3}(\mathrm{CO})_{2} \mathrm{O} \frac{55^{\circ} \mathrm{C}}{13 \text { days }} \mathrm{Na}_{2} \mathrm{MOO}_{2}\left(\left(\mathrm{O}_{2} \mathrm{C}\right)_{2}\left(\mathrm{CF}_{2}\right)_{3}\right)$

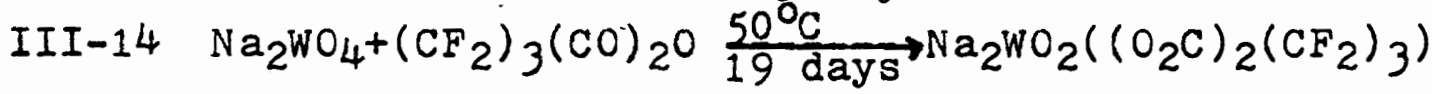

Perfluoroglutaric anhydride appears to be less reactive than trifluoroacetic anhydride in the addition across metaloxygen double bonds. This is clearly reflected in the temperature and time required for analogous reactions. The cyclic structure of perfluoroglutaric anhydride is probably responsible for this effect. Perfluoroglutarate compounds are also relatively unstable when compared to the trifluoroacetate compounds. The longer fluorocarbon chain and the presence of the less shielded $-\mathrm{CF}_{2}$ - group may be the cause of this instability as chromyl perfluorobutyrate $\left(\mathrm{CrO}_{2}\left(\mathrm{O}_{2} \mathrm{CC}_{3} \mathrm{~F}_{7}\right)_{2}\right)$ was also found to be unstable, decomposing at room temperature (4). 
Physical and structural data for the perfluoroglutarate compounds appear in the experimental and discussion sections.

\section{Experimental}

Reaction of Chromium Trioxide With Perfluoroglutaric Anhydride. Chromium trioxide $(8.58$ mmoles) was added to a thoroughly dried $100 \mathrm{ml}$ Pyrex glass vessel. Perfluoroglutaric anhydride ( 112 mmoles) was then condensed into the vessel via vacuum distillation. The reaction mixture was protected from light, and heated with stirring at $35^{\circ} \mathrm{C}$ for 5 days. The violet crystals of $\mathrm{CrO}_{3}$ slowly turned to a red-brown powder while the liquid organic anhydride phase remained clear. Upon evacuation of the vessel at $0^{\circ} \mathrm{C}$, through a trap cooled with liquid nitrogen, no non-condensable gases were found. After removal of the excess anhydride, the vessel was found to contain a slightly volatile tan-brown powder. The weight pickup of the vessel corresponded to 8.49 mmoles of perfluoroglutaric anhydride, 99\% of that expected for 1:1 stoichiometry. Analysis for $\mathrm{CrO}_{2}\left(\left(\mathrm{O}_{2} \mathrm{C}\right)_{2}\left(\mathrm{CF}_{2}\right)_{3}\right)$ (chromyl perfluoroglutarate)Cr; Requires: 16.15\% Found: $17.67 \%, \mathrm{C}$; Requires: $18.65 \%$ Found: $17.01 \%$, F; Requires: $35.4 \%$ Found: $35.1 \%$. The product is very hygroscopic, hydrolyzing to a yellow chromic acid solution according to the equation:

III-15 $\mathrm{CrO}_{2}\left(\left(\mathrm{O}_{2} \mathrm{C}\right)_{2}\left(\mathrm{CF}_{2}\right)_{3}\right)+2 \mathrm{H}_{2} \mathrm{O} \rightarrow \mathrm{CrO}_{4}^{+}+-0 \mathrm{OC}\left(\mathrm{CF}_{2}\right)_{3} \mathrm{COO}^{-}+4 \mathrm{H}^{+}$ Based on this equation, the compound was analyzed for chromium in this laboratory by iodometric and acid/base titration. 
Analysis for $\mathrm{CrO}_{2}\left(\left(\mathrm{O}_{2} \mathrm{C}\right)_{2}\left(\mathrm{CF}_{2}\right)_{3}\right)$ - Requires: $\mathrm{Cr}, 16.15 \%$ Found: $\mathrm{Cr}, 15.6 \%$ via iodometry, $16.1 \%$ via acidity.

Chromyl perfluoroglutarate is a strong oxidizer which ignites acetone and methanol, oxidizes $\mathrm{CH}_{3} \mathrm{CN}$, is insoluble in $\mathrm{CS}_{2}$ and perfluoroalkane -70 , and is only very slightly soluble in $\mathrm{CCl}_{4}$ forming a brown solution. An ultraviolet spectrum of the product in $\mathrm{CCl}_{4}$ showed two absorbtions, one at $274 \mathrm{~nm}$ and a weaker transition at $408 \mathrm{~nm}$.

An attempt was made to purify the product via vacuum sublimation. From ambient temperature to $60^{\circ} \mathrm{C}$, very small amounts of an orange-brown solid condensed in the cold trap. Near $85^{\circ} \mathrm{C}$ a violent explosion occurred producing $\mathrm{CO}_{2}, \mathrm{COF}_{2}$, and $\mathrm{CF}_{3} \mathrm{COF}$ among other products, as identified by their respective infrared spectra $(42,33,43)$. When the product is slowly heated in a sealed glass capillary, decomposition occurs above $80^{\circ} \mathrm{C}$, rapid heating results in explosive decomposition around $70^{\circ} \mathrm{C}$ to $90^{\circ} \mathrm{C}$.

The $\mathrm{x}$-ray diffraction powder pattern of the product is listed in Table I. An infrared spectrum is listed in Table II and also appears in the appendix.

Reaction of Chromium Trioxide With Perfluoroglutaryl Fluoride. Perfluoroglutaryl fluoride $(75.5$ mmoles $)$ was vacuum distilled into a $100 \mathrm{ml}$ quartz vessel containing 7.87 mmoles of $\mathrm{CrO}_{3}$. The mixture was heated with stirring in the dark at $30^{\circ} \mathrm{C}$. After 20 hours red-brown vapors started to form which were periodically removed from the vessel by brief 
TABLE I

$X-R A Y$ POWDER PATTERN OF CHRONYI PERFLUOROGLUTARATE d $(\stackrel{\circ}{A} \quad$ Intensity

d $(\stackrel{\circ}{A}) \quad$ Intensity

13.89

w

3.43

s

11.21

vw

3.29

vw

11.13

m

3.10

VW

9.24

Vw

2.98

Vw

8.37

w

2.87

m

7.54

w

2.62

vw

6.51

w

2.47

vw

5.85

vw

2.39

vw

5.69

vw

2.34

vw

5.47

vw

2.25

vw

4.95

m

2.23

vw

4.73

vw

2.19

w

4.55

m

1.92

vw

4.18

s

1.82

vw

3.99

vw

1.74

vw

3.84

m

1.50

vw

\footnotetext{
$s=$ strong

$\mathrm{m}=$ medium

$w=$ weak

$\mathrm{vw}=$ very weak
} 


\section{TABIE II}

INFRARED SPECTRA OF CHROMYL PERFLUOROGLUTARATE IN $\mathrm{CM}^{-1}$

(A) $\mathrm{CrO}_{3}+\left(\mathrm{CF}_{2}\right)_{3}(\mathrm{CO})_{2} \mathrm{O} \longrightarrow \mathrm{CrO}_{2}\left(\left(\mathrm{O}_{2} \mathrm{C}\right)_{2}\left(\mathrm{CF}_{2}\right)_{3}\right)$

(B) $2 \mathrm{CrO}_{3}+\mathrm{FOC}\left(\mathrm{CF}_{2}\right)_{3} \mathrm{COF} \longrightarrow \mathrm{CrO}_{2}\left(\left(\mathrm{O}_{2} \mathrm{C}\right)_{2}\left(\mathrm{CF}_{2}\right)_{3}\right)+\mathrm{CrO}_{2} \mathrm{~F}_{2}$

(C) $\mathrm{CrO}_{2} \mathrm{~F}_{2}+2\left(\mathrm{CF}_{2}\right)_{3}(\mathrm{CO})_{2} \mathrm{O} \longrightarrow \mathrm{CrO}_{2}\left(\left(\mathrm{O}_{2} \mathrm{C}_{2}\left(\mathrm{CF}_{2}\right)_{3}\right)+\mathrm{FOC}\left(\mathrm{CF}_{2}\right)_{3} \mathrm{COF}\right.$

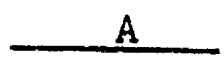

$1780 \mathrm{~s}$

$1655 \mathrm{~s}, \mathrm{~b}$

$1415 \mathrm{~m}, \mathrm{~b}$

$1255 \mathrm{~m}$

1170 vs

$1055 \mathrm{~m}$

$970 \mathrm{~s}$

$950 \mathrm{~s}$

$905 \mathrm{~m}$

$815 \mathrm{~m}$

$700 \mathrm{~s}, \mathrm{~b}$

$565 \mathrm{~m}$

$325 w$

$280 \mathrm{w}$

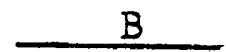

$3740 \mathrm{w}$

$1875 \mathrm{~m}$

$1755 \mathrm{~s}$

$1630 \mathrm{~s}, \mathrm{~b}$

$1418 \mathrm{~s}$

$1265 \mathrm{~m}$

1150 vs

$1035 \mathrm{~m}$

975 s,b

$890 \mathrm{~m}$

$810 \mathrm{~s}$

$680 \mathrm{~s}, \mathrm{~b}$

$540 \mathrm{~m}$

$975 \mathrm{~s}, \mathrm{~b}$

$890 \mathrm{~m}$

$805 \mathrm{~m}$

$700 \mathrm{~s}, \mathrm{~b}$

$555 \mathrm{~m}$

$310 \mathrm{w}$

$1760 \mathrm{~s}$

$1630 \mathrm{~s}, \mathrm{~b}$

$1425 \mathrm{~s}$

$1035 \mathrm{~m}$
Assignment

impurity

impurity

$V\left(\operatorname{asym~} \mathrm{CO}_{2}\right) \longrightarrow$

$\mathcal{V}\left(\right.$ asym $\left.\mathrm{CO}_{2}\right) \Delta \omega=365$

$\mathcal{V}\left(\operatorname{sym~CO} \mathrm{CO}_{2}\right)$

$\nu\left(\mathrm{C}-\mathrm{F}\right.$ or sym $\left.\mathrm{CCO}_{2}\right)$

$\nu(\mathrm{C}-\mathrm{F})$

$\nu(C-F)$

$\nu$ (asym $\mathrm{Cr}=0)$

$v($ sym Cr=0)

$v(C-C)$

$v(C-F)$

$\delta\left(\mathrm{CCO}_{2}\right)$

$v(\mathrm{Cr}-0)$

and

$\delta(C-F)$

vs = very strong

$s=$ strong

$m=$ medium

$w=$ weak

$\mathrm{b}=$ broad 
evacuation through a $-196^{\circ} \mathrm{C}$ trap. The red-brown vapor was identified as $\mathrm{CrO}_{2} \mathrm{~F}_{2}$ by its infrared spectrum (36). The reaction appeared to be complete after 43 hours as evident by a decrease in the production of $\mathrm{CrO}_{2} \mathrm{~F}_{2}$ vapors and the formation of a chocolate-brown solution. The excess acid fluoride was distilled out of the vessel at $0^{\circ} \mathrm{C}$ under vacuum. A gummy brown solid remained in the vessel which slowly turned into a fine chocolate-brown powder under dynamic vacuum. The constant weight product corresponded to 4.65 mmoles of chromyl perfluoroglutarate $(3.94$ mmoles theoretical). Analysis for $\mathrm{CrO}_{2}\left(\left(\mathrm{O}_{2} \mathrm{C}\right)_{2}\left(\mathrm{CF}_{2}\right)_{3}\right)-\mathrm{Cr}$; Requires: $16.15 \%$ Found: $12.34 \%$, C ; Requires: $18.65 \%$ Found: $20.00 \%$. F; Requires: $35.4 \%$ Found: $43.9 \%$.

The product was very hygroscopic, hydrolyzing to a yellow solution. Upon slow heating, the brown product slowly decomposed above $85^{\circ} \mathrm{C}$. The infrared spectrum is listed in Table II.

\section{Reaction of Chromyl Fluoride with Perfluoroglutaric}

Anhydride. Perfluoroglutaric anhydride (18.7 mmoles) and chromyl fluoride ( 5.36 mmoles) were vacuum distilled into a $100 \mathrm{ml}$ quartz vessel and stirred at $0^{\circ} \mathrm{C}$ in the dark. After 25 hours, all red-brown vapors of $\mathrm{CrO}_{2} \mathrm{~F}_{2}$ had disappeared and the solution had gone from orange to dark brown in color. An infrared spectrum of the vapors showed the presence of perfluoroglutaryl fluoride.

The vessel was evacuated at $0^{\circ} \mathrm{C}$. A small amount of tanbrown solids sublimated out of the vessel. The material 
remaining in the vessel reduced to a sticky dark brown semisolid. Pumping on the vessel to constant weight resulted in the recovery of a dark brown powder. The weight of the product corresponded to 5.34 mmoles of chromyl perfluoroglutarate. Analysis for $\mathrm{CrO}_{2}\left(\left(\mathrm{O}_{2} \mathrm{C}\right)_{2}\left(\mathrm{CF}_{2}\right)_{3}\right)$ - $\mathrm{Cr}$; Requires: $16.15 \%$ Found: $12.49 \%$, C : Requires: $18.65 \%$ Found: $19.65 \%$, F; Requires $35.4 \%$ Found: $43.6 \%$.

The hygroscopic dark brown product hydrolyzes to a yellow solution and decomposed when heated above $60^{\circ} \mathrm{C}$. The infrared spectrum is listed in Table II.

Reaction of Molybdenum Trioxide With Perfluoroglutaric Anhydride. Perfluoroglutaric anhydride ( $81.2 \mathrm{mmoles})$ was vacuum distilled into a $100 \mathrm{ml}$ Pyrex glass vessel containing 2.7 mmoles of predried molybdenum trioxide. After 9 days at $60^{\circ} \mathrm{C}$ the reaction mixture had a slight blue tint, indicating reduced states of molybdenum. The excess perfluoroglutaric anhydride was distilled out of the vessel after a total reaction time of 13 days.

The vessel contained a non-volatile, light blue solid which was hygroscopic and melted at $93.5^{\circ} \mathrm{C}$. The weight pickup corresponded to the coordination. of $2.4 \mathrm{mmoles}$ of perfluoroglutaric anhydride. The infrared spectrum of the product is listed in Table III and also appears in the appendix.

Reaction of Tungsten Trioxide and Perfluoroglutaric Anhydride. To a $100 \mathrm{ml}$ Pyrex glass vessel containing 4.6 


\section{TABLE III}

INFRARED SPECTRA OF $\mathrm{MOO}_{2}\left(\left(\mathrm{O}_{2} \mathrm{C}\right)_{2}\left(\mathrm{CF}_{2}\right)_{3}\right)$ AND $\mathrm{WO}_{2}\left(\left(\mathrm{O}_{2} \mathrm{C}\right)_{2}\left(\mathrm{CF}_{2}\right)_{3}\right)$ IN CM-1

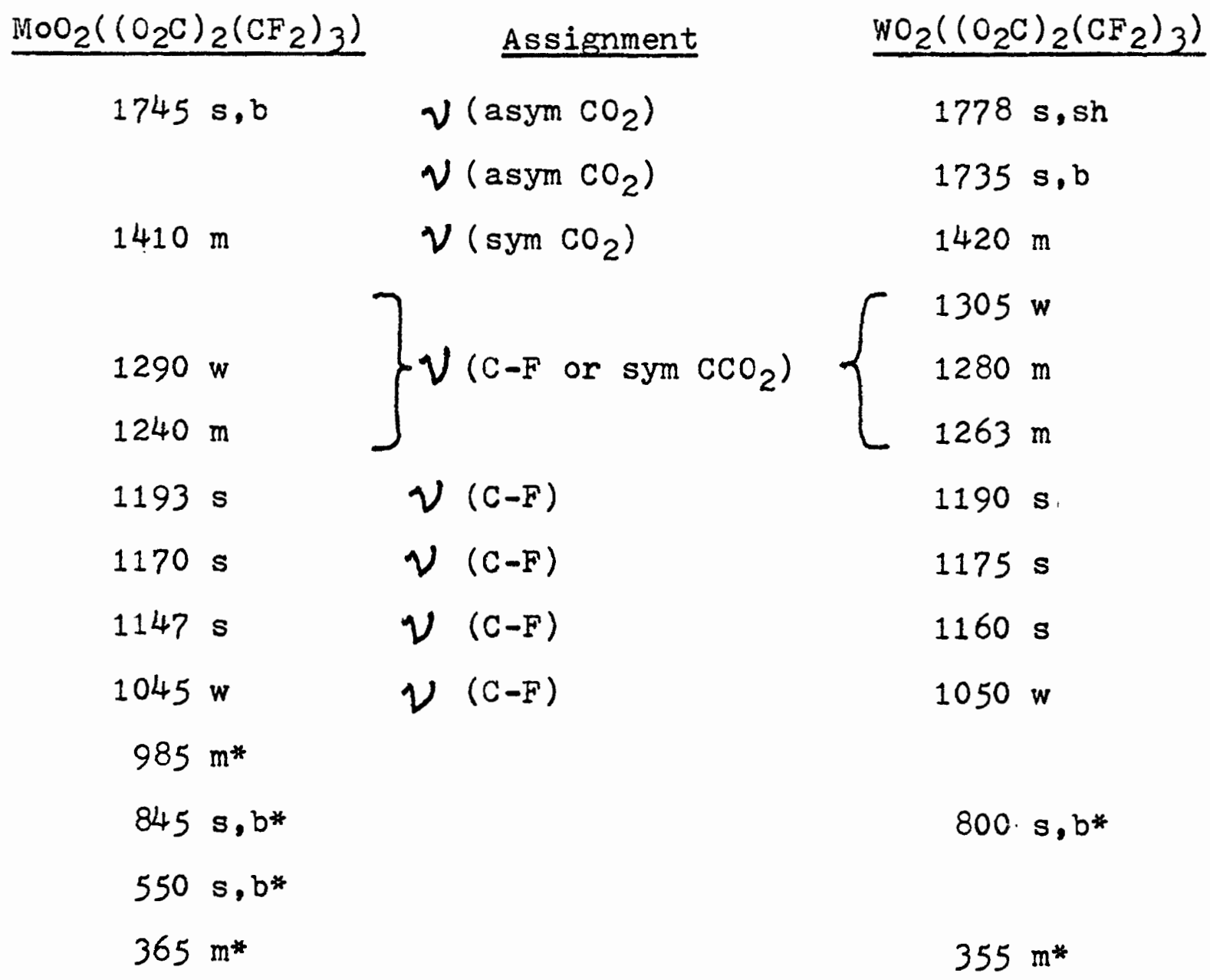

*Band attributed to unreacted $\mathrm{MOO}_{3}$ and $\mathrm{WO}_{3}$.

$s=$ strong

m=medium

$w=$ weak

$\mathrm{b}=$ broad

sh=sharp 
mmoles of predried $\mathrm{WO}_{3}$ was added 73.5 mmoles of perfluoroglutaric anhydride via vacuum distillation. The reaction mixture was heated at $80^{\circ} \mathrm{C}$ with stirring for 50 days. Upon evacuation of the vessel at $20^{\circ} \mathrm{C}$, a pale-yellow non-volatile solid was found which melted at $85.5^{\circ} \mathrm{C}$. The weight pickup of the vessel corresponded to 4.3 mmoles of perfluoroglutaric anhydride. Analysis for $\mathrm{WO}_{2}\left(\left(\mathrm{O}_{2} \mathrm{C}\right)_{2}\left(\mathrm{CF}_{2}\right)_{3}\right)$ - C; Requires: $13.22 \%$ Found: $10.08 \%$, W; Requires: $40.51 \%$ Found: $48.3 \%$, F; Requires: $25.1 \%$ Found: $20.7 \%$.

The infrared spectrum of the product is listed in Table III and appears in the appendix.

Reaction of Potassium Chromate with Perfluoroglutaric Anhydride. To 2.69 mmoles of $\mathrm{K}_{2} \mathrm{CrO}_{4}$ contained in a $100 \mathrm{ml}$ Pyrex glass vessel was added 42.5 mmoles of perfluoroglutaric anhydride via vacuum distillation. The reaction mixture was stirred in the dark for 24 days at $50^{\circ} \mathrm{C}$. Upon evacuation of the vessel at $20^{\circ} \mathrm{C}$ a green solid was found. The weight gain of the vessel corresponded to 5.42 mmoles of the anhydride or a stoichiometry of $2: 1$ anhydride to salt. Analysis for $\mathrm{K}_{2} \mathrm{CrO}_{2}\left(\left(\mathrm{O}_{2} \mathrm{C}\right)_{2}\left(\mathrm{CF}_{2}\right)_{3}\right)_{2}-\mathrm{Cr}$; Requires: $8.2 \%$ Found: $9.8 \%$, C ; Requires: $18.80 \%$ Found: $16.95 \%$, F; Requires $35.7 \%$ Found: $33.0 \%$.

The product was hygroscopic, hydrolyzing to a yellow solution, and melted at $150^{\circ} \mathrm{C}$. A unique $\mathrm{x}$-ray powder pattern was obtained in which only the two strongest lines for $\mathrm{K}_{2} \mathrm{CrO}_{4}$ appear as medium intensity lines. The $x$-ray powder pattern is listed in Table IV and the infrared spectrum is listed in Table $V$ and appears in the appendix. 
TABLE IV

X-RAY POWDER PA'TTERN OF $\mathrm{K}_{2} \mathrm{CrO}_{2}\left(\left(\mathrm{O}_{2} \mathrm{C}\right)_{2}\left(\mathrm{CF}_{2}\right)_{3}\right)_{2}$

\begin{tabular}{|c|c|c|c|}
\hline $\mathrm{d}(\AA)$ & Intensity & $d(\AA)$ & Intensity \\
\hline 19.53 & $\mathrm{~m}$ & 3.23 & $w$ \\
\hline 8.34 & $w$ & 3.08 & $m^{*}$ \\
\hline 7.52 & $\mathrm{~m}$ & 2.98 & $m^{*}$ \\
\hline 6.20 & $\mathrm{~m}$ & 2.91 & $v w$ \\
\hline 5.53 & $\mathbf{s}$ & 2.84 & $w$ \\
\hline 5.29 & vs & 2.75 & $w$ \\
\hline 5.16 & vs & 2.71 & $\mathrm{vw}$ \\
\hline 4.96 & $w$ & 2.64 & vw \\
\hline 4.76 & $w$ & 2.57 & $\mathrm{~m}$ \\
\hline 4.62 & $\mathbf{s}$ & 2.47 & $w$ \\
\hline 4.31 & $\mathbf{s}$ & 2.40 & vw \\
\hline 4.16 & $w$ & 2.34 & vw \\
\hline 3.88 & $\mathbf{s}$ & 2.30 & $\mathrm{~m}$ \\
\hline 3.73 & $w$ & 2.23 & vw \\
\hline 3.41 & $w$ & 2.14 & $w$ \\
\hline 3.30 & $w$ & & \\
\hline
\end{tabular}

* $\mathrm{K}_{2} \mathrm{CrO}_{4}$ impurity

$s=s$ trong

vs=very strong

$\mathrm{m}=$ medium

$w=$ weak

$\mathrm{vw}=\mathrm{very}$ weak 


\section{TABLE V}

INFRARED SPECTRUM OF $\mathrm{K}_{2} \mathrm{CrO}_{2}\left(\left(\mathrm{O}_{2} \mathrm{C}\right)_{2}\left(\mathrm{CF}_{2}\right)_{3}\right)_{2}$ IN $\mathrm{CM}^{-1}$

$\underline{\mathrm{K}_{2} \mathrm{Cr}_{2} \mathrm{O}_{2}\left(\left(\mathrm{O}_{2} \mathrm{C}\right)_{2}\left(\mathrm{CF}_{2}\right)_{3}\right)_{2}}$

Assignment

$1780 \mathrm{~s}$

$V\left(\operatorname{asym~} \mathrm{CO}_{2}\right)$

$1650 \mathrm{~m}, \mathrm{~b}$

$\mathcal{V}\left(\right.$ asym $\left.\mathrm{CO}_{2}\right)$

$1430 \mathrm{~m}, \mathrm{~b}$

$V\left(\operatorname{sym~} \mathrm{CO}_{2}\right)$

$1325 \mathrm{w}$

$V\left(\operatorname{sym~} \mathrm{CCO}_{2}\right)$

$1283 \mathrm{w}$

$V\left(\operatorname{sym} \mathrm{CCO}_{2}\right)$

$1262 \mathrm{~m}$

$\nu\left(\mathrm{C}-\mathrm{F}\right.$ or sym $\left.\mathrm{CCO}_{2}\right)$

$1180 \mathrm{~s}, \mathrm{~b}$

$\nu(C-F)$

$1155 \mathrm{~s}$

V $(C-F)$

$1051 \mathrm{~m}$

$V(C-F)$

$957 \mathrm{~m}$

V $(\mathrm{Cr}-\mathrm{O}-\mathrm{C})$.

$919 \mathrm{w}$

$894 \mathrm{~m}$

$\mathcal{V}(\mathrm{C}-\mathrm{C})$

$818 w$

V $(\mathrm{C}-\mathrm{F})$

$789 \mathrm{w}$

757 w

737 w

$\delta\left(\mathrm{CCO}_{2}\right)$

$630 \mathrm{w}$

$\delta \quad\left(\mathrm{CCO}_{2}\right)$

$s=$ strong

vs=very strong

$\mathrm{m}=$ medium

$\mathrm{b}=$ broad

$w=$ weak 
Reaction of Sodium Molybdate with Ferfluoroglutaric

Anhydride. Sodium molybdate $(2.47$ moles) and perfluoroglutaric anhydride $(36.8 \mathrm{mmoles})$ were placed in a $100 \mathrm{ml}$ Pyrex glass vessel and stirred at $55^{\circ} \mathrm{C}$ in the dark for 13 days. The excess perfluoroglutaric anhydride was removed from the vessel by evacuation at $20^{\circ} \mathrm{C}$. The vessel contained a light green non-volatile solid with a weight which indicated the addition of 2.50 mmoles of perfluoroglutaric anhydride, or an apparent stoichiometry of $1: 1$. Analysis for $\mathrm{Na}_{2} \mathrm{MOO}_{3}\left(\left(\mathrm{O}_{2} \mathrm{C}\right)_{2}\left(\mathrm{CF}_{2}\right)_{3}\right)-\mathrm{Na}$; Requires: $10.7 \%$ Found: 10.8\%, Mo; Requires: $22.4 \%$ Found: $21.4 \%$, C; Requires: $14.02 \%$ Found: $13.47 \%$, F; Requires: $26.6 \%$ Found: $26.3 \%$.

The product was hygroscopic and decomposed above $125^{\circ} \mathrm{C}$. An infrared spectrum appears in the appendix and is listed in Table VI.

Reaction of Sodium Tungstate with Ferfluoroglutaric Anhydride. Perfluoroglutaric anhydride $(45.9$ mmoles) was vacuum distilled into a $100 \mathrm{ml}$ Pyrex glass vessel containing 1.89 mmoles of $\mathrm{Na}_{2} \mathrm{WO}_{4}$. The reaction mixture was stirred in the dark for 19 days at $55^{\circ} \mathrm{C}$. Upon removal of the excess anhydride, the vessel was found to contain a white solid with a weight indicating the addition of 1.92 mmoles of perfluoroglutaric anhydride. Analysis for $\mathrm{Na}_{2} \mathrm{WO}_{3}\left(\left(\mathrm{O}_{2} \mathrm{C}\right)_{2}\left(\mathrm{CF}_{2}\right)_{3}\right)-\mathrm{Na}$; Requires: $5.43 \%$ Found: $6.21 \%$, W: Requires: $35.64 \%$ Found: $43.63 \%$, C; Requires: $11.63 \%$ Found: $7.34 \%$, F ; Requires: $22.1 \%$ Found: $19.8 \%$. 
TABIE VI

INFRARED SPECTRA OF $\mathrm{Na}_{2} \mathrm{MOO}_{3}\left(\left(\mathrm{O}_{2} \mathrm{C}\right)_{2}\left(\mathrm{CF}_{2}\right)_{3}\right)$

AND $\mathrm{Na}_{2} \mathrm{WO}_{3}\left(\left(\mathrm{O}_{2} \mathrm{C}\right)_{2}\left(\mathrm{CF}_{2}\right)_{3}\right)$ IN $\mathrm{CM}^{-1}$

$\mathrm{Na}_{2} \mathrm{MoO}_{3}\left(\left(\mathrm{O}_{2} \mathrm{C}\right)_{2}\left(\mathrm{CF}_{2}\right)_{3}\right)$

$1765 \mathrm{~m}$

1670 vs

$1420 \mathrm{~m}$

$1400 \mathrm{~m}$

$1282 \mathrm{w}$

$1245 \mathrm{~s}$

$1210 \mathrm{~s}$

1160 vs

$1115 \mathrm{w}$

$1075 \mathrm{w}$

$1056 \mathrm{~m}$

$945 \mathrm{~s}, \mathrm{~b}$

$830 \mathrm{~m}$

$785 \mathrm{w}$

$750 \mathrm{~m}$

$630 \mathrm{~m}, \mathrm{~b}$

$550 \mathrm{~m}$

$505 \mathrm{~m}$
Assignment

$V\left(\operatorname{asym} \mathrm{CO}_{2}\right)$

$V\left(\operatorname{asym~} \mathrm{CO}_{2}\right)$

$\mathcal{V}\left(\right.$ sym $\left.\mathrm{CO}_{2}\right)$

$v\left(\operatorname{sym} \mathrm{CO}_{2}\right)$

$\mathcal{V}\left(\operatorname{sym} \mathrm{CCO}_{2}\right)$

$\mathcal{V}\left(\mathrm{C}-\mathrm{F}\right.$ or sym $\left.\mathrm{CCO}_{2}\right)$

$V(C-F)$

$V(C-F)$

$\nu(C-F)$

$\mathcal{V}(\mathrm{M}=0$ ? $)$

$\nu(c-c)$

$6\left(\mathrm{CCO}_{2}\right)$

$\delta\left(\mathrm{CCO}_{2}\right)$

$v($ MO-O-C)
$\mathrm{Na}_{2} \mathrm{NO}_{3}\left(\left(\mathrm{O}_{2} \mathrm{C}\right)_{2}\left(\mathrm{CF}_{2}\right)_{3}\right)$

$1650 \mathrm{vs}, \mathrm{b}$

$1430 \mathrm{~s}$

$1410 \mathrm{~s}$

$1280 \mathrm{~m}$

$1245 \mathrm{w}$

$1205 \mathrm{w}$

$1150 \mathrm{vs}$

$1125 \mathrm{~m}$

$1080 \mathrm{w}$

$1050 \mathrm{~m}$

$945 \mathrm{~s}, \mathrm{~b}$

$820 \mathrm{~m}$

$745 \mathrm{~m}$

$\mathrm{s}=$ strong

vs=very strong

m=medium

$\mathrm{b}=$ broad

$w=$ weak 
The product melted with decomposition at $298 \pm 2 \mathrm{C}$ and had a unique $\mathrm{x}$-ray powder pattern which is listed in Table VII. An infrared spectrum is listed in Table VI and also appears in the appendix.

\section{Discussion}

Chromyl Perfluoroglutarate. Three synthetic routes were found to yield chromyl perfluoroglutarate. Unfortunately, common methods of purification are unsuitable for this compound as it is essentially insoluble or oxidizes, common solvents and decomposes upon attempts at vacuum sublimation. The highest quality samples of chromyl perfluoroglutarate are a light tan to orange-brown color and come from the established method of reaction of chromium trioxide with acid anhydrides (equation III-7). Some care must be taken to isolate the product from the excess anhydride once the reaction is complete, for oxidation reactions occur with time. The reaction of chromium trioxide with perfluoroglutaric anhydride was first investigated in this laboratory by Mr. Robert Deatherage. 1

Chromyl perfluoroglutarate appears to be slightly volatile and attempts were made to purify the initial products by vacuum sublimation at elevated temperature. The new compound, however, was found to be explosive around $80^{\circ} \mathrm{C}$, producing $\mathrm{CO}_{2}$, $\mathrm{COF}_{2}$, and $\mathrm{CF}_{3} \mathrm{COF}$, among other products. This decomposition behavior was also observed for transition metal trifluoroacetates $(44,45)$

\footnotetext{
${ }^{1} \mathrm{Mr}$. Robert Deatherage; personal communication.
} 
TABLE VII

X-RAY POWDER PATTERN OF $\mathrm{Na}_{2} \mathrm{WO}_{3}\left(\left(\mathrm{O}_{2} \mathrm{C}\right)_{2}\left(\mathrm{CF}_{2}\right)_{3}\right)$

$\begin{array}{lccc}\mathrm{d}(\AA) & \text { Intensity } & \frac{\mathrm{d}(\AA)}{2} & \text { Intensity } \\ 5.87 & \mathrm{~m} & 1.95 & \mathrm{w} \\ 5.29 & \mathrm{~s} & 1.90 & \mathrm{w} \\ 4.95 & \mathrm{w} & 1.86 & \mathrm{~m} \\ 3.57 & \mathrm{w} & 1.79 & \mathrm{vw} \\ 3.31 & \mathrm{~m} & 1.76 & \mathrm{~m} \\ 3.24 & \mathrm{vs} & 1.61 & \mathrm{~m} \\ 3.06 & \mathrm{~m} & 1.54 & \mathrm{~m} \\ 2.92 & \mathrm{~ms} & 1.48 & \mathrm{w} \\ 2.84 & \mathrm{w} & 1.44 & \mathrm{w} \\ 2.76 & \mathrm{~s} & 1.39 & \mathrm{w} \\ 2.58 & \mathrm{vw} & 1.35 & \mathrm{vw} \\ 2.33 & \mathrm{w} & 1.32 & \mathrm{vw} \\ 2.27 & \mathrm{w} & 1.28 & \mathrm{vw} \\ 2.11 & \mathrm{w} & 1.22 & \mathrm{w} \\ 2.07 & \mathrm{w} & 1.19 & \mathrm{w}\end{array}$

$s=$ strong

vs=very strong

$\mathrm{ms}=$ medium strong

$\mathrm{m}=$ medium

$w=$ weak

$\mathrm{vw}=\mathrm{very}$ weak 
The ultraviolet spectrum of chromyl perfluoroglutarate in $\mathrm{CCl}_{4}$ (saturated solution) shows two absorbtions at 268 and and $368 \mathrm{~nm}$. Similar spectra were found for other chromyl compounds which have been assigned to charge transfer transitions (46). The ultraviolet spectra of selected chromyl compounds are listed in Table VIII.

\section{TABIE VIII}

ULTRAVIOLET SPECTRA OF CHROMYL COMPOUNDS IN $\mathrm{CCl}_{4}$

Compound

$\mathrm{CrO}_{2} \mathrm{Cl}_{2}$

$\mathrm{CrO}_{2} \mathrm{~F}_{2}$

$\mathrm{CrO}_{2}\left(\mathrm{O}_{2} \mathrm{CCH}_{3}\right)_{2}$

$\mathrm{CrO}_{2}\left(\mathrm{O}_{2} \mathrm{CCF}_{3}\right)_{2}$

$\mathrm{CrO}_{2}\left(\mathrm{O}_{2} \mathrm{CCF}_{2} \mathrm{Cl}\right)_{2}$

$\mathrm{CrO}_{2}\left(\mathrm{O}_{2} \mathrm{CC}_{3} \mathrm{~F}_{7}\right)_{2}$

$\mathrm{CrO}_{2}\left(\left(\mathrm{O}_{2} \mathrm{C}\right)_{2}\left(\mathrm{CF}_{2}\right)_{3}\right)$

$\mathrm{CrO}_{2}\left(\mathrm{OSO}_{2} \mathrm{~F}\right)_{2}$

$\mathrm{CrO}_{2}\left(\mathrm{OSO}_{2} \mathrm{CF}_{3}\right)_{2}$ $\lambda \max (\mathrm{nm})$

$298 \quad 415$

$278 \quad 383$

283400

$286 \quad 410$

$281 \quad 410$

$278 \quad 380$

$268 \quad 368$

285360

$284 \quad 407$
Reference

46

47

3

4

4

4

48

48

The infrared spectrum of chromyl perfluoroglutarate, prepared by three different methods, is listed in Table II. Spectral assignments are based largely after the work of Sharpe et al. on anhydrous transition metal trifluoroacetates (44). The asymmetric carboxylate stretching mode is widely split while symmetric carboxylate stretching shows little, or no splitting. This vibrational coupling has been observed 
when two carboxylate groups are bound to the same metal (49). The separation $(\Delta \omega)$ between the higher frequency asymmetric $\mathrm{CO}_{2}$ stretch and the symmetric $\mathrm{CO}_{2}$ stretch is $365 \mathrm{~cm}^{-1}$, well within the range commonly taken for unidentate carboxylate coordination (15). The absorption band around $1255 \mathrm{~cm}^{-1}$ is possibly due to carbon-fluorine stretching, but its position and intensity suggest that it is more likely a coupling of the symmetric $\mathrm{CO}_{2}$ and $\mathrm{C}-\mathrm{C}$ stretching modes, sometimes assigned as $\mathrm{CCO}_{2}$ (13). Carbon-fluorine stretching is easily assigned to intense absorptions around $1150 \mathrm{~cm}^{-1}$. Asymmetric and symmetric $\mathrm{Cr}=0$ stretching was observed at 970 and $950 \mathrm{~cm}^{-1}$. In chromyl trifluoroacetate these bands were unresolved at $960 \mathrm{~cm}^{-1}$ (4). The remaining band assignments were made following the spectra of the trifluoroacetates.

From infrared spectral data and the insolubility in nonpolar solvents, chromyl perfluoroglutarate is assumed to have a bridged (polymeric) structure with unidentate carboxylate groups.

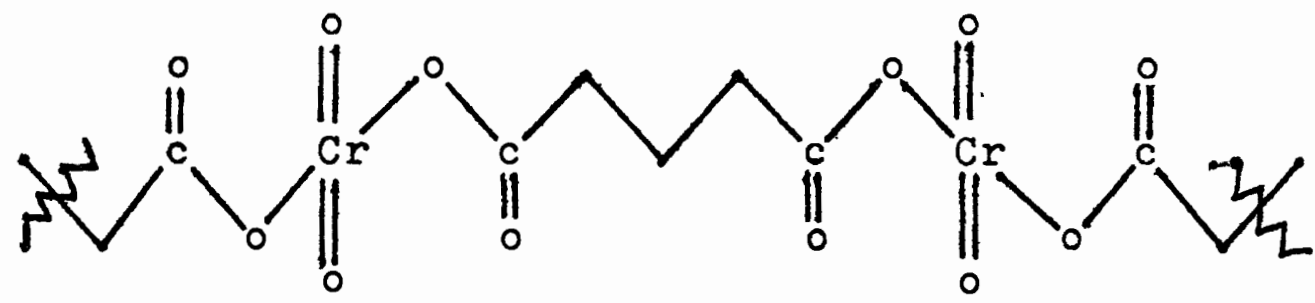

Figure 9. Proposed structure of chromyl perfluoroglutarate. 
The reaction of chromium trioxide with perfluoroglutaryl fluoride (equation III-8) is similar to a previously reported preparation of chromyl fluoride:

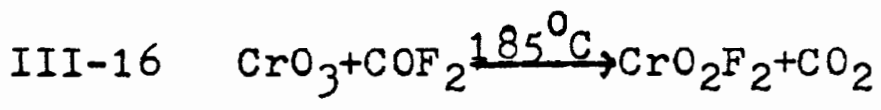

In this case, perfluoroglutaric anhydride is formed instead of the anhydride of carbonic acid $\left(\mathrm{CO}_{2}\right)$. The perfluoroglutaric anhydride thus formed reacts with $\mathrm{CrO}_{3}$ to produce the chromyl compound.

The high weight and dark color of the sample prepared by this method indicate that the chromyl fluoride by-product oxidized a significant amount of the perfluoroglutaryl fluoride. Two impurity peaks are seen in the infrared spectrum listed in Table II, and as expected, the elemental analysis is rather poor. The high values for carbon and fluorine also indicate that oxidation products are present.

Surprisingly, the infrared spectra are in good agreement. There is a slight shifting of spectra $B$ and $C$, as they were obtained as neat smears at a fast scan rate, while spectrum $\mathrm{A}$ is a slow scan of a $\mathrm{KBr}$ pellet.

The third preparative route to chromyl perfluoroglutarate, the reaction of chromyl fluoride with the anhydride (equation III-9), also is analogous to previously reported schemes. It was found that halide exchange occurred when covalent halides acted on trifluoroacetic anhydride:

$\mathrm{III}-17 \mathrm{KCrO}_{3} \mathrm{Cl}+2\left(\mathrm{CF}_{3} \mathrm{CO}\right)_{2} \mathrm{O} \rightarrow \mathrm{KCrO}_{2}\left(\mathrm{O}_{2} \mathrm{CCF}_{3}\right)_{3}+\mathrm{CF}_{3} \mathrm{COCl}$

$\mathrm{III}-18 \mathrm{Cs}\left(\mathrm{IF}_{4}\right)+4\left(\mathrm{CF}_{3} \mathrm{CO}\right)_{2} \mathrm{O} \longrightarrow \mathrm{Cs}\left(\mathrm{I}\left(\mathrm{O}_{2} \mathrm{CCF}_{3}\right)_{4}\right)+4 \mathrm{CF}_{3} \mathrm{COF}$ 
III-19 $\mathrm{CrO}_{2} \mathrm{~F}_{2}+2\left(\mathrm{CF}_{3} \mathrm{CO}\right)_{2} \mathrm{O} \longrightarrow \mathrm{CrO}_{2}\left(\mathrm{O}_{2} \mathrm{CCF}_{3}\right)_{2}+2 \mathrm{CF}_{3} \mathrm{COF}$

Again, the presence of $\mathrm{CrO}_{2} \mathrm{~F}_{2}$ caused considerable oxidation to occur, and in fact, the elemental analysis for the products from these last two methods are very similar. Overall, the preferred method for the preparation of chromyl perfluoroglutarate is the reaction of chromium trioxide with perfluoroglutaric anhydride.

Molybdenyl Perfluoroglutarate. Molybdenyl perfluoroglutarate was prepared by the same method used for the chromyl compound. Mass balance indicated that the reaction was $90 \%$ complete. Further attempts to obtain complete reactions failed, usually resulting in reduced states of molybdenum. The infrared spectrum is listed in Table III. Except for the unsplit asymmetric $\mathrm{CO}_{2}$ stretching band, which is shifted somewhat to lower frequency, the spectrum is very similar to the other transition metal perfluoroglutarates. Spectral assignments were made, as before, with unidentate carboxylate linkage indicated.

The small amount of unreacted molybdenum trioxide obscured the low frequency region of the infrared spectrum and also dominated the $x$-ray powder pattern. For this reason, the $x$-ray data is not reported, although a few strong lines indicate the presence of a new compound and no lines were observed for any lower oxides of molybdenum.

Molybdenum blue $\left(\mathrm{M}_{2} \mathrm{O}_{5}\right.$ with variations in Mo and 0$)$, resulting from mild reduction of $\mathrm{MoO}_{3}$ (formal oxidation states 
between 5 and 6 ) has an intense blue color, therefore, this impurity is believed to be a minor one in the light blue product which was obtained.

Tungstenvl Perfluoroglutarate. After an extremely long reaction period $\left(50\right.$ days at $80^{\circ} \mathrm{C}$ ) tungstenyl perfluoroglutarate was prepared in $93 \%$ yield. Compared to $\mathrm{CrO}_{3}, \mathrm{NO}_{3}$ was found to be even less reactive than $\mathrm{MOO}_{3}$ towards addition to perfluoroglutaric anhydride. Longer reaction times and somewhat higher temperatures failed to produce pure products. One problem with this reaction scheme is the absence of a solvent, either for the metal trioxide or the particular product. Anhydrous trifluoroacetic acid was tried as a possible solvent for the tungsten trioxide-perfluoroglutaric anhydride system. Unfortunately, the cyclic anhydride dehydrates the acid, a reaction that was later found to have been studied for the hydrocarbon analogues?

$$
\begin{array}{r}
\text { III-2O( } \left.\mathrm{CH}_{2}\right)_{3}(\mathrm{CO})_{2} \mathrm{O}+2 \mathrm{CH}_{3} \mathrm{COOH} \frac{25^{\circ} \mathrm{C}}{\longrightarrow}\left(\mathrm{CH}_{3} \mathrm{CO}\right)_{2} \mathrm{O}+\left(\mathrm{CH}_{2}\right)_{3}(\mathrm{COOH})_{2} \\
\mathrm{~K}=4.6 \cdot 10^{-1} \mathrm{M}^{-1}
\end{array}
$$

The infrared spectrum of the product is listed in Table III. Again, unidentate carboxylate linkage is indicated, and the remainder of the spectrum follows previous assignments. Reaction of Potassium Chromate with Perfluoroglutaric Anhydride. Reaction of potassium chromate with perfluoroglutaric anhydride resulted in addition across both metal-oxygen double bonds of the salt. The infrared spectrum of the product, listed in Table IV, is almost identical to the covalent chromyl compound except that absorption bands due to $\mathrm{Cr}=0$ 
stretching are absent (52). The $\mathrm{Cr}-0-\mathrm{C}$ stretching frequency is assigned to the peak at $957 \mathrm{~cm}^{-1}$. this band was observed at $940 \mathrm{~cm}^{-1}$ in $\mathrm{K}_{2} \mathrm{CrO}_{2}\left(\mathrm{O}_{2} \mathrm{CCF}_{3}\right)_{4}$ (41). The spectrum indicates unidentate carboxylate Iinkage, in accord with the stoichiometry of the reaction.

A unique $x$-ray powder pattern was produced by the product with only the two strongest lines of $\mathrm{K}_{2} \mathrm{CrO}_{4}$ appearing as medium intensity Iines.

Reaction of Sodium Molybdate and Sodium Tungstate with Perfluoroglutaric Anhydride. Reaction of perfluoroglutaric anhydride with the molybdenum and tungsten salts resulted in addition across only one of the metal-oxygen double bonds. It appears that the lower reactivity of these salts, relative to $\mathrm{K}_{2} \mathrm{CrO}_{4}$, is responsible for this fact, not simply an incomplete reaction, for further reaction with time was not noted after 1:1 stoichiometry was achieved.

The $x$-ray powder pattern for the tungsten compound (Table VII) is unique, with no lines for unreacted $\mathrm{Na}_{2} \mathrm{WO}_{4}$ present. While most of the diffraction pattern for the molybdenum compound was that of $\mathrm{Na}_{2} \mathrm{MoO}_{4}$ (therefore it is not reported), no unreacted $\mathrm{Na}_{2} \mathrm{MoO}_{4}$ appeared in the infrared spectrum. It is assumed that the molybdenum compound decomposed in the $\mathrm{x}$-ray beam.

The infrared spectra of the tungstate and molybdate salts are listed in Table VI. The spectra are similar to the other perfluoroglutarate complexes except that the symmetric 
$\mathrm{CO}_{2}$ stretching modes are also split by about $20 \mathrm{~cm}^{-1}$. The difference between the asymmetric and symmetric $\mathrm{CO}_{2}$ stretching frequencies indicate that the carboxylate linkages to the metal in both compounds have considerable unidentate character. This persistence of unidentate carboxylate linkage, in all of the compounds discussed, may be the preferred configuration for coordination to metals when they are in high oxidation states.

The metal-oxygen stretching frequencies for these complexes are difficult to assign. It is tempting to identify the strong band at $945 \mathrm{~cm}^{-1}$ with $M=0$ stretching, but the fact that the absorption appears at identical positions in both spectra makes this assignment somewhat suspect. In $\mathrm{WO}_{2}(\mathrm{acac})_{2}$ the asymmetric and symmetric $W=0$ stretching occurred at 954 and $968 \mathrm{~cm}^{-1}$, but with $\mathrm{MOO}_{2}(\mathrm{acac})_{2}$ only one band in the metaloxygen double bond region $\left(904 \mathrm{~cm}^{-1}\right)$ was found (53).

It appeared that the $\mathrm{MOO}_{2}^{+2}$ group was not bent, like the $\mathrm{WO}_{2}{ }^{+2}$ group, therefore, this comparison may be a poor one for the molybdenum compounds. Molybdenum-oxygen double bonded stretching occurred at $961 \mathrm{~cm}^{-1}$ in the molybdenum( $\left.V\right)$ compound, $\left((\mathrm{acac}) 2^{\mathrm{M}=0)}\right)_{2} \mathrm{O},(54)$. These examples show that Mo=0 and $W=0$ stretching occur in the same region and that small differences in band position could be masked by their broad nature. The Mo-O-C stretching band is assigned at $550 \mathrm{~cm}^{-1}$. This band was observed at 576 and $550 \mathrm{~cm}^{-1}$ in $\mathrm{MOO}_{2}(\mathrm{acac})_{2}$ (53). 


\section{CHAPTER IV}

\section{CHEMISTRY OF CHROMIUM OXIDE FIUORIDES}

\section{Introduction}

Few properties of chromium oxide tetrafluoride, (CrOF 4 ), are known. They have been reviewed in Chapter I. It seems Edwards et al. (31) have been the only group able to prepare this compound. Their success is probably because of their fluorination apparatus, which was not described. The static system has a cooled zone which allows them to isolate the intermediate product $\left(\mathrm{CrOF}_{4}\right)$ in the stepwise elemental fluorination of $\mathrm{CrO}_{3}$. Since the only reported chemistry of $\mathrm{CrOF}_{4}$ is its fluorination to $\mathrm{CrF}_{5}$, new preparative routes to $\mathrm{CrOF}_{4}$ were sought with the intention to study its reaction chemistry. All new attempts to prepare $\mathrm{CrOF}_{4}$ failed.

Various oxides and oxyfluorides were used as starting materials for the attempted preparations of $\mathrm{CrOF}_{4}$. Chromyl fluoride was prepared by the methods of Green and Gard (27): $\mathrm{IV}-1 \quad \mathrm{CrO}_{2} \mathrm{Cl}_{2}+2 \mathrm{CIF} \stackrel{-78^{\circ} \mathrm{C}}{\longrightarrow} \mathrm{CrO}_{2} \mathrm{Fr}_{2}+2 \mathrm{Cl}_{2}$

$\mathrm{IV}-2 \quad \mathrm{CrO}_{3}+\mathrm{WF}_{6} \stackrel{125^{\circ} \mathrm{C}}{\longrightarrow} \mathrm{CrO}_{2} \mathrm{~F}_{2}+\mathrm{WOF}_{4}$

The reactions were quantitative and are described in the experimental and discussion sections.

Chromium oxide difluoride was prepared from the thermal decomposition of chromyl fluoride (21):

$\mathrm{IV}-3 \quad \mathrm{CrO}_{2} \mathrm{~F}_{2} \stackrel{550^{\circ} \mathrm{C}}{\longrightarrow} \mathrm{CrOF}_{2}+\frac{2}{2} \mathrm{O}_{2}$ 
The infrared spectrum of $\mathrm{CrOF}_{2}$ is reported and an estimation was made of its surface area, as prepared.

Attempts to prepare $\mathrm{CrOF}_{4}$ by a continuation of equations IV-2 and IV-5 failed.

$\mathrm{IV}-4 \quad \mathrm{CrO}_{2} \mathrm{~F}_{2}+\mathrm{WF}_{6} \rightarrow \underset{\mathrm{CrOF}}{4}+\mathrm{WOF}_{4}$

$\mathrm{IV}-5 \quad \mathrm{CrO}_{3}+\mathrm{COF}_{2} \stackrel{185^{\circ} \mathrm{C}}{\longrightarrow} \mathrm{CrO}_{2} \mathrm{~F}_{2}+\mathrm{CO}_{2}$

$\mathrm{IV}-6 \quad \mathrm{CrO}_{2} \mathrm{~F}_{2}+\mathrm{COF}_{2} \rightarrow \mathrm{CrOF}_{4}+\mathrm{CO}_{2}$

Chromyl fluoride did not react with tungsten hexafluoride at temperatures up to its decomposition point $\left(500^{\circ} \mathrm{C}\right)$. No reaction occurred between chromyl fluoride and carbonyl fluoride from $200^{\circ} \mathrm{C}$ to $350^{\circ} \mathrm{C}$. At $400^{\circ} \mathrm{C}$ an incomplete reaction produced small amounts of $\mathrm{O}_{2}, \mathrm{CO}_{2}$, and $\mathrm{CrF}_{3}$.

Direct fluorination of chromium oxide difluoride did not produce $\mathrm{CrOF}_{4}$, but resulted in the loss of oxygen and oxidation to $\mathrm{CrF}_{5}$ :

$\mathrm{IV}-7 \quad \mathrm{CrOF}_{2}+3 / 2 \mathrm{~F}_{2} \stackrel{250^{\circ} \mathrm{C}_{\longrightarrow}}{\longrightarrow} \mathrm{CrF}_{5}+1 / 2 \mathrm{O}_{2}$

No reaction was observed between $25^{\circ} \mathrm{C}$ and $200^{\circ} \mathrm{C}$.

Since new preparations for $\mathrm{CrOF}_{4}$ were unsuccessful, the reported method of fluorination of $\mathrm{CrO}_{3}$ at $220^{\circ} \mathrm{C}$ was tried. A top-loading Inconel vessel was equipped with a water-cooled jacket at the 1id. It was found that the reaction products are not easily controlled by temperature:

IV-8 $\mathrm{CrO}_{3}+5 / 2 \mathrm{~F}_{2}(17 \mathrm{~atm}) \stackrel{210^{\circ} \mathrm{C}}{\longrightarrow} \mathrm{CrF}_{5}+3 / 2 \mathrm{O}_{2}$

IV $-9 \quad \mathrm{CrO}_{3}+\mathrm{F}_{2}(2.6 \mathrm{~atm}) \stackrel{190^{\circ} \mathrm{C}}{\longrightarrow} \mathrm{CrO}_{2} \mathrm{~F}_{2}+\frac{1}{2} \mathrm{O}_{2}$

The reactions were quantitative with no trace of $\mathrm{CrOF}_{4}$ found. It appeared that the reaction products may be determined by 
the initial fluorine pressure as well, for even at $250^{\circ} \mathrm{C}$ it was reported that the products were a mixture of $\mathrm{CrOF}_{4}$ and $\mathrm{CrF}_{5}$ (31). Edwards prepared $\mathrm{CrOF}_{4}$ with an initial fluorine pressure of 2 atmospheres. This fluorine pressure was used with $\mathrm{CrO}_{2} \mathrm{~F}_{2}$ as the starting chromium species: $\mathrm{IV}-10 . \mathrm{CrO}_{2} \mathrm{~F}_{2}+\mathrm{F}_{2}(2 \mathrm{~atm}) \stackrel{200^{\circ} \mathrm{C}}{\longrightarrow} \mathrm{CrOF}_{4}+\frac{1}{2} \mathrm{O}_{2}\left(+\mathrm{CrO}_{2} \mathrm{~F}_{2}\right)$ The reaction products were a mixture of $\mathrm{CrO}_{2} \mathrm{~F}_{2}$ and $\mathrm{CrOF}_{4}$. Direct fluorination of $\mathrm{CrO}_{3}$ was found to be difficult to control, with many attempts failing to produce $\mathrm{CrOF}_{4}$. Chromium oxide tetrafluoride was not produced in sufficient quantities to study its physical properties or chemistry.

\section{Experimental}

Fluorination of Chromium Prioxide. A passivated $200 \mathrm{ml}$ Inconel top-loading vessel containing $40 \mathrm{mmoles}$ of $\mathrm{CrO}_{3}$ was charged with $140 \mathrm{mmoles}(17 \mathrm{~atm})$ of $\mathrm{F}_{2}$ at $-196^{\circ} \mathrm{C}$. The vessel Iid was then equipped with a water-cooled cooling jacket and heated at $210^{\circ} \mathrm{C}$. After 40 hours the excess $\mathrm{F}_{2}$ was vented at room temperature, then the vessel was cooled to $-78^{\circ} \mathrm{C}$ and was evacuated through a $\mathrm{CaCl}_{2}$ tube. The $\mathrm{CaCl}_{2}$ tube became not, indicating unreacted fluorine:

$\mathrm{IV}-11 \quad \mathrm{~F}_{2}+\mathrm{CaCl}_{2} \longrightarrow \mathrm{CaF}_{2}+\mathrm{Cl}_{2}$ theat

The vessel contents were non-volatile at room temperature. Upon opening the vessel, a deep red, stickey solid was found. The solid hydrolyzed violently to a yellow-green solution indicating a mixture of trivalent and hexavalent chromium. Most pentavalent chromium compounds disproportionate 
immediately in aqueous solution according to the equation: $\mathrm{IV}-12.3 \mathrm{Cr}^{\mathrm{V}} \stackrel{\mathrm{H}_{2} \mathrm{O}}{\longrightarrow} 2 \mathrm{Cr}^{\mathrm{VI}}+\mathrm{Cr}$ III

The infrared spectrum of the product matched that of $\mathrm{CrF}_{5}$ (55) with no extraneous absorbances present. The weight of the

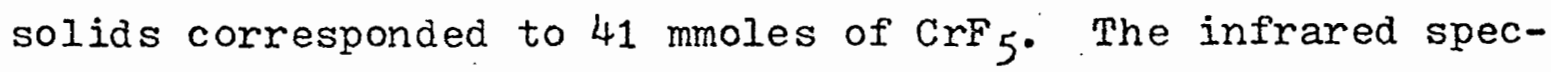
trum appears in the appendix.

In a second run, 8 mmoles of $\mathrm{CrO}_{3}$ was reacted with 21 mmoles $(2.6 \mathrm{~atm})$ of $\mathrm{F}_{2}$ at $190^{\circ} \mathrm{C}$. After 70 hours the vessel was cooled to $-196^{\circ} \mathrm{C}$ and evacuated through a $\mathrm{CaCl}_{2}$ tube. Again unreacted $F_{2}$ was indicated. The weight of the vessel contents corresponded to 8 mmoles of $\mathrm{CrO}_{2} \mathrm{~F}_{2}$. At $20^{\circ} \mathrm{C}$ the vessel contents were volatile, and the infrared spectrum showed $\mathrm{CrO}_{2} \mathrm{~F}_{2}$ to be the only compound present (36). Brief evacuation at room temperature resulted in the complete transfer of all material out of the vessel with no indication of the presence of $\mathrm{CrOF}_{4}$. Preparation of Chromyl Fluoride by the Reaction of Chromyl Chloride with Chlorine Monofluoride. Chlorine monofluoride, (100 mmoles), was condensed at $-196^{\circ} \mathrm{C}$ into a passivated $75 \mathrm{ml}$ stainless steel vessel containing 48 mmoles of $\mathrm{CrO}_{2} \mathrm{Cl}_{2}$. The vessel was warmed to $-78^{\circ} \mathrm{C}$ and maintained at this temperature for 24 hours. Excess $\mathrm{CIF}$ and $\mathrm{Cl}_{2}$ were pumped away at $-78^{\circ} \mathrm{C}$. The vessel was warmed to $20^{\circ} \mathrm{C}$, shaken, then cooled to $-78^{\circ} \mathrm{C}$ and evacuated for one hour. This proceedure was repeated three times to ensure the complete removal of $\mathrm{ClF}$ and $\mathrm{Cl}_{2}$. The final weight of the vessel contents corresponded to 46 moles of $\mathrm{CrO}_{2} \mathrm{~F}_{2}$. The infrared spectrum of chromyl fluoride appears in the appendix. 
Preparation of Chromyl Fluoride by the Reaction of

Chromium Trioxide with Tungsten Hexafluoride. Tungsten hexafluoride, (111 mmoles), was vacuum distilled into a passivated $75 \mathrm{ml}$ stainless steel vessel containing 115 mmoles of $\mathrm{CrO}_{3}$. The reaction mixture was heated at $120^{\circ} \mathrm{C}$ for 17 hours. Upon opening the vessel to the vacuum line at $20^{\circ} \mathrm{C}$, the only volatile compound found was $\mathrm{CrO}_{2} \mathrm{~F}_{2}$, as identified by its infrared spectrum (36). A total of 13.4 grams, ( 110 mmoles), of $\mathrm{CrO}_{2} \mathrm{~F}_{2}$ was recovered.

Fluorination of Chromyl Fluoride. Freshly prepared $\mathrm{CrO}_{2} \mathrm{~F}_{2}$, (19 mmoles), was sublimated into the $200 \mathrm{ml}$ Inconel top loading vessel. The vessel was charged with $24 \mathrm{mmoles}$, $\left(2 \mathrm{~atm}\right.$ ), of $\mathrm{F}_{2}$ and heated at $200^{\circ} \mathrm{C}$ while cooling the lid. After 24 hours the vessel was evacuated at $-196^{\circ} \mathrm{C}$ through a $\mathrm{CaCl}_{2}$ tube, unreacted fluorine was indicated. The contents of the vessel were volatile at $20^{\circ} \mathrm{C}$ with $\mathrm{CrO}_{2} \mathrm{~F}_{2}$ being the major component as identified by its characteristic infrared spectrum. One strong absorption was found at $1089 \mathrm{~cm}^{-1}$ which compares favorably with the calculated value of $1080 \mathrm{~cm}^{-1}$ for the chromium-oxygen stretching frequency of $\mathrm{CrOF}_{4}$ (32). The vessel was evacuated briefly in an attempt to remove the $\mathrm{CrO}_{2} \mathrm{~F}_{2}$, then the reactor was heated to $60^{\circ} \mathrm{C}$ while connected to a quartz vessel cooled to $-196^{\circ} \mathrm{C}$. A dark red solid transferred in vacuo to the quartz vessel very slowly, with the recovery of only .25 grams in 2 hours. The quartz vessel at $25^{\circ} \mathrm{C}$ contained a dark red solid that stuck to the stirring bar and a red to red- 
brown gas. The upper Pyrex-glass portions of the graded seal appeared to be coated with $\mathrm{CrO}_{3}$. A low resolution infrared spectrum of the vessel atmosphere, which appears in the appendix, showed $\mathrm{CrO}_{2} \mathrm{~F}_{2}, \mathrm{SiF}_{4}$, again the strong absorption at 1089 $\mathrm{cm}^{-1}$ and an unidentified absorption at $1245 \mathrm{~cm}^{-1}$. The dark red solids hydrolyzed to a yellow solution.

The reactor contained 1.8 grams of a non-volatile material. Upon opening the reactor in the dry box, a brown solid was found which also hydrolyzed to a yellow solution. An infrared spectrum of this solid revealed one strong absorption at $975 \mathrm{~cm}^{-1}$ due to chromium-oxygen stretching and a very strong, broad, complex chromium-fluorine stretching absorption which was unresolved from $850 \mathrm{~cm}^{-1}$ to $450 \mathrm{~cm}^{-1}$. An attempted melting point determination of the solids in a Pyrex glass capillary resulted in glass attack at $45^{\circ} \mathrm{C}$ which became severe at $60^{\circ} \mathrm{C}$.

Reaction of Chromyl Fluoride with Carbonyl Fluoride. To 33 mmoles of $\mathrm{CrO}_{2} \mathrm{~F}_{2}$ contained in a $75 \mathrm{ml}$ passivated stainless steel vessel was added 18 mmoles of $\mathrm{COF}_{2}$ at $-196^{\circ} \mathrm{C}$ via vacuum distillation. The reaction mixture was heated at $440^{\circ} \mathrm{C}$ for 4 hours, then cooled to $-196^{\circ} \mathrm{C}$. A non-condensible gas was present which was found by its molecular weight to be 13 moles of $\mathrm{O}_{2}$. Requires: 32.0 grams/mole Found: $32.1 \mathrm{grams} / \mathrm{mole}$. The infrared spectrum of the volatiles at $20^{\circ} \mathrm{C}$ showed $\mathrm{CO}_{2}$, unreacted $\mathrm{COF}_{2}$, and $\mathrm{CrO}_{2} \mathrm{~F}_{2}$. After evacuation of the volatile materials, the vessel was found to contain 0.8 grams of an inert, light green solid which was identified as $\mathrm{CrF}_{3}$. (? mmoles). by its infrared spectrum (56). The spectrum appears in the appendix. 
Reaction of Chromyl Fluoride with Tungsten Hexafluoride. Tungsten hexafluoride ( 17.4 mmoles) was vacuum distilled into a $75 \mathrm{ml}$ passivated stainless steel vessel containing 11.5 mmoles of freshly prepared chromyl fluoride. The vessel was heated in a stepwise manner, for one day, at $110^{\circ} \mathrm{C}, 178^{\circ} \mathrm{C}$, $252^{\circ} \mathrm{C}, 350^{\circ} \mathrm{C}, 440^{\circ} \mathrm{C}$, and $550^{\circ} \mathrm{C}$. An infrared spectrum of the volatiles at room temperature, made between each heating, revealed the presence of $\mathrm{WF}_{6}$ and $\mathrm{CrO}_{2} \mathrm{~F}_{2}$. After heating for one day at $550^{\circ} \mathrm{C}$, the vessel was found to contain a non-condensable gas at $-196^{\circ} \mathrm{C}$. An infrared spectrum of the volatile contents at $20^{\circ} \mathrm{C}$ showed only $\mathrm{WF}_{6}$. After the $\mathrm{WF}_{6}$ was distilled away, the vessel was found to contain 2.6 grams of a mixture of gray, off white, and brown solids. The solids were insoluble in $\mathrm{H}_{2} \mathrm{O}$, an infrared spectrum qualitatively resembled the spectrum of $\mathrm{CrOF}_{2}$ which appears in the appendix.

\section{Preparation of Chromium Oxide Difluoride. Chromyl flu-} oride, ( 64 mmoles), was condensed into a $75 \mathrm{ml}$ stainless steel vessel which had been passivated with fluorine at $400^{\circ} \mathrm{C}$. The vessel was heated at $550^{\circ} \mathrm{C}$ for 5 hours, then chilled to $-196^{\circ} \mathrm{C}$. Upon opening the vessel to the vacuum manifold, a non-condensible gas was found which was identified as 31 moles of $\mathrm{O}_{2}$, ( 32 mmoles theo.), by its molecular weight. Requires: 32.0 grams/mole Found: 32.06 grams/mole. Upon opening the vẻssel, a fine black powder was found which was insoluble in $\mathrm{H}_{2} \mathrm{O}$ and anhydrous HF. The $x$-ray powder pattern of the product matches that of $\mathrm{CrOF}_{2}(21)$ and is listed in Table IX. The weight of 
$\mathrm{CrOF}_{2}$ produced was 6.8 grams, ( 64 mmoles), for a yield of $100 \%$. The infrared spectrum of the product is listed in Table $X$ and appears in the appendix. This sample of chromium oxide difluoride was found to have a surface area of 0.59 square meters $/ \mathrm{gram}^{2}{ }^{2}$ Fluorination of Chromium Oxide Difluoride. To a $100 \mathrm{ml}$ passivated Monel vessel containing 9.4 moles of $\mathrm{CrOF}_{2}$, was added 34 mmoles of $F_{2}$. The reaction mixture was slowly heated to $250^{\circ} \mathrm{C}$ over a period of 3 hours, then the vessel was cooled to $-196^{\circ} \mathrm{C}$ and evacuated through a $\mathrm{CaCl}_{2}$ tube. Excess fluorine was found to be present. An infrared spectrum of volatile materials at $20^{\circ} \mathrm{C}$ revealed only a trace of $\mathrm{HF}$ to be present. The vessel contained 1.3 grams of a dark red sticky semi-solid. The solids hydrolyzed violently to a yellow green solution and oxidized cotton explosively. An infrared spectrum of the solids matched that of $\mathrm{CrF}_{5}$, ( 8.8 mmoles), which appears in the appendix.

2

The surface area measurement was made by Ms. Maria M. Iudvig at Portland State University. The author wishes to thank Ms. Iudvig for her assistance. 
EXPERIMENTAI AND IITERATURE (21)

VALUES OF THE X-RAY POWDER

PATTERN FOR $\mathrm{CrOF}_{2}$

\begin{tabular}{|c|c|c|c|}
\hline$d(\AA)$ & $\mathrm{CrOF}_{2 \text { Intensity }}$ & 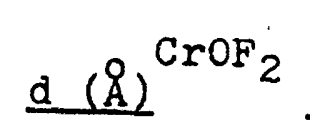 & $\begin{array}{l}(21) \\
\text { Intens }\end{array}$ \\
\hline 6.38 & $\mathbf{s}$ & 6.32 & $\mathbf{s}$ \\
\hline 5.89 & $m$ & 5.84 & $\mathbf{s}$ \\
\hline 4.17 & $w$ & & \\
\hline 3.75 & vs & 3.75 & $s$ \\
\hline 3.64 & $w$ & 3.66 & $m$ \\
\hline \multirow[t]{2}{*}{3.53} & $w$ & & \\
\hline & & 3.24 & $v w$ \\
\hline 3.18 & vs & 3.17 & vs \\
\hline 3.07 & $v w$ & 3.06 & $w$ \\
\hline \multirow{3}{*}{2.48} & & 2.93 & $w$ \\
\hline & $w$ & 2.42 & vw \\
\hline & & 2.30 & $w$ \\
\hline 2.17 & $w$ & 2.27 & $w$ \\
\hline 2.11 & $v w$ & 2.11 & $v w$ \\
\hline \multirow{3}{*}{2.03} & & 2.07 & $v w$ \\
\hline & $v w$ & 2.01 & $\mathrm{vw}$ \\
\hline & & 1.98 & $v w$ \\
\hline 1.95 & $v w$ & 1.95 & $w$ \\
\hline 1.88 & $w$ & 1.88 & $w$ \\
\hline 1.83 & $w$ & 1.83 & $m$ \\
\hline
\end{tabular}


TABLE X

INFRARED SFECTRUM OF $\mathrm{CrOF}_{2}$ IN $\mathrm{CM}^{-1}$

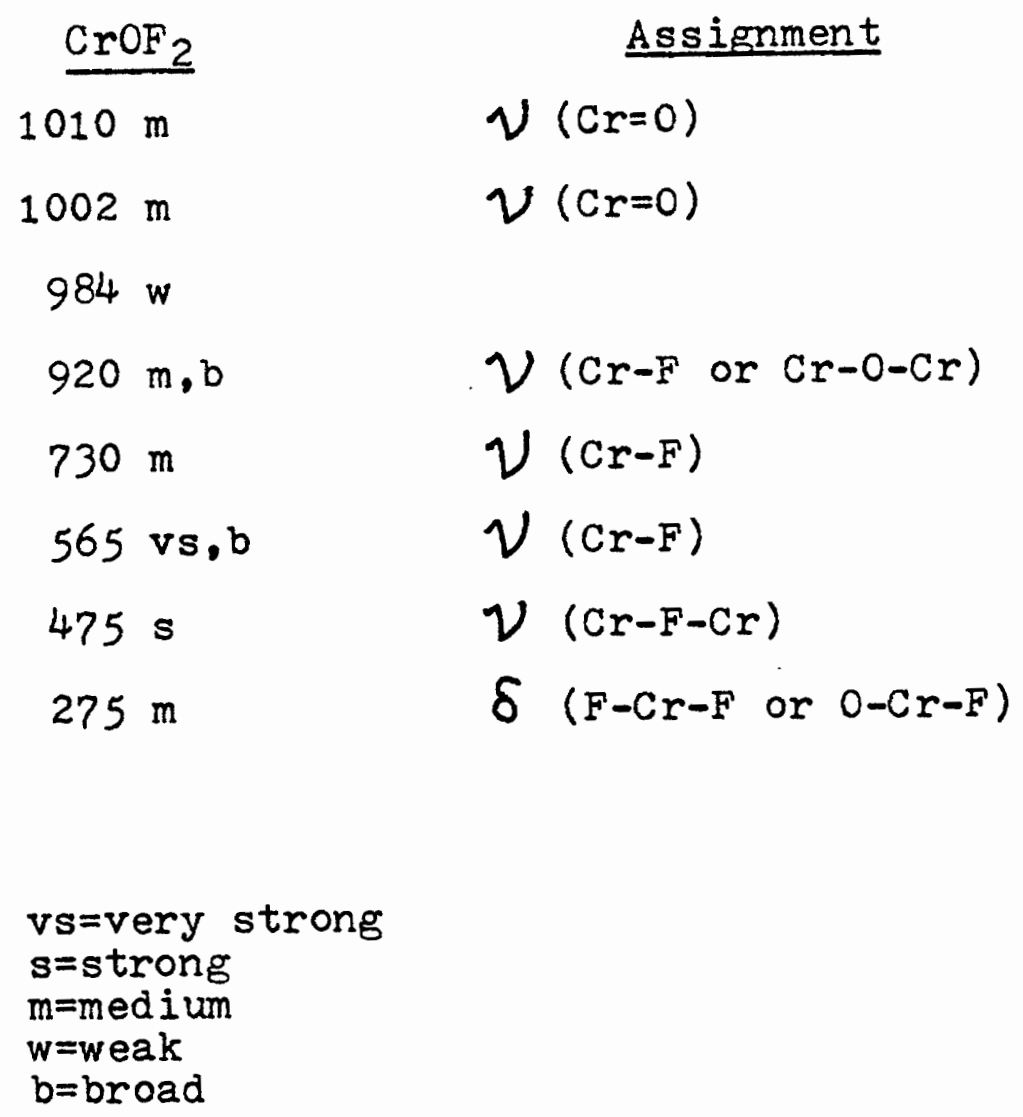




\section{Discussion}

Eluorination of Chromium Trioxide and Chromium Dioxide Difluoride. Direct fluorination of $\mathrm{CrO}_{3}$ at $20^{\circ} \mathrm{C}$ was exothermic, producing $\mathrm{CrO}_{2} \mathrm{~F}_{2}$. In addition to temperature, the reaction products appear to be dependent on the fluorine pressure. Edwards et al. (31), with an initial fluorine pressure of 2 atmospheres, obtained $\mathrm{CrO}_{2} \mathrm{~F}_{2}$ exclusively at $150^{\circ} \mathrm{C}$. At $220^{\circ} \mathrm{C}$ a little $\mathrm{CrO}_{2} \mathrm{~F}_{2}$ remained, but the major product was $\mathrm{CrOF}_{4}$. Heating to $250^{\circ} \mathrm{C}$ produced mainly $\mathrm{CrF}_{5}$ with a minor amount of $\mathrm{CrOF}_{4}$. In contrast with these results, $\mathrm{CrF}_{5}$ was found to be the only chromium species present when the initial fluorine pressure was 17 atmospheres, and a temperature of $210^{\circ} \mathrm{C}$. Reducing the temperature to $190^{\circ} \mathrm{C}$ (but also reducing the initial fluorine pressure to 2.6 atmospheres) resulted in the quantitative conversion of $\mathrm{CrO}_{3}$ to $\mathrm{CrO}_{2} \mathrm{~F}_{2}$. This is a relatively small range of temperatures and fluorine pressures to work with in order to isolate $\mathrm{CrOF}_{4}$. The problem may have been solved by a change in the reactor design. Close temperature control is needed as well as a cooled zone where the intermediate $\mathrm{CrOF}_{4}$ can escape complete fluorination to $\mathrm{CrF}_{5}$

The fluorination of chromyl fluoride was carried out under the conditions reported by Edwards et al. The reactor containing $\mathrm{CrO}_{2} \mathrm{~F}_{2}$ was charged with 2 atmospheres of $\mathrm{F}_{2}$ and heated at $200^{\circ} \mathrm{C}$. A mixture of $\mathrm{CrO}_{2} \mathrm{~F}_{2}$ and $\mathrm{CrOF}_{4}$ was obtained. Chromium oxide tetrafluoride was tentatively identified by its physical properties and by its previously reported attack of glass 
apparatus with the formation of $\mathrm{CrO}_{2} \mathrm{~F}_{2}$ and $\mathrm{CrO}_{3}$. Preliminary infrared spectral data for $\mathrm{CrOF}_{4}$ in the gas phase indicates terminal chromium-oxygen stretching at $1089 \mathrm{~cm}^{-1}$.

Fluorination of chromyl fluoride to $\mathrm{CrOF}_{4}$, in the same resion that Edwards et al, obtained $\mathrm{CrOF}_{4}$ from $\mathrm{CrO}_{3}$, seems to support his assumption that the reaction is a stepwise replacement of fluorine for oxygen.

Preparation of Chromyl Fluoride. Chromyl fluoride was prepared by two of the methods of Green and Gard (27), and were essentially quantitative. In the halogen exchange reaction between $\mathrm{CrO}_{2} \mathrm{Cl}_{2}$ and $\mathrm{ClF}$, a slight excess of ClF must be used to ensure complete reaction and to prevent the formation of the mixed halide $\mathrm{CrO}_{2} \mathrm{ClF}$. Chromyl chlorofluoride can be distinguished from chromyl fluoride by a strong absorption band at $750 \mathrm{~cm}^{-1}$ (57). A large excess of ClF or temperatures above $-78^{\circ} \mathrm{C}$ must be avoided however, or the yield of $\mathrm{CrO}_{2} \mathrm{~F}_{2}$ decreases because of the formation of $\mathrm{CrOF}_{3} \cdot \mathrm{XClF}$ (25).

The reaction of $\mathrm{CrO}_{3}$ with $\mathrm{WF}_{6}$ is the method of choice for the preparation of $\mathrm{CrO}_{2} \mathrm{~F}_{2}$. The reactants are the least expensive and easiest to handle, when compared to the other methods reported thus far. Yields are quantitative at $120^{\circ} \mathrm{C}$ and as long as an excess of $\mathrm{CrO}_{3}$ is maintained, pure $\mathrm{CrO}_{2} \mathrm{~F}_{2}$ is easily recovered from $\mathrm{CrO}_{3}$ and $\mathrm{WOF}_{4}$ by vacuum sublimation at room temperature.

Reaction of Chromyl Fluoride with Carbonyl Fluoride and Tungsten Hexafluoride. Carbonyl fluoride and tungsten hexa- 
fluoride were found to be not powerful enough as fluorinating agents to produce $\mathrm{CrOF}_{4}$ from $\mathrm{CrO}_{2} \mathrm{~F}_{2}$. Carbonyl fluoride did not react with chromyl fluoride past $330^{\circ} \mathrm{C}$. At $440^{\circ} \mathrm{C}$ some of the starting materials did react, by a seemingly complex mechanism. to produce $\mathrm{O}_{2}, \mathrm{CO}_{2}$, and $\mathrm{CrF}_{3}$. A balanced equation is given below.

$\mathrm{IV}-132 \mathrm{CrO}_{2} \mathrm{~F}_{2}+\mathrm{COF}_{2} \stackrel{440^{\circ} \mathrm{C}}{\longrightarrow} 2 \mathrm{CrF}_{3}+3 / 2 \mathrm{O}_{2}+\mathrm{CO}_{2}$ Tungsten hexafluoride did not react past the decomposition point of chromyl fluoride. At $550^{\circ} \mathrm{C}$ chromium oxide difluoride was produced along with some attack of the vessel by $W_{6}$. Molybdenum hexafluoride was found to be more reactive than tungsten hexafluoride in the fluorination of $\mathrm{CrO}_{3}$ to $\mathrm{CrO}_{2} \mathrm{~F}_{2}$ (25). Possibly the fluorination reaction could be carried one step further to produce $\mathrm{CrOF}_{4}$ with this reagent. Preparation and Fluorination of Chromium oxide Difluoride. Chromium oxide difluoride was prepared from the thermal decomposition of chromyl fluoride (21). The infrared spectrum of $\mathrm{CrOF}_{2}$ is listed in Table $X$. The physical properties of $\mathrm{CrOF}_{2}$ (non-volatility, insolubility in polar and non-polar solvents) indicate that it is extensively polymerized. Since the structure is unknown, direct normal mode assignments are not possible, but based on the group frequencies of other metal oxyfluorides, approximate assignments can be made. Terminal chromiumoxygen stretching is observed at $1010 \mathrm{~cm}^{-1}$ and $1002 \mathrm{~cm}^{-1}$. The weak, unassigned absorption at $984 \mathrm{~cm}^{-1}$ is possibly a combination of chromium-fluorine stretching modes unresolved in the 
strong, broad band centered at $565 \mathrm{~cm}^{-1}$. Absorption at 920 $\mathrm{cm}^{-1}$ is high for $\mathrm{Cr}-\mathrm{F}$ stretching. The position and broad nature of the band suggest that it is more likely a bridged chromium-oxygen stretching mode. This vibration occurs at $893 \mathrm{~cm}^{-1}$ in $\mathrm{CrO}_{3}$. Strong absorption bands between $840 \mathrm{~cm}^{-1}$ and $550 \mathrm{~cm}^{-1}$ are generally assigned to metal-fluorine stretching (58), although metal-fluorine bridged stretching modes may also, occur at the lower end of this region. Bridged metalfluorine stretching was assigned in the region of $440 \mathrm{~cm}^{-1}$ to $500 \mathrm{~cm}^{-1}$ in transition metal pentafluorides $(59-61)$ and as high as $540 \mathrm{~cm}^{-1}$ in solid chromyl fluoride (62). The peak at $475 \mathrm{~cm}^{-1}$ is assigned as bridged chromium-fluorine stretching. This vibration was also assigned at $475 \mathrm{~cm}^{-1}$ in $\mathrm{CrF}_{5}$ (55) and at $480 \mathrm{~cm}^{-1}$ in $\mathrm{CrOF}_{3}$ (c. 2. Chapter V). Absorption bands below $400 \mathrm{~cm}^{-1}$ are assigned to deformational modes.

The surface area of $\mathrm{CrOF}_{2}$ was determined for future investigations into its possible catalytic activity. The value of 0.59 square meters/gram is somewhat disappointing for catalytic uses, but is within the range expected for crystalline solids.

Fluorination of $\mathrm{CrOF}_{2}$ at $250^{\circ} \mathrm{C}$ resulted in loss of oxygen and oxidation to $\mathrm{CrF}_{5}$. No reaction was observed below $200^{\circ} \mathrm{C}$ and while $\mathrm{CrOF}_{4}$ may be formed between $200^{\circ} \mathrm{C}$ and $250^{\circ} \mathrm{C}$, no advantage can be seen in this possible preparation, over that of fluorination of $\mathrm{CrO}_{3}$.

${ }^{3}$ Personal communication, Dr. P. H. Emmett. 
SYNTHESIS OF CHROMIUM OXIDE TRIFLUCRIDE

AND SOME REACTION CHEMISTRY

\section{Introduction}

Various halochromate(V) salts have been prepared but few have been isolated in pure form and well characterized (63, 64). The only known neutral chromium(V) compounds are chromium pentafluoride, $\left(\mathrm{CrF}_{5}\right)$, chromium oxide trichloride, $\left(\mathrm{CrOCl}_{3}\right)$, and chromium oxide trifluoride, $\left(\mathrm{CrOF}_{3}\right)$, which until now has never been obtained in pure form.

Hexavalent chromium compounds are usually reduced to the pentavalent state upon strong halogenation. Chromium oxide trichloride was first prepared by Krauss et al, as a minor by-product in the reaction of chromium trioxide with either thionyl chloride or sulfuryl chloride $(65,66)$ :

$\mathrm{V}-1 \quad \mathrm{CrO}_{3}+\mathrm{SOCl}_{2} \stackrel{\mathrm{O}^{\circ} \mathrm{C}}{\longrightarrow} \mathrm{CrO}_{2} \mathrm{Cl}_{2}+\mathrm{SO}_{2}$

$\mathrm{CrO}_{2} \mathrm{Cl}_{2}+\mathrm{SOCl}_{2} \longrightarrow \mathrm{CrOCl}_{3}+\mathrm{SO}_{2}+\frac{1}{2} \mathrm{Cl}_{2}$
$\mathrm{CrO}_{3}+\mathrm{SO}_{2} \mathrm{Cl}_{2} \stackrel{\mathrm{O}^{\mathrm{O}}}{\longrightarrow} \mathrm{CrO}_{2} \mathrm{Cl}_{2}+\mathrm{SO}_{3}$
$\mathrm{CrO}_{2} \mathrm{Cl}_{2}+\mathrm{SO}_{2} \mathrm{Cl}_{2} \rightarrow \mathrm{CrOCl}_{3}+\mathrm{SO}_{3}+\frac{1}{2} \mathrm{Cl}_{2}$

The major product of the reactions is chromyl chloride, but the less volatile $\mathrm{CrOCl}_{3}$ can be isolated in two percent yield by fractional distillation of the reaction mixture. Higher yields of $\mathrm{CrOCl}_{3}$ are obtained by the reaction of $\mathrm{CrO}_{2} \mathrm{Cl}_{2}$ with $\mathrm{BCl}_{3}(67)$ :

$\mathrm{V}-3 \quad \mathrm{CrO}_{2} \mathrm{Cl}_{2}+2 / 3 \mathrm{BCl}_{3} \rightarrow \mathrm{CrOCl}_{3}+1 / 3 \mathrm{~B}_{2} \mathrm{O}_{3}+\frac{1}{2} \mathrm{Cl}_{2}$ $50 \%$ yield 
Chromium oxide trichloride is unstable at room temperature, disproportionating to $\mathrm{CrO}_{2} \mathrm{Cl}_{2}$ and presumably $\mathrm{CrCl}_{3}$.

A recent investigation of the spectral properties of $\mathrm{CrOCl}_{3}(68)$, indicates that by analogy to $\mathrm{VOCl}_{3}$, the vapor phase species is mono-molecular with a trigonal pyramidal structure $\left(\mathrm{C}_{3 \mathrm{v}}\right.$ symmetry), but in the solid state a chlorinebridged polymer is indicated.

Chromium pentafluoride can be prepared by direct fluorination of chromium metal (69), $\mathrm{CrF}_{3}(70)$, or $\mathrm{CrO}_{3}$ (31). The initial product is believed to be $\mathrm{CrF}_{6}$ which is unstable above $-100^{\circ} \mathrm{C}$, decomposing to $\mathrm{CrF}_{5}$ and $\mathrm{F}_{2}(71)$.

Chromium trioxide has been found to react with the strong fluorinating agents $\mathrm{BrF}_{3}, \mathrm{BrF}_{5}$, and $\mathrm{ClF}_{3}$, to produce $\mathrm{CrOF}_{3}$. $.25 \mathrm{BrF}_{3} \cdot \mathrm{CrOF}_{3} \cdot 25 \mathrm{BrF}_{5}$, and $\mathrm{CrOF}_{3} \cdot 30 \mathrm{ClF}_{3}(24)$. Again, chromium has been reduced to the pentavalent state, but only partial fluorination has occurred. Attempts to remove the particular interhalogen fluorinating agent by heating the products in vacuo resulted in decomposition, although reaction of $\mathrm{K}_{2} \mathrm{Cr}_{2} \mathrm{O}_{7}$ with $\mathrm{BrF}_{3} \cdot$ produced $\mathrm{KCrOF}_{4} \cdot .5 \mathrm{BrF}_{3}$ which when heated in vacuo at $160^{\circ} \mathrm{C}$, yielded pure $\mathrm{KCrOF}_{4}(24)$.

In the preparation of chromyl fluoride from $\mathrm{CrO}_{3}$ and CIF. Green (25) noted that a large excess of CIF or a reaction temperature above $0^{\circ} \mathrm{C}$, caused a reduction in the yield of $\mathrm{CrO}_{2} \mathrm{~F}_{2}$ and formation of an unstable brick red solid. This solid hydrolyzed to a yellow-green solution and had a magnetic moment consistent with a d chromium(V) compound. As with the 
previous work with interhalogen fluorides, elemental analysis indicated an impure product of composition $\mathrm{CrOF}_{3} \cdot 14 \mathrm{ClF}$ to $\mathrm{CrOF}_{3} \cdot .21 \mathrm{ClF}$.

In an attempt to prepare $\mathrm{CrOF}_{4}$, the $\mathrm{CrOF}_{3} \cdot \mathrm{XCIF}$ was reacted with fluorine at $120^{\circ} \mathrm{C}$. The product of this reaction was a non-volatile purple solid with a greatly reduced chlorine content. Elemental analysis of the purple product gave an approximate composition of $\mathrm{CrOF}_{3}$.

In an extension of this work, the reaction of $\mathrm{CrO}_{3}$ and $\mathrm{ClF}$ at $110^{\circ} \mathrm{C}$ was found to yield unstable adducts of $\mathrm{CrOF}_{3}$ (and apparently (IF) of non-stoichometric composition:

$\mathrm{V}-3 \quad \mathrm{CrO}_{3}+(4$ to 5$) \mathrm{ClF} \stackrel{100^{\circ} \mathrm{C}}{\longrightarrow} \mathrm{CrOF}_{3} \cdot \mathrm{XClF}+\mathrm{O}_{2}+3 / 2 \mathrm{Cl}_{2}+\mathrm{yClO}_{2} \mathrm{~F}$ The equation is unbalanced because ClF appears to be incorporated in some form with the product, and is also consumed by the formation of $\mathrm{ClO}_{2} \mathrm{~F}$.

The chlorine containing $\mathrm{CrOF}_{3}$ was heated at $120^{\circ} \mathrm{C}$ in a fluorine atmosphere.

$\mathrm{V}-4 \mathrm{CrOF}_{3} \cdot \mathrm{XClF}+\mathrm{F}_{2} \frac{1}{4 \text { hours }} \underset{\mathrm{atm}}{\longrightarrow} \mathrm{CrOF}_{3}+\mathrm{F}_{2}+\mathrm{ClO}_{2} \mathrm{~F}$

Multiple fluorine treatments yields a bright purple solid which was shown by elemental analysis to be essentially free from chlorine. The only volatile product of the fluorine treatments giving an infrared spectrum was $\mathrm{C}_{2} \mathrm{O}_{2} \mathrm{~F}(72)$. Infrared spectral data suggests that $\mathrm{CrOF}_{3}$ is a fluorine-bridged polymer with terminal oxygen groups. An $x$-ray powder pattern was also measured.

Pure $\mathrm{CrOF}_{3}$ was found to be stable to $300^{\circ} \mathrm{C}$ where it appears to melt with decomposition, producing oxygen and $\mathrm{CrF}_{3}$. 
$\mathrm{V}-5 \quad \mathrm{CrOF}_{3} \stackrel{500^{\circ} \mathrm{C}}{\longrightarrow} \frac{1}{2} \mathrm{O}_{2}+\mathrm{CrF}_{3}$

Chromium oxide trifluoride was found to react with

fluorine at elevated temperatures with the loss of oxygen to produce $\mathrm{CrF}_{5}$.

$\mathrm{V}-6 \quad \mathrm{CrOF}_{3}+\mathrm{F}_{2} \stackrel{190^{\circ} \mathrm{C}}{\longrightarrow} \mathrm{CrF}_{5}+\frac{1}{2} \mathrm{O}_{2}$

A limited study of the reaction chemistry of pure $\mathrm{CrOF}_{3}$ was undertaken. With the Lewis bases, $\mathrm{KF}$ and $\mathrm{NO}_{2} \mathrm{~F} ; 1: 1$ adducts were formed:

$\mathrm{V}-7 \quad \mathrm{CrOF}_{3}+\mathrm{KF} \stackrel{\mathrm{HF}}{\longrightarrow} \mathrm{KCrOF}_{4}$

$\mathrm{V}-8 \mathrm{CrOF}_{3}+\mathrm{NO}_{2} \mathrm{~F} \longrightarrow \mathrm{NO}_{2} \mathrm{CrOF}_{4}$

Infrared spectral data indicates that a monomeric, square pyramidal $\mathrm{CrOF}_{4}^{-}$anion, $\left(\mathrm{C}_{4 \mathrm{v}}\right.$ symmetry), is present in both of these compounds and that the nitryl salt contains a linear $\mathrm{ONO}^{+}$cation. X-ray powder patterns were also measured.

Reaction of $\mathrm{CrOF}_{3}$ with the strong Lewis acid, $\mathrm{SbF}_{5}$, resulted in the loss of oxygen and formation of a 1:2 adduct. $\mathrm{V}-9 \mathrm{CrOF}_{3}+2 \mathrm{SbF}_{5} \longrightarrow \mathrm{CrF}_{2} \mathrm{Sb}_{2} \mathrm{~F}_{11}+\frac{1}{2} \mathrm{O}_{2}$

The ultraviolet spectrum of the product in DMSO is consistent with a chromium (III) compound and infrared data indicates the presence of the $\mathrm{Sb}_{2} \mathrm{~F}_{11}$ anion.

Chromium oxide trifluoride was found to be insoluble and unreactive with $\mathrm{WF}_{6}$ at $110^{\circ} \mathrm{C}$.

Experimental

Preparation of Chromium Oxide Trifluoride. Dried $\mathrm{CrO}_{3}$, ( 35 mmoles), was added to a passivated $100 \mathrm{ml}$ Monel vessel in the dry box. Chlorine monofluoride, (151 mmoles), was then 
condensed into the vessel at $-196^{\circ} \mathrm{C}$ and the reaction mixture was heated at $110^{\circ} \mathrm{C}$ for 4 hours with periodic shaking. Upon opening the vessel at $-196^{\circ} \mathrm{C}$, a gas was found which was identified as oxygen by its molecular weight. Requires: 32.0 grams/mole Found: 31.7 grams/mole. At $-78^{\circ} \mathrm{C}$, the volatile materials consisted of $\mathrm{CIF}$ and $\mathrm{ClO}_{2} \mathrm{~F}$, identified by their infrared spectra $(34,72)$ and $\mathrm{Cl}_{2}$, a yellow-green liquid at $-78^{\circ} \mathrm{C}$. No volatile materials were found at $20^{\circ} \mathrm{C}$, the weight of the vessel contents corresponded to $\mathrm{CrOF}_{3} \cdot 0.1 \mathrm{ClF}$.

The vessel containing the chlorine contaminated $\mathrm{CrOF}_{3}$ was charged with $1.2 \mathrm{~atm}$. of fluorine and heated at $120^{\circ} \mathrm{C}$ for 12 hours. After cooling to $-196^{\circ} \mathrm{C}$, the vessel was evacuated thrsugh a $\mathrm{CaCl}_{2}$ tube, fluorine was indicated. At $20^{\circ} \mathrm{C}$ the vessel contained $850 \mathrm{~mm}$ of volatiles, identified as $\mathrm{ClO}_{2} \mathrm{~F}$ by its infrared spectrum. The vessel was evacuated and again charged with $1.2 \mathrm{~atm}$. of fluorine, then heated at $120^{\circ} \mathrm{C}$ for 2 hours. After removal of the fluorine, $60 \mathrm{~mm}$ of volatiles were found at $20^{\circ} \mathrm{C}, \mathrm{C} 1 \mathrm{O}_{2} \mathrm{~F}$ was the only infrared active material present. The vessel contents were treated with $1.2 \mathrm{~atm}$. of fluorine a third time at $120^{\circ} \mathrm{C}$ for 3 hours, only $5 \mathrm{~mm}$ of volatiles were found at $20^{\circ} \mathrm{C}$.

After evacuation, the vessel was opened in the dry box and found to contain 4.3 grams, ( 34 mmoles), of $\mathrm{CrOF}_{3}$, a nonvolatile, bright purple solid. Analysis for $\mathrm{CrOF}_{3}-\mathrm{Cr}$;

Requires: $41.6 \%$ Found: $41.72 \%$. F; Requires: $45.6 \%$ Found: $45.4 \%$, Cl; Found: 0.49\%. Purple $\mathrm{CrOF}_{3}$ is mildly hygroscopic, turning 
dark in air, and hydrolyzes to a yellow-green solution. The compound slowly attacks glass above $230^{\circ} \mathrm{C}$, but at $300^{\circ} \mathrm{C}$ there is sudden, extensive glass attack with apparent melting. Chromium oxide trifluoride attacks acetone, hexane, DMSO, and is insoluble in $\mathrm{CCI}_{4}$. Preliminary work suggests that $\mathrm{CrOF}_{3}$ is slightly soluble in anhydrous $\mathrm{HF}$ and $\mathrm{BrF}_{3}$. The $\mathrm{x}$-ray powder pattern is listed in Table XI. An infrared spectrum is given in Table XII, and also appears in the appendix. Thermal Decomposition of Chromium oxide Trifluoride. To a well-passivated $100 \mathrm{ml}$ Monel vessel was added 33 moles of $\mathrm{CrOF}_{3}$. The vessel was placed in a tube furnace and heated to $500^{\circ} \mathrm{C}$ over a period of 5 hours, then cooled to $-196^{\circ} \mathrm{C}$. Upon opening the vessel to the vacuum manifold, a non-condensable gas was found which was identified as oxygen, ( 16 mmoles), by its molecular weight. Requires: 32.0 grams/mole Found: 32.2 grams $/$ mole. At $20^{\circ} \mathrm{C}$ no other volatile materials were present. The vessel contained an inert, light green solid which was identified as $\mathrm{CrF}_{3}$, ( 34 moles), by its infrared spectrum and $x$-ray powder pattern which is listed in Table XIII. Analysis for $\mathrm{CrF}_{3}$-Cr; Requires: $47.7 \%$ Found: $44.72 \%$, F; Requires: $52.3 \%$ Found: $48.4 \%$.

Fluorination of Chromium Oxide Trifluoride. Fluorine,

(71 mmoles), was condensed at $-196^{\circ} \mathrm{C}$ into a passivated $100 \mathrm{ml}$ Monel vessel containing 40 mmoles of $\mathrm{CrOF}_{3}$. The reaction mixture was heated at $190^{\circ} \mathrm{C}$ for 15 hours, then the excess fluorine was removed at $-196^{\circ} \mathrm{C}$. At $20^{\circ} \mathrm{C}$ no volatile materials were present. The vessel was found to be coated with 


\section{TABIE XI}

$X-R A Y$ POWDER PATTERN OF $\mathrm{CrOF}_{3}$

\begin{tabular}{lccc}
$\mathrm{d}(\AA)$ & Intensity & $\frac{\mathrm{d}(\AA)}{\text { Intensity }}$ & ( $)$ \\
\hline 4.96 & $\mathrm{~m}$ & 1.95 & $\mathrm{w}$ \\
4.46 & $\mathrm{~s}$ & 1.89 & $\mathrm{vw}$ \\
4.04 & $\mathrm{~m}$ & 1.86 & $\mathrm{~m}$ \\
3.76 & $\mathrm{~s}$ & 1.82 & $\mathrm{~m}$ \\
3.64 & $\mathrm{~s}$ & 1.69 & $\mathrm{~s}$ \\
3.37 & $\mathrm{vs}$ & 1.58 & $\mathrm{w}$ \\
2.83 & $\mathrm{w}$ & 1.53 & $\mathrm{w}$ \\
2.75 & $\mathrm{vw}$ & 1.49 & $\mathrm{vw}$ \\
2.58 & $\mathrm{~m}$ & 1.46 & $\mathrm{~m}$ \\
2.48 & $\mathrm{~s}$ & 1.43 & $\mathrm{~m}$ \\
2.24 & $\mathrm{~s}$ & 1.41 & $\mathrm{~m}$ \\
2.04 & $\mathrm{~m}$ & 1.20 & \\
2.01 & $\mathrm{w}$ & &
\end{tabular}

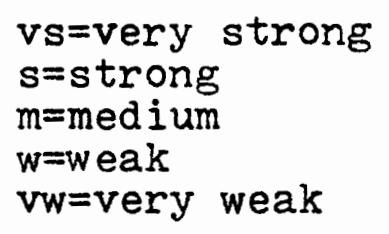


TABLE XII

VIBRATIONAL FREQUENCIES OF SOIID $\underset{\text { CrOF }}{3}, \mathrm{VOF}_{3}(60)$,
AND MOOF
(73) IN CM-1

Raman*

$1000 \mathrm{~s}$

$718 \mathrm{~s}$

$682 \mathrm{~s}$

600 vs

$565 \mathrm{~s}$

$512 \mathrm{~s}$

$480 \mathrm{~m}$

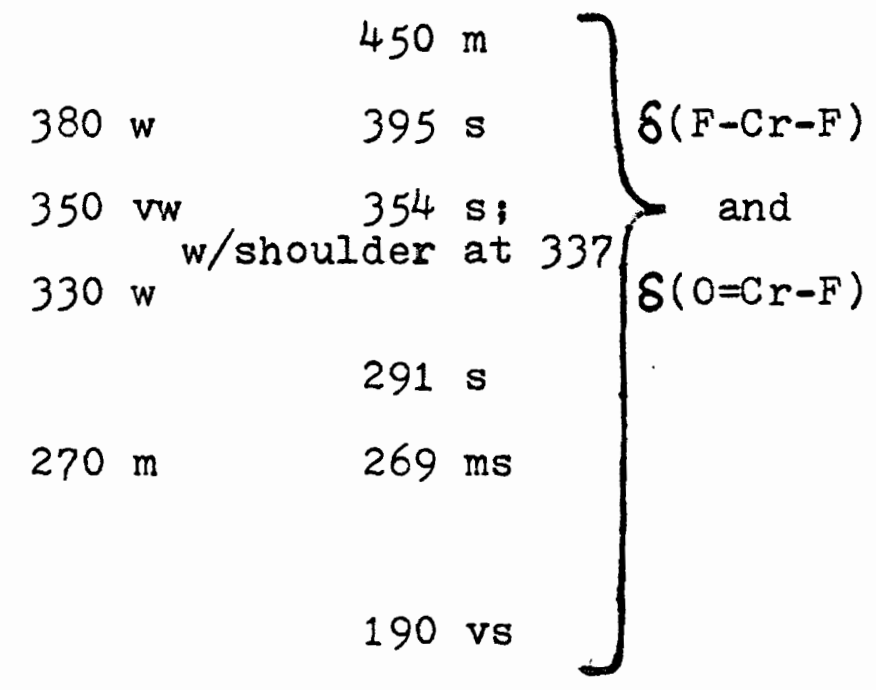

\section{$\mathrm{CrOF}_{3}$}

$789 \mathrm{w}$

$714 \mathrm{~m}, \mathrm{~b} ; \boldsymbol{V}(\mathrm{Cr}-\mathrm{F})$

$\mathrm{VOF}_{3}$

$\underline{\text { Raman }}$

1039 vs

$512+270$

$\mathcal{V}(\mathrm{Cr}=0)$

$\mathcal{V}(\mathrm{Cr}-\mathrm{F})$

$690 \mathrm{~m}$

$\mathcal{V}(\mathrm{Cr}-\mathrm{F})$

$V(C r-F)$

$\mathcal{V}(\mathrm{Cr}-\mathrm{F}-\mathrm{Cr} ?)^{* *}$

$527 \mathrm{~m}$

$\mathcal{V}(\mathrm{Cr}-\mathrm{F}-\mathrm{Cr} ?) * *$

$741 \mathrm{~s}$

$678 \mathrm{w}$

680

$620 \mathrm{~m}$

625

$530 \mathrm{~m}$

545

490
$408 \mathrm{vw}$

$358 \mathrm{~m}$

326 s

312 vw

$232 \mathrm{~s}$

$216 \mathrm{~m}$

$172 \mathrm{Vw}$

$138 \mathrm{~m}$

* Spectrum obtained from Dr. Tom M. Loehr at the Oregon Graduate Center.

**Two types of fluorine bridging were found in solid $\mathrm{VOF}_{3}$ ( 80 ), but one of these bands may be due to chromiumfluorine stretching or bending. 


\section{TABLE XIII}

X-RAY POWDER , RATTERNS OF THE $\mathrm{CrOF}_{3}$ DECOMPOSITION PRODUCT AND $\mathrm{CrF}_{3}(74)$

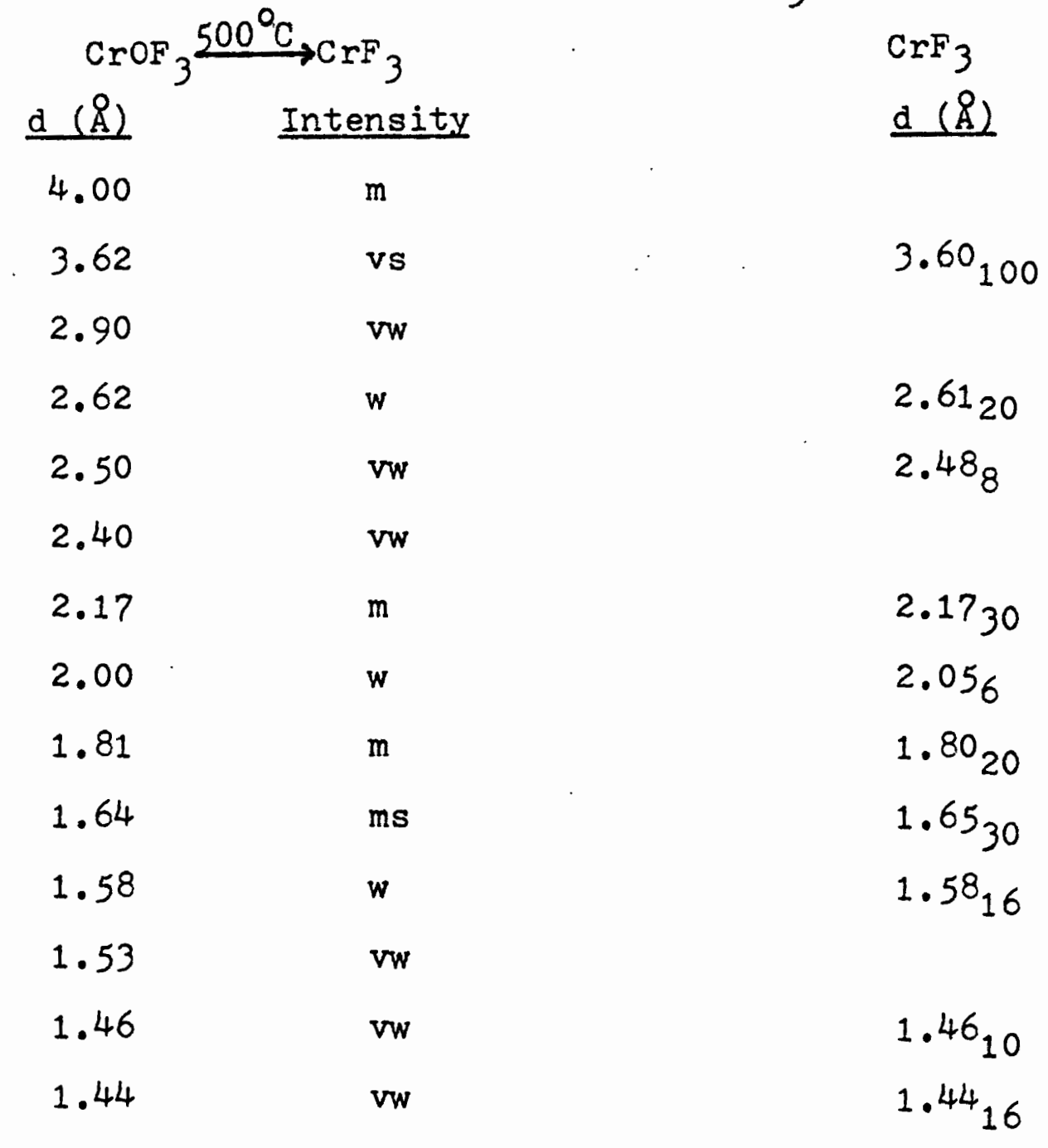

vs=very strong $\mathrm{m}=$ medium $w=w e a k$

$v w=v e r y$ weak 
a deep red semisolid which fumed in air, hydrolyzed to a yellow-green solution, and ignited acetone. An infrared spectrum of the solid showed it to be $\mathrm{CrF}_{5}$, ( 35 mmoles), produced in $88 \%$ yield.

Reaction of Chromium Oxide Trifluoride with Potassium

Fluoride. Chromium oxide trifluoride, ( $26 \mathrm{mmoles}$ ), and potassium fluoride, ( 26 mmoles) were placed in a $40 \mathrm{ml} \mathrm{Kel-F}$ vessel in the dry box. Anhydrous hydrogen fluoride, ( 0.71 moles), was vacuum distilled into the vessel and the mixture was magnetically stirred for 1 hour. A deep purple solution formed immediately and no solids could be detected in the translucent vessel. After evacuation of the vessel at $40^{\circ} \mathrm{C}$, a weight pickup of 25 mmoles $\mathrm{HF}$, $\left(\mathrm{KCrOF}_{4} \cdot \mathrm{HF}\right)$, was found. Evacuation of the vessel at $100^{\circ} \mathrm{C}$ for 1 hour removed all of the residual $H F$, leaving behind solids which equaled the original weight of the reactants.

The vessel contents were a tan-green crystalline solid which darkened in moist air and hydrolyzed to a yellow-green solution. Analysis for $\mathrm{KCrOF}_{4}-\mathrm{Cr}$; Requires: $28.4 \%$ Found: $28.26 \%$, F; Requires: $41.5 \%$ Found: $42.5 \%$. The product did not melt at temperatures above $400 \mathrm{C}$ but attacked the glass capillary above $170^{\circ} \mathrm{C}$. An $x$-ray powder pattern was obtained which correlated well with a pattern calculated from the unit cell constant data of Clark and Sadana (24) for $\mathrm{KCrOF}_{4} \cdot{ }^{4}$ 4 The $x$-ray powder pattern was calculated with the help of a computer program (75) adapted with modifications for the Honeywell H-66/20 by Dr. Bruce $W$. Brown of Portland State University. The author wishes to thank Dr. Brown for his assistance. 
The $\mathrm{x}$-ray pattern showed no unreacted $\mathrm{KF}$ or $\mathrm{CrOF}_{3}$ and is listed in Table XIV. The infrared spectrum of the product is listed in Table XV and also appears in the appendix.

\section{Reaction of Chromium Oxide Trifluoride with Nitryl}

Fluoride. Purified $\mathrm{NO}_{2} \mathrm{~F},\left(77\right.$ mmoles), was condensed at $-196^{\circ} \mathrm{C}$ into a passivated $75 \mathrm{ml}$ stainless steel vessel containing 21 mmoles $\mathrm{CrOF}_{3}$. The vessel was heated at $50^{\circ} \mathrm{C}$ for 11 days with periodic shaking. Upon evacuation of the vessel, no non-condensables were found at $-196^{\circ} \mathrm{C}$. At $20^{\circ} \mathrm{C}$ the only volatile substance was $\mathrm{NO}_{2} \mathrm{~F}$, identified by its infrared spectrum (38). The weight pickup of the vessel corresponded to 21 mmoles of $\mathrm{NO}_{2} \mathrm{~F}$. The vessel contents were a non-volatile tan colored powder which was mildly hygroscopic, hydrolyzing to a yellowgreen solution. Analysis for $\mathrm{NO}_{2} \mathrm{CrOF}_{4}-\mathrm{N} ;$ Requires: $7.4 \%$ Found: 5.91\%, Cr; Requires: 27.4\% Found: 29.49\%, F; Requires $40.0 \%$ Found: $41.9 \%$. The product decomposes above $80^{\circ} \mathrm{C}$ evolving a brown gas, probably $\mathrm{NO}_{2}$. A unique $x$-ray powder pattern was obtained which is listed in Table XVI. The $\mathrm{x}$-ray pattern shows that no unreacted $\mathrm{CrOF}_{3}$ is present. The infrared spectra of the product differ when the sample is prepared as a KBr pellet, compared to a Nujol mull between KRS-5 plates. The spectra are listed in Table XVII, and the Nujol mull spectrum appears in the appendix.

Reaction of Chromium Oxide Trifluoride with Antimony Pentafluoride. To a $68 \mathrm{ml}$ quartz vessel was added 2.75 mmoles of $\mathrm{CrOF}_{3}$ and 59 mmoles of $\mathrm{SbF}_{5}$ via vacuum distillation. The reaction mixture was heated at $110^{\circ} \mathrm{C}$ for 13 days 
TABIE XIV

$$
\begin{aligned}
& \text { OBSERVED AND CAICULATED ( } 24) \mathrm{X} \text {-RAY } \\
& \text { POWDER PATTERNS FOR KC YOF } 4
\end{aligned}
$$

Observed

d ( $(\AA)$

8.12

5.56

5.17

4.90

4.70

4.37

4.21

4.06

3.97

3.51

3.46

3.35

3.29

3.23

2.70
Calculated

$\mathrm{d}(\Omega)$

8.13

$5 \cdot 5 ?$

5.18

4.80

4.63

4.38

4.16

4.06

3.97

3.52

3.44

3.35

3.31

3.24

2.70
Observed

$\mathrm{d}(\mathrm{R})$

2.64

2.58

2.38

2.35

2.33

2.30

2.21

2.16

2.02

1.99

1.97

1.95

1.94

1.91

1.87
Intensity

w

w

w

$w$

w

$w$

m

m

vw

vw

vw

vw

vw

m

w
Calculated

d ( $)$

2.64

2.58

2.38

2.35

2.31

2.99

2.18

2.16

2.02

1.98

1.97

1.95

1.94

1.91

1.87

$s=s$ trong

$m=$ medium

$w=$ weak

$v w=v e r y$ weak 
TABLE XV INFRARED SPECTRA OF KCrOF 4 AND
CSVOF $4(76)$ IN $\mathrm{CM}^{-1}$

$\mathrm{KCrOF}_{4}$

$1020 \mathrm{~s}$

$962 \mathrm{w}$

$\frac{640+350}{625+335}$

1023-310

640 vs, b

$500 \mathrm{~s}$

$V(\mathrm{Cr}-\mathrm{F})$

$\nu(\mathrm{Cr}-\mathrm{F})$

$350 \mathrm{~m}$

$285 \mathrm{~m}$

$\delta(F-C r-F)$

$\delta(0=C r-F)$

595-335
$\mathrm{CsVOF}_{4}$

1023 vs

1016 vs

$973 w$

713 w

$625 \mathrm{~s}$

$595 \mathrm{~s}$

$480 \mathrm{~m}$

$335 \mathrm{~s}$

$310 \mathrm{~m}$

$260 \mathrm{~m}$

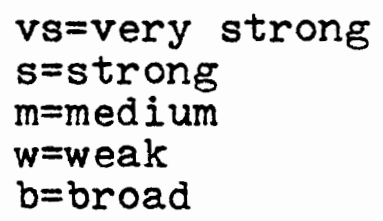


TABIE XVI

X-RAY POWDER PATTERN OF $\mathrm{NO}_{2} \mathrm{CrOF}_{4}$

$\begin{array}{lcrc}\frac{d}{d}(\AA) & \text { Intensity } & \frac{d(\AA)}{2} & \text { Intensity } \\ 5.45 & \mathrm{~m} & 2.47 & \mathrm{w} \\ 5.21 & \mathrm{~m} & 2.24 & \mathrm{w} \\ 4.91 & \mathrm{~s} & 2.18 & \mathrm{w} \\ 4.48 & \mathrm{~m} & 1.82 & \mathrm{w} \\ 4.04 & \mathrm{~s} & 1.78 & \mathrm{w} \\ 3.73 & \mathrm{w} & 1.69 & \mathrm{w} \\ 3.37 & \mathrm{~s} & & \mathrm{w} \\ 3.06 & \mathrm{w} & & \\ \begin{array}{l}\text { s=strong } \\ \text { m=medium } \\ \text { w=weak }\end{array} & \begin{array}{l}\text { vs=very strong } \\ \text { vb=very broad }\end{array} & \end{array}$

\section{TABIE XVII}

INFRARED SPECTRA OF $\mathrm{NO}_{2} \mathrm{CrOF}_{4}$ IN $\mathrm{CM}^{-1}$

\begin{tabular}{|c|c|c|}
\hline KBr Pellet & Assignment & Nujol Mull \\
\hline $2280 \mathrm{~m}$ & $\mathcal{V}\left(\operatorname{asym~} \mathrm{NO}_{2}{ }^{+}\right)$ & $2285 \mathrm{~s}$ \\
\hline $2070 w$ & & \\
\hline $1815 \mathrm{~s}$ & & \\
\hline $1500 \mathrm{~s}$ & & \\
\hline $1380 w$ & $\mathcal{V}\left(\operatorname{sym~\mathrm {NO}_{2}}{ }^{+}\right)$ & \\
\hline $1300 \mathrm{~m}$ & & \\
\hline $1255 \mathrm{w}$ & & \\
\hline $985 \mathrm{~s}$ & $\mathcal{V}(\mathrm{Cr}=0)$ & $980 \mathrm{~s}$ \\
\hline & $V(C r-F)$ & $700 \mathrm{~s}$ \\
\hline 530 vs, vb & $\mathcal{V}(\mathrm{Cr}-\mathrm{F})$ & $540 \mathrm{vs}, \mathrm{vb}$ \\
\hline
\end{tabular}


resulting in a red-brown solution. After evacuation of the vessel for 5 hours at $40^{\circ} \mathrm{C}$, a red-brown solid was obtained. The weight pickup of the vessel corresponded to 13.8 mmoles of $\mathrm{SbF}_{5}$ or an apparent stoichiometry of $\mathrm{CrF}_{3} \cdot 5.0 \mathrm{SbF}_{5}$, subjecting the red-brown solid to a dynamic vacuum while heating at $100^{\circ} \mathrm{C}$ for 35 hours, produced a light green powder. The non-volatile product at constant weight corresponded to $\mathrm{CrF}_{3} \cdot 2 \mathrm{SbF}_{5} \cdot$ Analysis for $\mathrm{CrF}_{2} \mathrm{Sb}_{2} \mathrm{~F}_{11}-\mathrm{Cr}$; Requires: $10.4 \%$ Found: $11.21 \%, F$; Requires: $45.5 \%$ Found: $44.7 \%$. The product is very hygroscopic, hydrolyzing violently to a green solution. Heating the green powder in a glass capillary resulted in no melting past $400^{\circ} \mathrm{C}$, but glass attack was apparent above $200^{\circ} \mathrm{C}$. The ultraviolet spectrum of the product in DMSO showed two absorption bands with the start of a third; $450 \mathrm{~nm}(\epsilon=49$ liter mole $\left.\mathrm{cm}^{-1}\right)$ and $652 \mathrm{~nm}\left(\epsilon=30\right.$ liter mole $\left.\mathrm{cm}^{-1}\right)$. $\mathrm{X}$-ray analysis resulted in no diffraction, indicating that the compound is amorphous. The infrared spectrum is listed in Table XVIII and also appears in the appendix.

Interaction of Chromium Oxide Trifluoride and Tungsten Hexafluoride. Chromium oxide trifluoride, $(7.2$ mmoles), was added to a $75 \mathrm{ml}$ passivated stainless steel vessel. Tungsten hexafluoride, ( $47 \mathrm{mmoles}$ ), was vacuum distilled into the vessel and the mixture was heated at $110^{\circ} \mathrm{C}$ for 3 days. The vessel was evacuated at $30^{\circ} \mathrm{C}$ through a $-196^{\circ} \mathrm{C}$-cooled trap. No non-condensables were found, all but 1 mmole of the $\mathrm{WF}_{6}$ was recovered. The vessel contained a bright purple powder which was confirmed to be $\mathrm{CrOF}_{3}$ by its infrared spectrum. 
TABLE XVIII

INFRARED SPECTRA OF $\mathrm{CrF}_{2} \mathrm{Sb}_{2} \mathrm{~F}_{11}$ AND $\mathrm{CrF}_{4} \mathrm{Sb}_{2} \mathrm{~F}_{11}$ (77) IN $\mathrm{CM}^{-11}$

$\mathrm{CrF}_{2} \mathrm{Sb}_{2} \mathrm{~F}_{11}$

$865 \mathrm{~m}$

$680 \mathrm{~s}$

660 vs

$545 \mathrm{~s}, \mathrm{~b}$

$280 \mathrm{w}$
Assignment

$V(\mathrm{Cr}-\mathrm{F} ?)$

$\mathcal{V}(\mathrm{Cr}-\mathrm{F})$

$V(S b-F)$

$\mathcal{V}(S b-F)$

$\mathcal{V}(\mathrm{Sb}-\mathrm{F}-\mathrm{Sb})$

$\delta(\mathrm{Cr}-\mathrm{F})$
$\mathrm{CrF}_{4} \mathrm{Sb}_{2} \mathrm{~F}_{11}$

$830 \mathrm{~s}$

$780 \mathrm{~m}$

$695 \mathrm{~s}$

$665 \mathrm{~s}$

$525 \mathrm{~s}, \mathrm{~b}$

$280 \mathrm{w}$

vs=very strong

$s=$ strong

m=medium

$\mathrm{b}=$ broad 
Discussion

Preparation and Purification of Chromium Oxide Trifluoride. Reaction of $\mathrm{CrO}_{3}$ with $\mathrm{ClF}$ at $110^{\circ} \mathrm{C}$ produced a brick red, unstable solid. As was found in the reaction of $\mathrm{CrO}_{3}$ with other interhalogen fluorides $(22,24)$, the product appeared to be an adduct of $\mathrm{CrOF}_{3}$ and the interhalogen fluorinating agent.

It is interesting that when the impure $\mathrm{CrOF}_{3}$ is purified by heating at $120^{\circ} \mathrm{C}$ in a fluorine atmosphere, $\mathrm{ClO}_{2} \mathrm{~F}$, not $\mathrm{ClF}$, is the only by-product yielding an infrared spectrum. It appears that the contaminating species may be $\mathrm{ClO}_{2}^{+} \mathrm{CrOF}_{4}{ }^{-}$. This speculation is supported by infrared spectral data of the impure $\mathrm{CrOF}_{3}$. Weak absorption bands are found at 1275 $\mathrm{cm}^{-1}$ and $1062 \mathrm{~cm}^{-1}$. Asymmetric and symmetric $\mathrm{ClO}_{2}^{+}$stretching is observed at $1296 \mathrm{~cm}^{-1}$ and $1044 \mathrm{~cm}^{-1}$ in $\mathrm{ClO}_{2}{ }^{+} \mathrm{AsF}_{6}^{-}$, and at $1294 \mathrm{~cm}^{-1}$ and between $1100 \mathrm{~cm}^{-1}$ and $990 \mathrm{~cm}^{-1}$ in $\mathrm{ClO}_{2}{ }^{+} \mathrm{BF}_{4}^{-}$ (78).

The purification of $\mathrm{CrOF}_{3}$ with fluorine is limited to temperatures between $120^{\circ} \mathrm{C}$ and $190^{\circ} \mathrm{C}$. Below $120^{\circ} \mathrm{C}$ the interactions ineffective and removal of the contaminating species is incomplete. At temperatures near $190^{\circ} \mathrm{C}, \mathrm{CrOF}_{3}$ is fluorinated to $\mathrm{CrF}_{5}$.

The infrared spectrum of $\mathrm{CrOF}_{3}$, listed in Table XII, is of high quality and reproducible when displayed as a neat solid between KRS-5 plates or as a KBr pellet. The physical properties of $\mathrm{CrOF}_{3}$ (non-volatility, insolubility in non-polar 
solvents) indicate that it is polymerized in the solid state, this makes definite spectral assignments and comparisons to compounds of known structure difficult. The polymeric nature of solid CrOF 3 is confirmed by the multiplicity of absorption bands in the chromium-fluorine stretching region between 718 $\mathrm{cm}^{-1}$ and $565 \mathrm{~cm}^{-1}$, and by the absorptions at $512 \mathrm{~cm}^{-1}$ and 480 $\mathrm{cm}^{-1}$ which are in the region of chromium-fluorine bridge bonded stretching (59-61). In the Raman spectra, fluorine-bridged bond stretching bands are usually weak $(60,79)$; however, with solid $\mathrm{CrO}_{2} \mathrm{~F}_{2}$ and in solid $\mathrm{CrOF}_{3}$ they are present as medium intensity bands (62). Terminal chromium-oxygen stretching is clearly indicated by the absorption bands at $1000 \mathrm{~cm}^{-1}$, both in the infrared, and in the Raman spectrum of $\mathrm{CrOF}_{3}$. No bands are attributable to chromium-oxygen bridging (52).

An unassigned infrared spectrum of $\mathrm{MOOF}_{3}$ has appeared in the Russian literature (73), but the spectrum of $\mathrm{CrOF}_{3}$ correlates more closely with $\mathrm{VOF}_{3}$ which suggests that they may be isostructural. The solid state structure of $\mathrm{VOF}_{3}$ has been determined (80) and is illustrated in Figure 10.

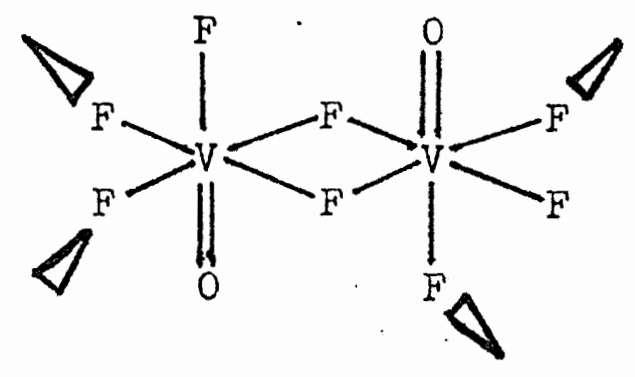

Figure 10. Structure of solid $\mathrm{VOF}_{3}$. 
Chromium oxide trifluoride appears to melt with decomposition at $300^{\circ} \mathrm{C}$ when heated in a glass capillary. When a sample of $\mathrm{CrOF}_{3}$ was sealed in a well passivated Monel vessel and heated at $500^{\circ} \mathrm{C}$, quantitative decomposition to $\mathrm{CrF}_{3}$ and oxygen was observed. This decomposition behavior is similar to that of chromyl fluoride, which loses oxygen at $500^{\circ} \mathrm{C}$ (21). Reaction of Potassium Fluoride with Chromium Oxide Trifluoride. In anhydrous $\mathrm{HF}$, the reaction of $\mathrm{KF}$ and $\mathrm{CrOF}_{3}$ not only produced $\mathrm{KCrOF}_{4}$, but apparently a $1: 1$ adduct was formed with the solvent. The $\mathrm{HF} \cdot \mathrm{KCrOF}_{4}$ adduct presumably could contain the bifluoride cation $\mathrm{KHF}^{+}$. This adduct was not further studied. The coordinated HF was removed by heating the adduct at $100^{\circ} \mathrm{C}$ in vacuo.

The infrared spectrum of $\mathrm{KCrOF}_{4}$ is listed in Table XIV. No absorption bands appear in the regions assigned to chromiumoxygen or chromium-fluorine bridging. The absence of these bands indicate a square pyramidal $\left(C_{4 \mathrm{v}}\right.$ symmetry) or a trigonal bipyrimidal ( $\mathrm{C}_{2 \mathrm{v}}$ symmetry) structure for the monomeric $\mathrm{CrOF}_{4}{ }^{-}$ anion. These two possible structures are illustrated in Figure 11.

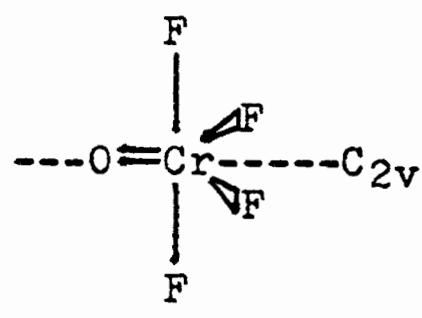

Trigonal bipryimidal

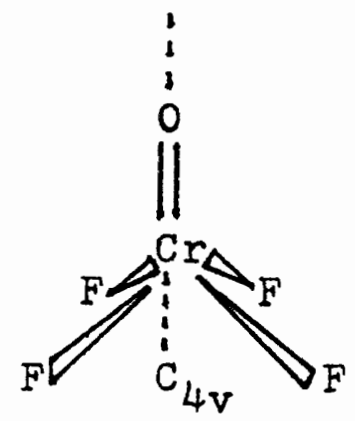

Square pyrimidal

Figure 11. Possible structures of the $\mathrm{CrOF}_{4}^{-}$anion. 
The total number of vibrations allowed for the $\mathrm{CrOF}_{4}^{-}$anion is 12. In $\mathrm{C}_{2 \mathrm{v}}$ symmetry the expected number of infrared active vibrational frequencies is 11 and for $C_{4 \mathrm{~V}}$ symmetry there are 6 expected infrared active bands. The infrared spectrum of $\mathrm{KCrOF}_{4}$ strongly suggests $\mathrm{C}_{4 \mathrm{~V}}$ symmetry (by comparison with the vibrational spectrum of $\mathrm{CsVOF}_{4}(81)$, for which $\mathrm{C}_{4 \mathrm{v}}$ symmetry is assumed). The only anomalies in the spectra are the split $V=0$ stretch which was explained by the authors as a solid state effect (81), and the absence of a sixth absorption band in $\mathrm{KCrOF}_{4}$, which is probably unresolved in the strong, broad absorptions around $600 \mathrm{~cm}^{-1}$

Assignment of $\mathrm{C}_{4 \mathrm{~V}}$ symmetry to the $\mathrm{CrOF}_{4}^{-}$anion is not surprising, this structure has been assumed for many oxo-tetrachloro chromate(V) salts (64) and has been confirmed for $\left(\mathrm{AsPh}_{4}\right)\left(\mathrm{CrOCl}_{4}\right)$ in an x-ray crystallographic study (82).

Reaction of Nitryl Fluoride with Chromium oxide Trifluoride. Direct reaction of solid CrOF 3 with gaseous $\mathrm{NO}_{2} \mathrm{~F}$ produced $\mathrm{NO}_{2} \mathrm{CrOF}_{4}$. The tan solid is non-volatile and decomposes above $80^{\circ} \mathrm{C}$, giving off a brown gas. Similar decomposition behavior was found for $\mathrm{NO}_{2} \mathrm{CrO}_{2} \mathrm{~F}_{3}$ (29) and $\mathrm{NO}_{2} \mathrm{CrF}_{6}$ (77), which decompose at $130^{\circ} \mathrm{C}$ and $142^{\circ} \mathrm{C}$.

The infrared spectrum of $\mathrm{NO}_{2} \mathrm{CrOF}_{4}$ closely resembles $\mathrm{KCrOF}_{4}$ in the low frequency region. This indicates a square pyramidal structure for the anion in $\mathrm{NO}_{2} \mathrm{CrOF}_{4}$. The high frequency region of the spectrum is confusing when the sample is displayed as a $\mathrm{KBr}$ pellet. A multitude of bands appear 
which cannot be accounted for by a simple $\mathrm{NO}_{2}{ }^{+}$cation. When the sample is displayed as a $\mathrm{NujOl}$ mull between KRS-5 plates, all but one of the high frequency bands disappear. Reaction of nitryl salts with sodium chloride and barium fluoride windows has been observed $(83,84)$, requiring the use of the more inert silver chloride plates for obtaining infrared spectra.

A total of three vibrations are expected for the nitronium cation. If the $\mathrm{NO}_{2}^{+}$group is bent, all three vibrations would be infrared active. For a linear $\mathrm{ONO}^{+}$ion, only the asymmetric stretching and bending vibrations would be infra-

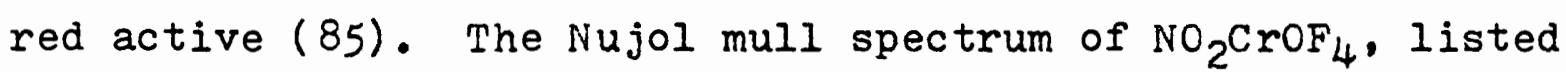
in Table XVII, supports a linear structure for the $\mathrm{ONO}^{+}$cation. Asymmetric stretching is observed at $2285 \mathrm{~cm}^{-1}$, this band was found at $2315 \mathrm{~cm}^{-1}$ in $\mathrm{NO}_{2} \mathrm{CrF}_{6}(77)$. The symmetric $\mathrm{NO}_{2}^{+}$stretch is missing, as expected. This band should occur around 1400 $\mathrm{cm}^{-1}$ (86), and may be represented at $1380 \mathrm{~cm}^{-1}$ in the $\mathrm{KBr}$ pellet spectrum as the result of distortion of the linear $\mathrm{ONO}^{+}$symmetry by pellet interactions. The bending mode should be observed in the infrared, but this band is expected around $650 \mathrm{~cm}^{-1}(86)$ and is therefore masked by the strong, broad chromium-fluorine stretching modes.

Reaction of Chromium Oxide Trifluoride with Antimony Pentafluoride. Attempts were made to prepare an adduct of $\mathrm{CrOF}_{3}$ with $\mathrm{SbF}_{5}$. However, the reaction proceeded with reduction of $\mathrm{CrOF}_{3}$ by the loss of oxygen. After removal of 
the excess $\mathrm{SbF}_{5}$, an initial solid product was obtained which had an apparent stiochiometry of $\mathrm{CrF}_{3} \cdot 5.0 \mathrm{SbF}_{5}$. This solid was not studied, further evacuation at $100^{\circ} \mathrm{C}$ resulted in a constant weight adduct of composition $\mathrm{CrF}_{3} \cdot 2 \mathrm{SbF}_{5}$.

An ultraviolet spectrum of the $1: 2$ adduct in DMSO gave two absorption bands at $450 \mathrm{~nm}\left(\epsilon=49\right.$ liter mole $\left.\mathrm{e}^{-1} \mathrm{~cm}^{-1}\right)$ and $652 \mathrm{~nm}\left(\epsilon=30\right.$ liter mole $\left.\mathrm{cm}^{-1}\right)$. These values correlate well with the spectrum of $\left(\mathrm{Cr}\left(\mathrm{DMSO}_{6}\right)\left(\mathrm{ClO}_{4}\right)_{3}(87)\right.$, which absorbs at $444 \mathrm{~nm}\left(\epsilon=33.4\right.$ liter mole $\left.\mathrm{e}^{-1} \mathrm{~cm}^{-1}\right)$ and $634 \mathrm{~nm}(\epsilon=34.6$ liter mole $\left.e^{-1} \mathrm{~cm}^{-1}\right)$.

The light green product did not give an $x$-ray powder pattern and would indicate that it is amorphous, but this may also be the result of poor crystal growth during its formation. The infrared spectrum of $\mathrm{CrF}_{3} \cdot 2 \mathrm{SbF}_{5}$ is listed in Table XVIII. Comparison with the spectrum of $\mathrm{CrF}_{4} \mathrm{Sb}_{2} \mathrm{~F}_{11}$ (77) indicates that the adduct contains the $\mathrm{Sb}_{2} \mathrm{~F}_{11}{ }^{-}$anion and is therefore formulated as $\mathrm{CrF}_{2} \mathrm{Sb}_{2} \mathrm{~F}_{11}$. The medium absorption band at $865 \mathrm{~cm}^{-1}$ occurs at a high frequency to be safely assigned as chromium-fluorine stretching, although a chromium-fluorine stretching mode also occurred at significantly higher frequency in $\mathrm{CrF}_{4} \mathrm{Sb}_{2} \mathrm{~F}_{11}$ than in $\mathrm{CrF}_{5}(77)$. 


\section{BIBIIOGRAPHY}

1. J.H. Simons, ed., "Fluorine Chemistry", Vol. 1, Academic Press, New York, 1950, p. 404.

2. J. H. Simons and I. P. Block, JACS, 59, 1407 (1937).

3. H. I. Krauss, Agnew. Chem, 70, 502 (1958).

4. J. N. Gerlach and G. I. Gard, Incrg. Chem., 9, 1565 (1970).

5. K. Yamasaki and K. Suzuki, Proc. Int. Conf. Coord. Chem., 8th Vienna, 357 (1964).

6. E. I. Chubakova and N. A. Skorik, Zh. Neorg. Khim., 18, $2723(1973)$.

7. E. C. C. Amaral and R. A. Guedes de Carvalho, J. Inorg. Nuc. Chem., 31,2695 (1969).

8. G. V. D. Tiers, 3M Company, Brit. 1,070,294.

9. D. M. Blake, S. Shields, and I. Wyman, Inorg. Chem., 13, $1595(1974)$.

10. F. A. Cotton and G. Wilkinson, "Advanced Inorganic Chemistry", 4th ed.. Wiley-Interscience, New York, 1980. p. 171 .

11. N. W. Alcock, V. M. Tracy, and T. C. Waddington, J.C.S. Dalton, 21, 2238 (1976).

12. C. Oldham, Prog. Inorg. Chem., 10, 223 (1968).

13. K. Nakamoto, and P. J. McCarthy, "Spectroscopy and Structure of Metal Chelate Compounds", Wiley-Interscience, New York, 1968.

14. C. D. Garner and B. Hughes, Adv. Inorg. Chem. Radiochem., 17. 1 (1975).

15. S. D. Robinson and M. F. Uttley, J.C.S. Dalton, 18, 1912 (1973).

16. J. Catterick and P. Thornton, Adv. Inorg. Chem. Radiochem., 20, 291 (1977).

17. H. Schaferafer and F. Wartenpfunl, Z. anorg. Allgem. Chem., $308,282(1961)$. 
18. M. Danot and J. Rouxel, Compt. Rend., 262C, 1879 (1966).

19. G. Petit and C. Bourlange, C. R. Acad. Sci., Ser. C., 237, 1065 (1971).

20. T. R. Fiske and D. W. Baugh, Dow Chemical Co., U. S. 4,147,733, 1979.

21. W. V. Rochat, J. N. Gerlach, and G. L. Gard, Inorg. Chem., 9. 998 (1970).

22. A. G. Sharpe and A. A. Woolf, J. Chem. Soc., 798 (1951).

23. H. C. Clark and Y. N. Sadana, Can. J. Chem., 42, 50 (1964).

24. H. C. Clark and Y. N. Sadana, Can. J. Chem., 42, 702 (1964).

25. P. J. Green, Master's Thesis, Portland State University, 1976.

26. A. Engelbrecht and A. V. Grosse, JACS, 74, 5262 (1952).

27. P. J. Green and G. I. Gard, Inorg. Chem., 16, 1243 (1977).

28. S. D. Brown, P. J. Green, and G. L. Gard, J. Fluorine Chem., 5, 203 (1975).

29. P. J. Green and G. I. Gard, Inorg. Nucl. Chem., Letters, 14, 179 (1978).

30. A. J. Edwards, Proc. Chem. Soc., 205 (1963).

31. A. J. Edwards, W. E. Falconer, and W. A. Sunder, J.C.S. Dalton, 541 (1974).

32. Rakov, Sudarikov, and Marinina, Tr. Mosk Khim. Tekhnol Inst., 71, 21 (1972).

33. P. J. H. Woltz and E. A. Jones, J.Chem. Phys,, 17, 502 (1949).

34. E. A. Jones, T. F. Parinson, and T. G. Burke, J. Chem. Phys., 18,235 (1950).

35. F. A. Miller, G. I. Carlson, and W. B. White, Spectrochim. Acta, 15, 709 (1959).

36. W. E. Hobbs, J. Chem. Phys, 28, 1220 (1958). 
37. R. M. Adams and J. J. Katz, J. Opt. Soc. Am., 36, 895 (1956).

38. R. E. Dodd, J. A. Rolfe, and I. A. Woodward, Trans, Faraday Soc., 52, 145 (1956).

39. M. Hauptschein, C. S. Stokes, and E. A. Nodiff, JACS, 74,4005 (1952).

40. T. G. Burke, D. F. Smith, and A. H. Nielsen, J. Chem. Phys., 20, 447 (1952).

41. J. N. Gerlach and G. I. Gard, Inorg. Chem., 10, 1541 (1971).

42. J. H. Taylor, W. S. Benedick, and J. Strong, J. Chem. Phys., 20,1884 (1952).

43. J. H. Simons, ed., "Fluorine Chemistry", Vol. 2, Academic Press, New York, 1954, p. 485.

44. M. J. Bailie, D. H. Brown, K. C. Moss, and D. W. Sharpe, J. Chem. Soc., A, 3110 (1968).

45. P. Sartori and M. Weidenbruch, Chem. Ber., 100, 2049 (1967).

46. I. Helmholz, H. Brennan, and M. Wolfsberg, J. Chem. Phys., 23, 853 (1955).

47. W. V. Rochat and G. L. Gard, unpublished work.

48. S. D. Brown and G. L. Gard, Inorg. Chem., 14, 2273 (1975).

49. C. A. Agambar and K. G. Orrell, J.Chem. Soc., A. 897 (1969).

50. D. Naumann, M. Schmeisser, and R. Scheele, J. Fluorine Chem.. 1, 321 (1972).

51. M. J. Haddadin, T. Higuchi, and V. Stella, J. Pharm. Sci., 64, 1759 (1975).

52. C. G. Barraclough, J. Lewis, and R. S. Nyholm, J. Chem. Soc., 3552 (1959).

53. B. Soptrajanov, A. Nikolovski, and I. Petrov, Spectrochim. Acta, 24A, 1617 (1968).

54. M. I. Larson and F. W. Moore, Inorg. Chem., 2, 881 (1963). 
55. S. D. Brown, T. M. Loehr, and G. I. Gard, J.Chem. Phys., $64,260(1976)$.

56. R. A. Nyquist and R. O. Kagel, "Infrared Spectra of Inorganic C'ompounds", Academic Press, New York, 1971, p. 357.

57. G. D. Flesch and H. J. Svec, JACS, 80, 3189 (1958).

58. G. Socrates, "Infrared Characteristic Group Frequencies", Wiley-Interscience, New York, 1980 , p. 141.

59. I. R. Beattie, K. M. S. Iivingston, G. A. Ozin, and D. J. Reynolds, J. Chem. Soc., A, 958 (1969).

60. I. R. Beattie, K: M. S. Livingston, D. J. Reynolds, and G. A. Ozin, J.Chem. Soc., A, 1210 (1970).

61. I. E. Alexander, I. R. Beattie, and P. J. Jones, J. Chem. Soc. Dalton Trans., 210 (1972).

62. S. D. Brown, T. M. Loehr, and G. I. Gard, J. Chem. Phys., 64, $1219(1976)$.

63. O. V. Ziebarth and J. Selbin, J. Inorg. Nucl. Chem., 32 , $849(1970)$.

64. K. R. Seddon and V. H. Thomas, J. Chem. Soc., Dalton Trans., 2195 (1977).

65. H. C. Krauss and G. Munster, Z. Naturforschg., 176, 344 (1962).

66. H. C. Krauss, M. Leder, and G. Munster, Chem. Ber., 96. 3008 (1963).

67. R. B. Johannesen and H. C. Krauss, Chem. Ber., 97, 2094 (1964).

68. W. Levason, J. S. Ogden, and A. J. Rest, J. Chem. Soc., Dalton Trans., 419 (1980).

69. H. V. Wartenberg, 2. Anorg. Allgem. Chem., 247, 135 (1941).

70. J. Sviliuk and B. Zemva, Z. Anorg, Allgem. Chem., 385, 138 (1971).

71. O. Glemser, H. Roesky, and K. H. Hellberg, Angew. Chem., Int. Ed., 2, 266 (1963).

72. D. F. Smith, G. M. Begun, and W. H. Fletcher, Spec. Acta, $20,1763(1964)$.

73. G. E. Blokhina, I. N. Belyaer, A. Opalovski, and I. I. Belan, Russ. J. Inorg. Chem., 17, 1113 (1972). 
74. K. Knox, Acta Cryst., 13, 507 (1960).

75. J. S. Miller and S. Z. Goldberg, Inorg. Chem., 14, 2294 (1975).

76. J.. A. S. Howell and K. C. Moss, J.Chem. Soc. (A), 270 (1971).

77. S. D. Brown, T. M. Loehr, and G. I. Gard, J. Fluorine Chem., 7. 19 (1976).

78. K. O. Christe, C. J. Schak, and D. Piliponch, Inorg. Chem., 8, 2489 (1969).

79. D. J. Reynolds, Adv. Fluorine Chem., 7, 1 (1974).

80. A. J. Edwards and F. Taylor, Chem. Comm., 1474 (1970). 81. J.A. S. Howell and K. C. Moss, J. Chem. Soc. (A), 270

82. C. D. Garner, J. Kendrick, P. Lambert, F. E. Mabbs, and I. H. Hillier, Inorg. Chem., 15, 1287 (1976).

83. D. Cook, S. J. Kuhn, and G. A. Olah, J.Chem. Phys., 33, 1669 (1960).

84. R. W. Sprague, A. B. Garrett, and H. H. Sisler, JACS, 82, 1059 (1960).

85. K. Nakamoto, "Infrared Spectra of Inorganic and Coordination Compounds", Wiley-Interscience, New York, 1963.

86. R. A. Marcus and J. Fresco, J. Chem. Phys., 27, 564 (1957).

87. D. W. Meek, R. S. Drago, and '. S. Piper, Inorg. Chem., 1, $285(1962)$. 


\section{APPENDIX}

\section{INFRARED SFECTRA OF PRODUCTS}

PAGE

Chromyl Perfluoroglutarate, $\mathrm{CrO}_{2}\left(\left(\mathrm{O}_{2} \mathrm{C}\right)_{2}\left(\mathrm{CF}_{2}\right)_{3}\right) \ldots .94,95$

Molybdenyl Perfluoroglutarate, $\mathrm{MoO}_{2}\left(\left(\mathrm{O}_{2} \mathrm{C}\right)_{2}\left(\mathrm{CF}_{2}\right)_{3}\right) \ldots 96$ Tungstanyl Perfluoroglutarate, $\mathrm{WO}_{2}\left(\left(\mathrm{O}_{2} \mathrm{C}\right)_{2}\left(\mathrm{CF}_{2}\right)_{3}\right) \ldots 9$ ? $\mathrm{Na}_{2}\left(\left(\mathrm{O}_{2} \mathrm{C}\right)_{2}\left(\mathrm{CF}_{2}\right)_{3}\right) \ldots \ldots \ldots \ldots \ldots . \ldots \ldots . \ldots \ldots$ $\mathrm{K}_{2} \mathrm{CrO}_{2}\left(\left(\mathrm{O}_{2} \mathrm{C}\right)_{2}\left(\mathrm{CF}_{2}\right)_{3}\right)_{2} \ldots \ldots \ldots \ldots \ldots \ldots \ldots \ldots \ldots . \ldots \ldots$

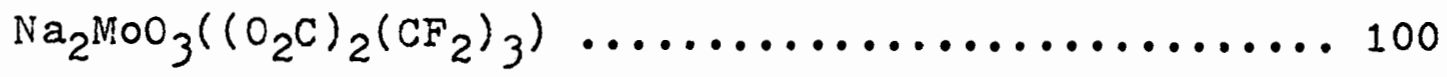

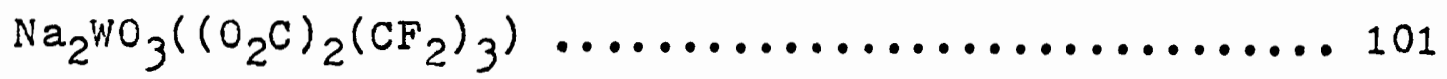
Chromium Pentafluoride, $\mathrm{CrF}_{5} \ldots \ldots \ldots \ldots \ldots . \ldots \ldots$ Chromyl Fluoride, $\mathrm{CrO}_{2} \mathrm{~F}_{2} \ldots \ldots \ldots \ldots \ldots \ldots$ Chromyl Fluoride Fluorination Products .......... 104 Chromium Trifluoride, $\mathrm{CrF}_{3} \ldots \ldots \ldots \ldots . \ldots \ldots$ Chromium Oxide Difluoride, $\mathrm{CrOF}_{2} \ldots \ldots \ldots \ldots$ Chromium Oxide Trifluoride, $\mathrm{CrOF}_{3} \ldots \ldots \ldots \ldots \ldots \ldots . \ldots 107,108$ Potassium 0xo-tetrafluorochromate(V), $\mathrm{KCrOF}_{4} \ldots . . .109$ Nitryl 0xo-tetrafluorochromate(V), $\mathrm{NO}_{2} \mathrm{CrOF}_{4} \ldots \ldots \ldots 110,111$

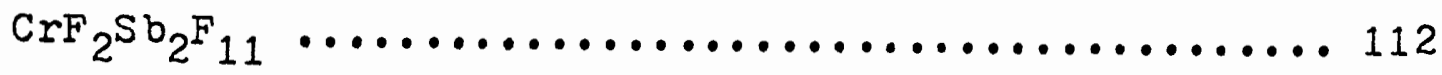




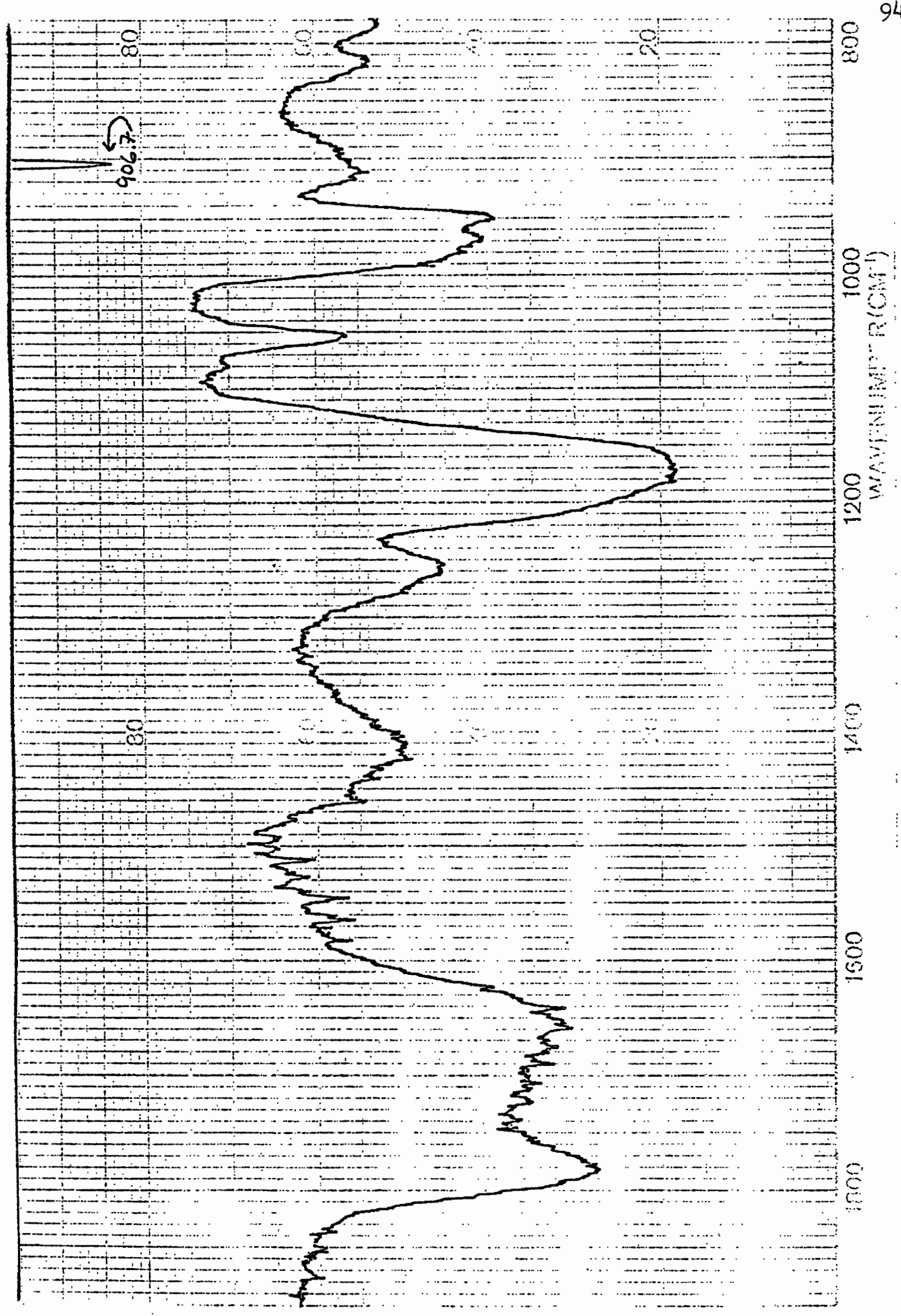

Infrared spectrum of $\mathrm{CrO}_{2}\left(\left(\mathrm{O}_{2} \mathrm{C}\right)_{2}\left(\mathrm{CF}_{2}\right)_{3}\right), 1900$ to $800 \mathrm{~cm}^{-1}$,
$(\mathrm{KBr}$ pellet $)$. 


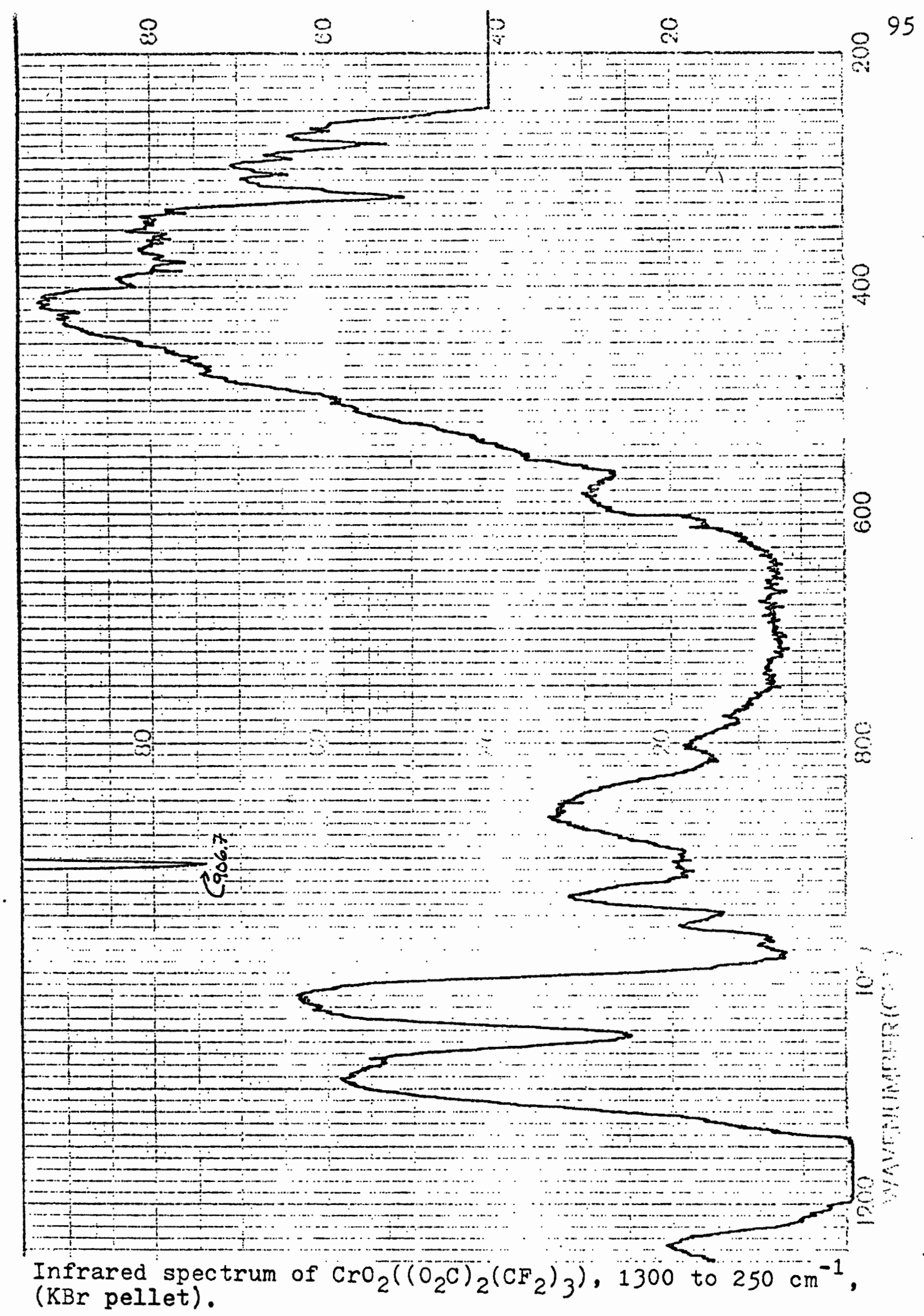




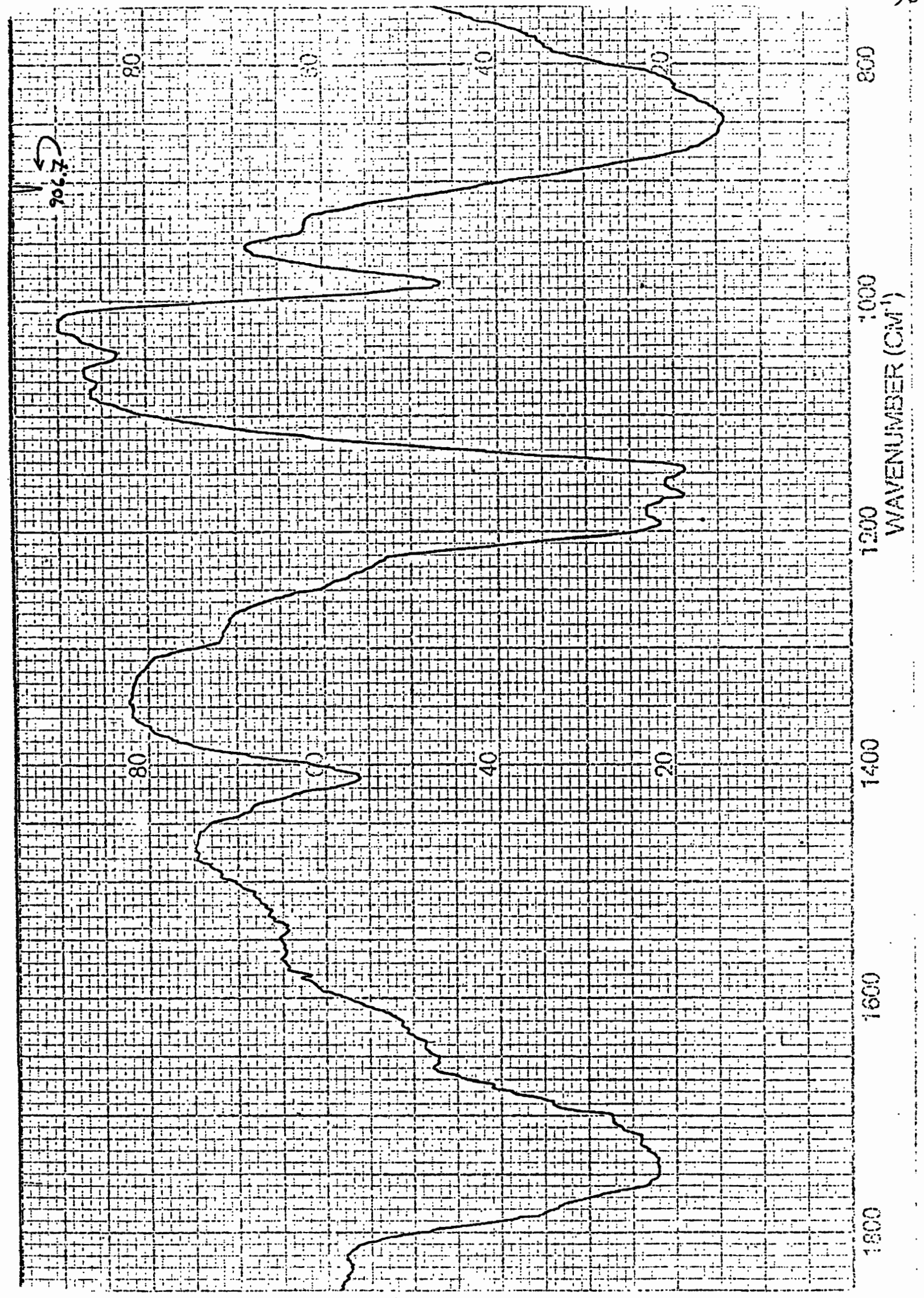

Infrared spectrum of $\mathrm{MOO}_{2}\left(\left(\mathrm{O}_{2} \mathrm{C}\right)_{2}\left(\mathrm{CF}_{2}\right)_{3}\right)$, (KBr pellet). 


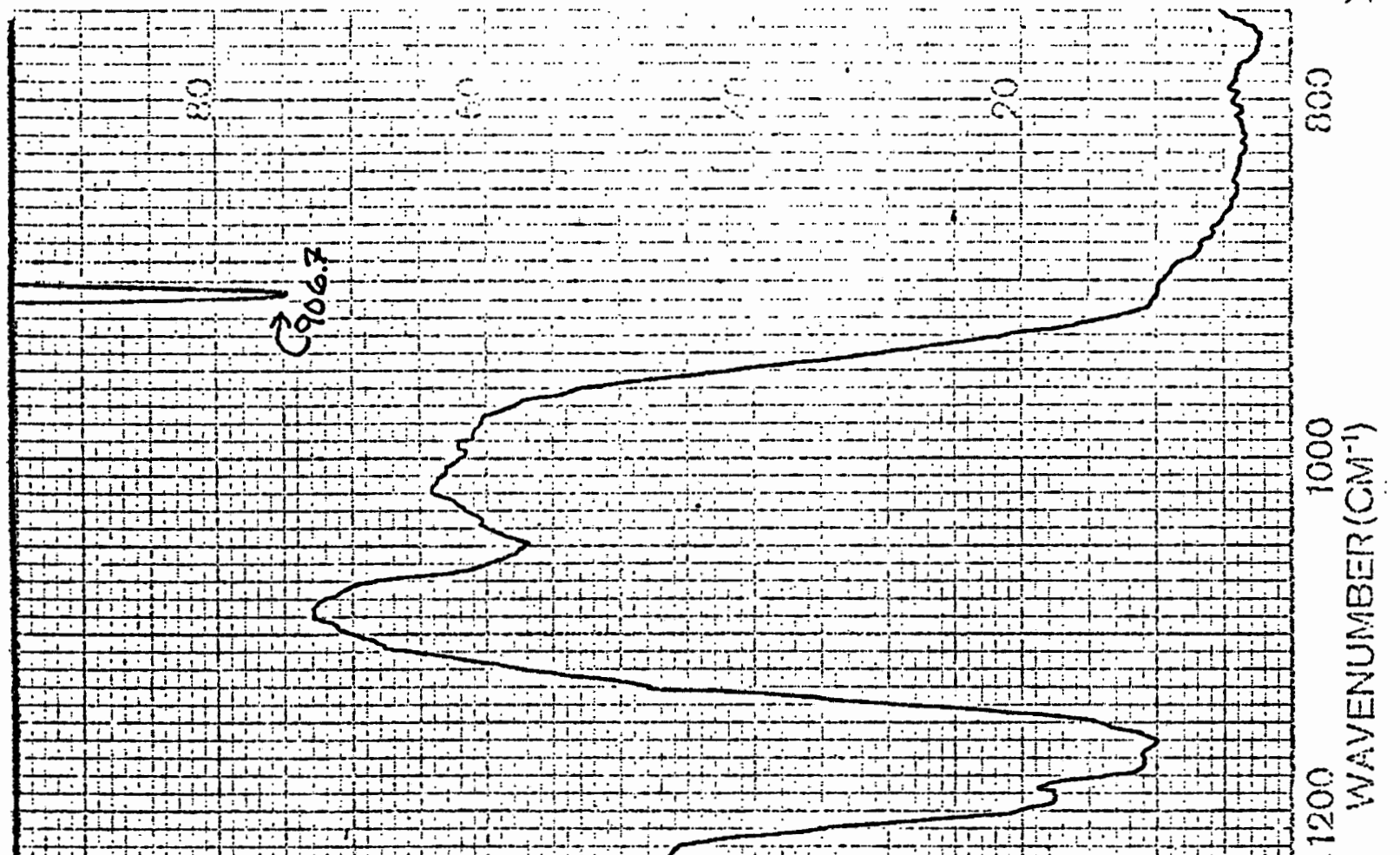

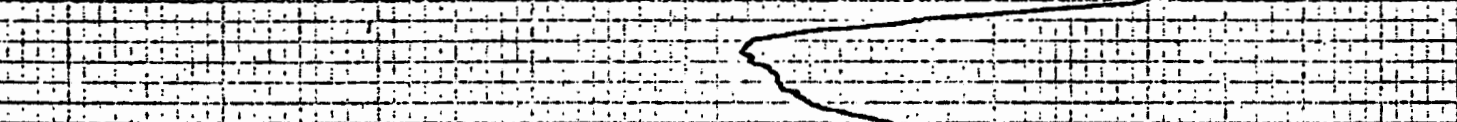

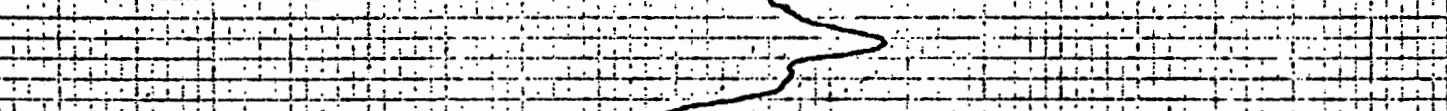

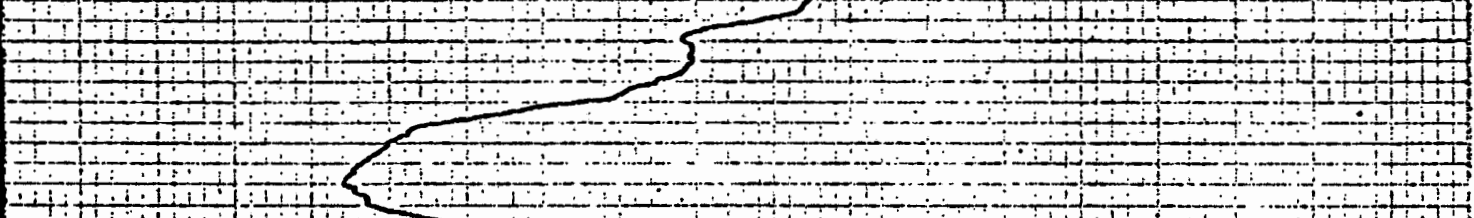

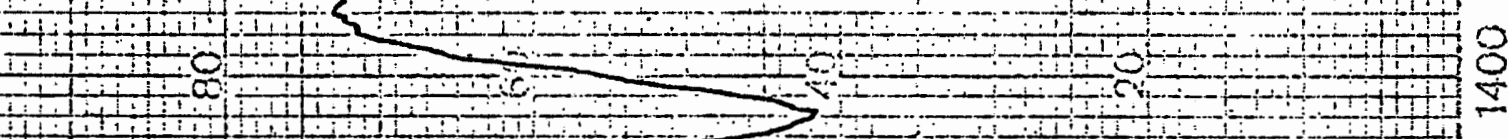

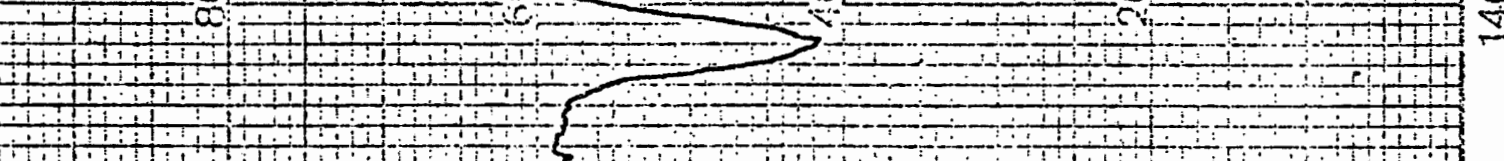
(1)

Infrared spectrum of $\mathrm{WO}_{2}\left(\left(\mathrm{O}_{2} \mathrm{C}\right)_{2}\left(\mathrm{CF}_{2}\right)_{3}\right)$, (KBr pellet). 


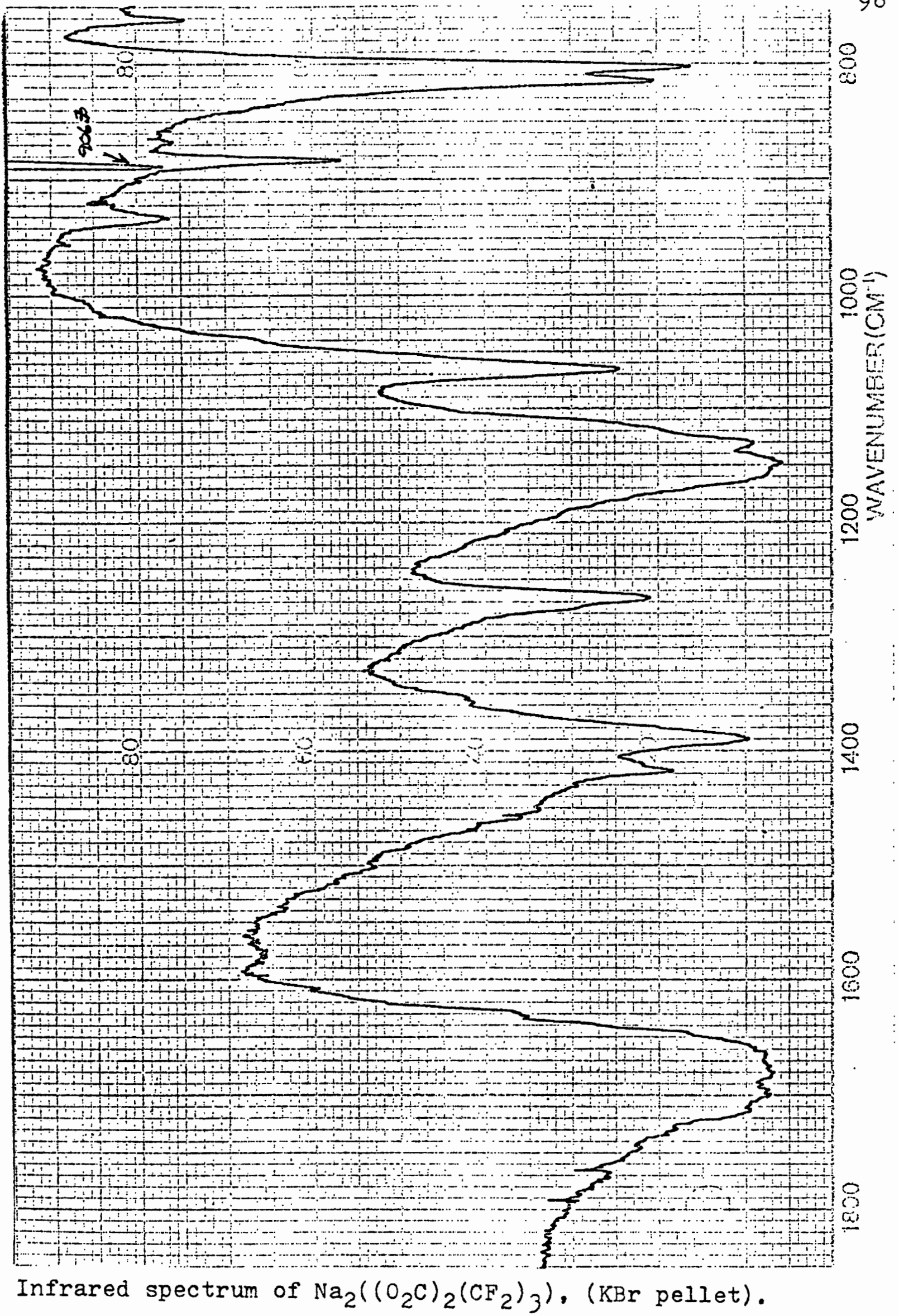




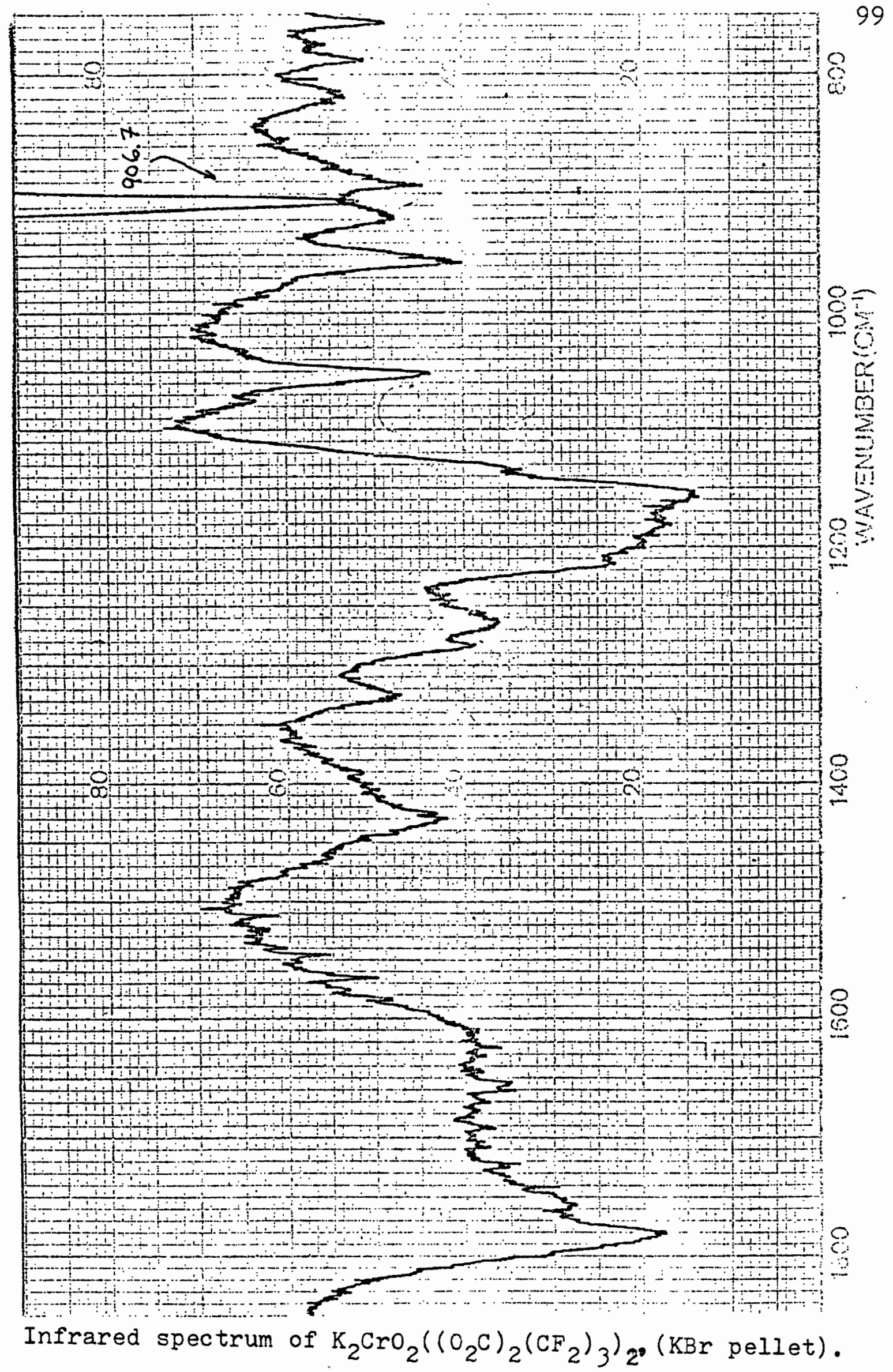




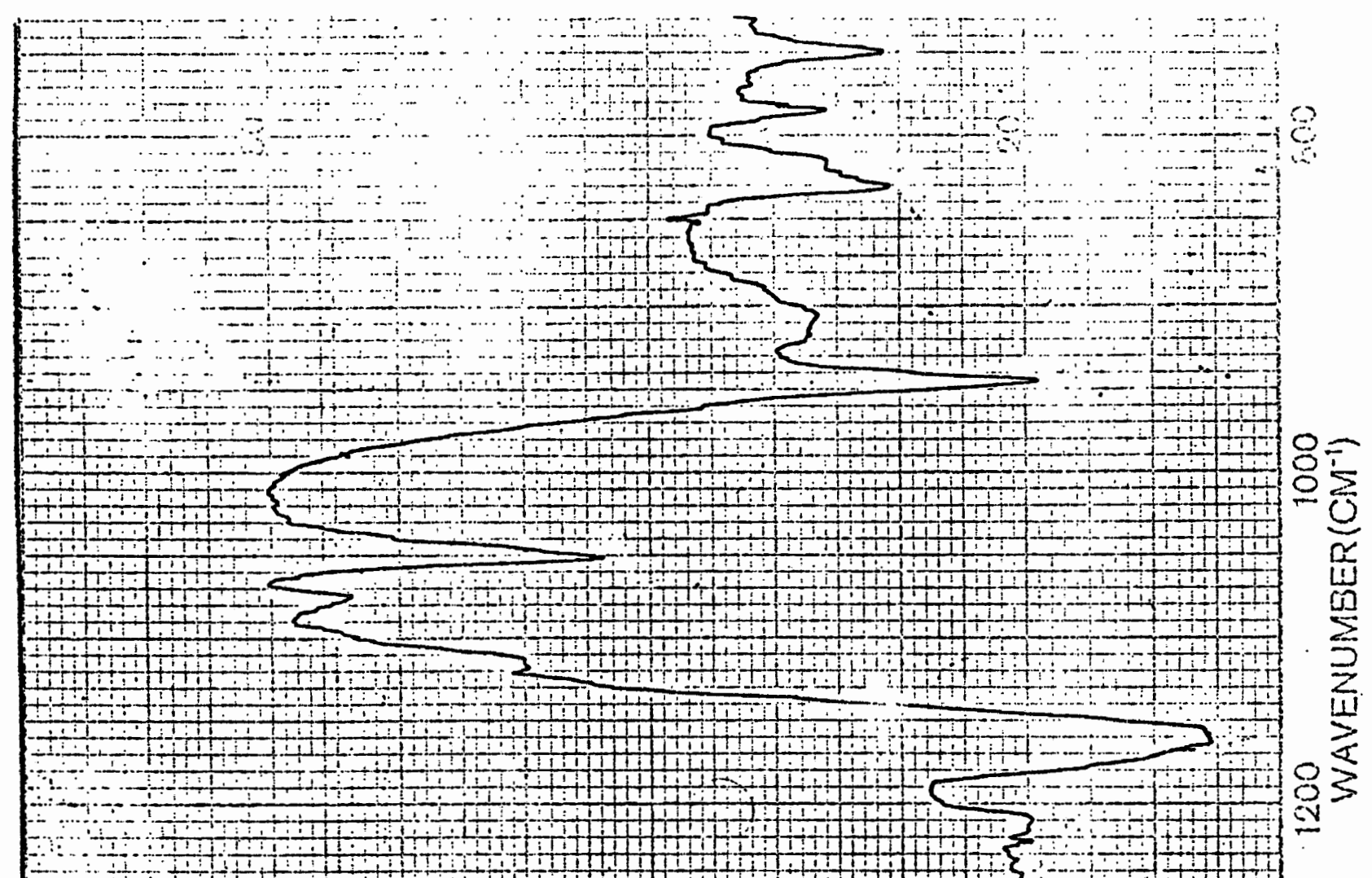

(1) (1)

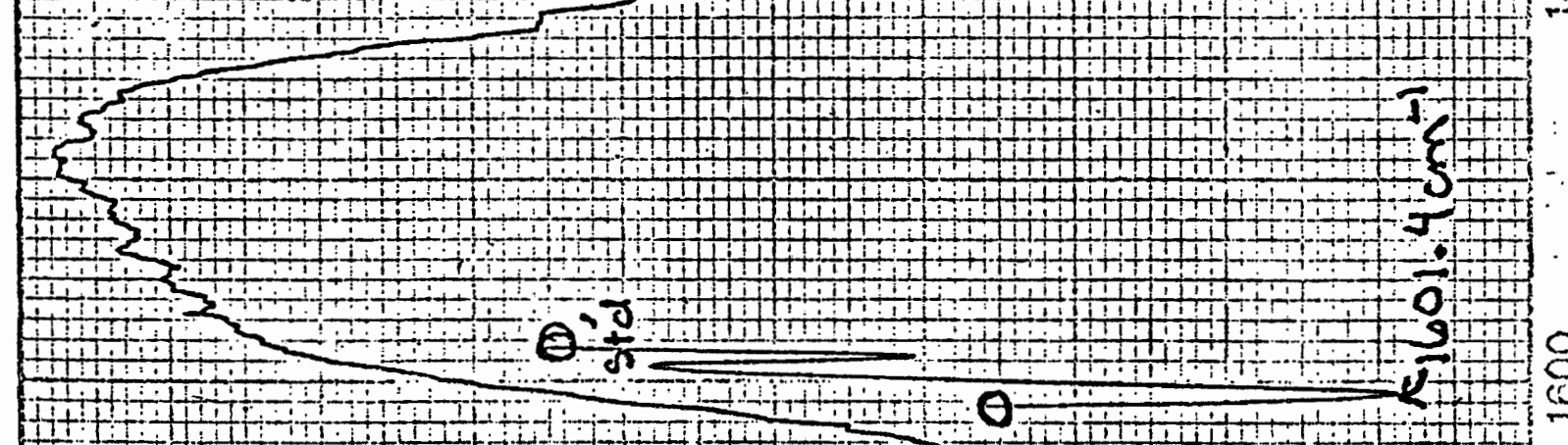

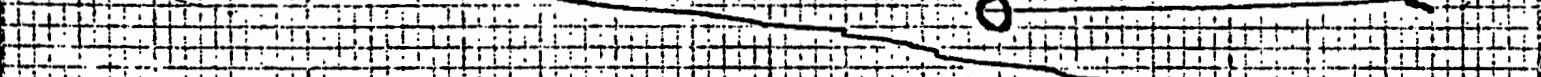

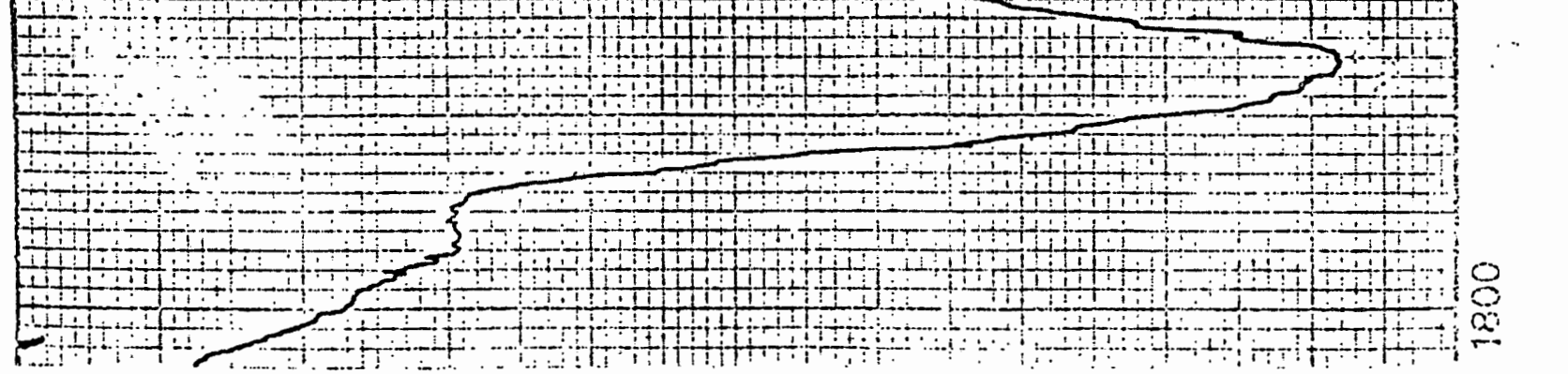

Infrared spectrum of $\left.\mathrm{Na}_{2} \mathrm{HOO}_{3}\left(\mathrm{O}_{2} \mathrm{C}\right)_{2}\left(\mathrm{CF}_{2}\right)_{3}\right)$, (KBr pellet). 


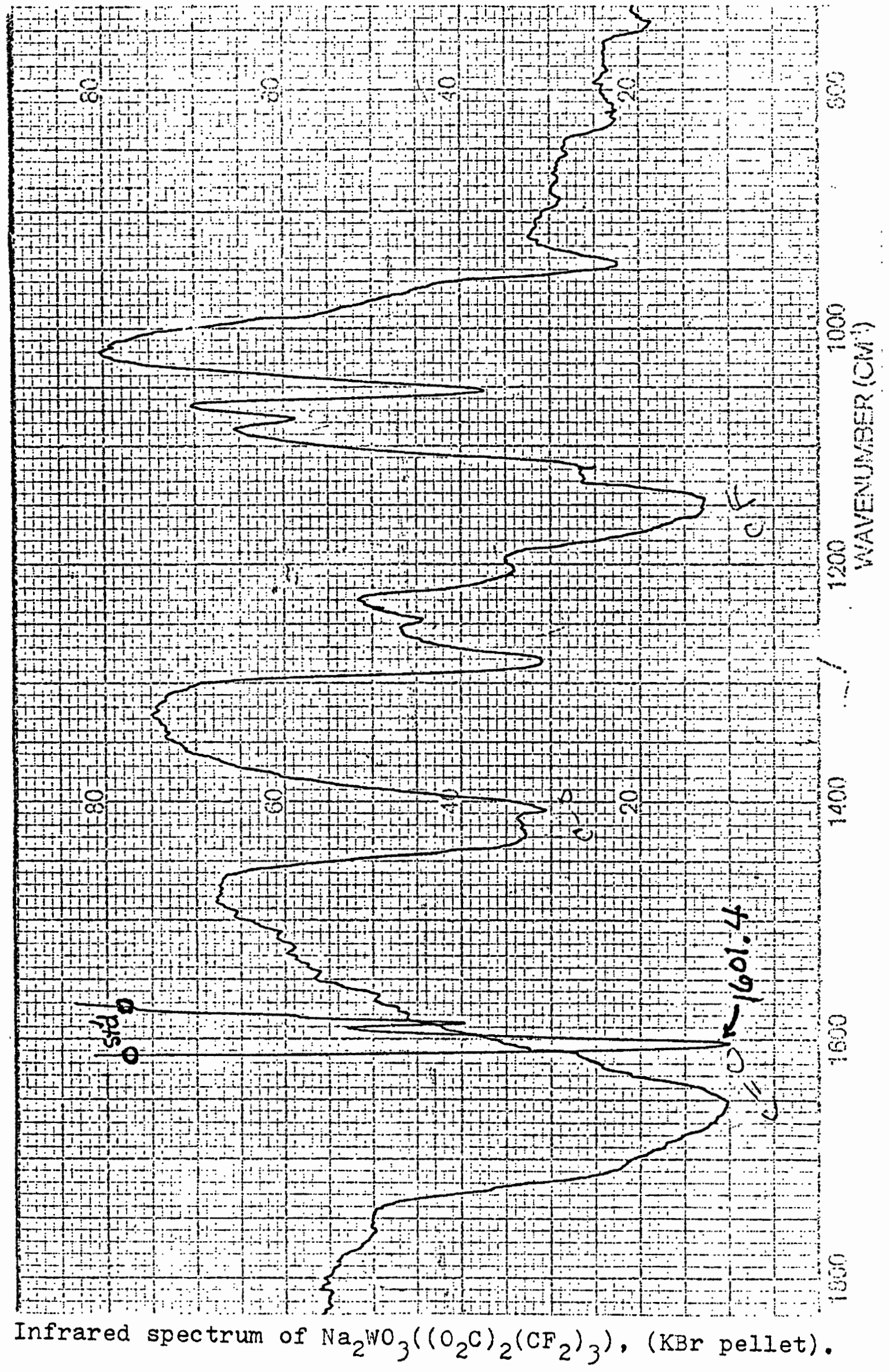




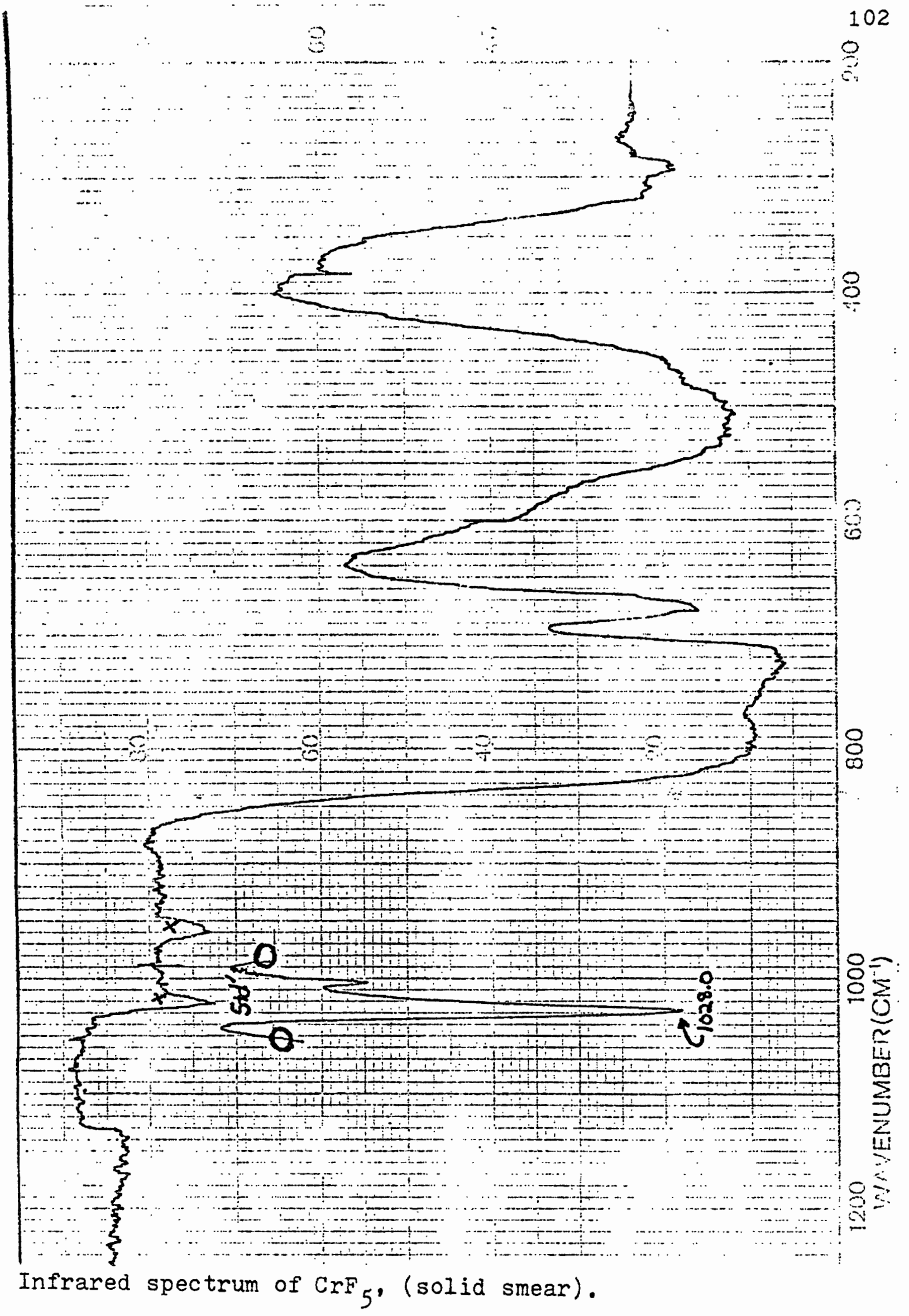




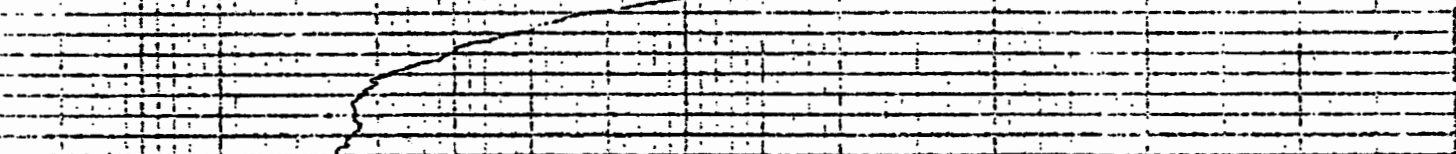

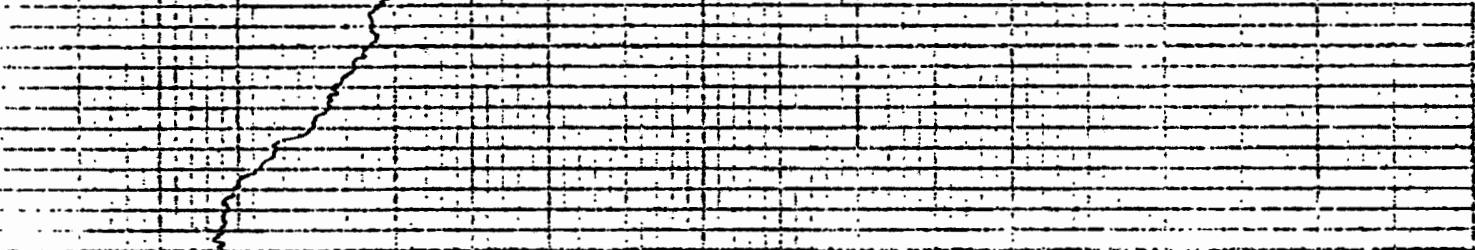
$-2 x^{3}$

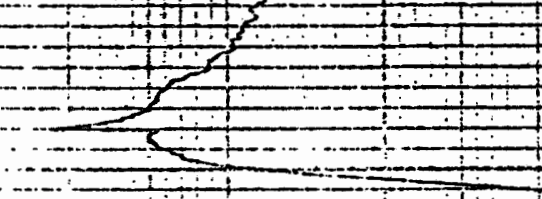




\section{$\begin{array}{llllll}0 & 0 & 0 & 0 & 0 & 0\end{array}$}

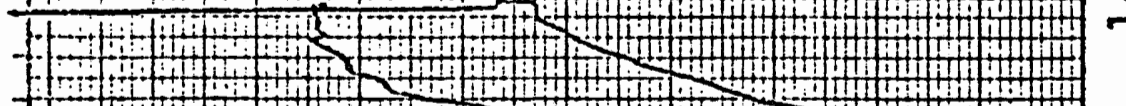

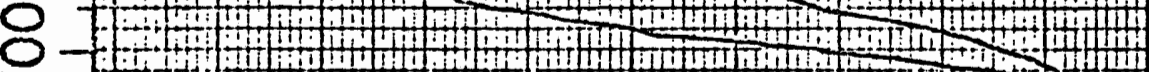

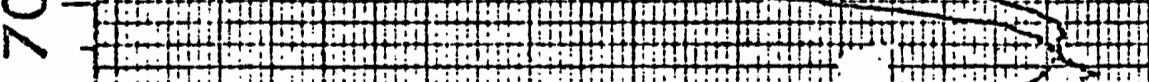

1+

fot 1

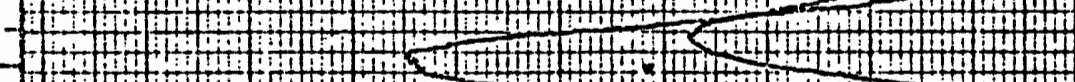

1fit

-15itflf

(4)

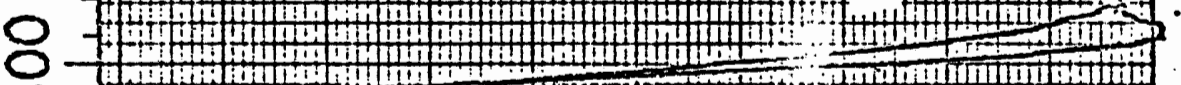

$\infty$

(f)

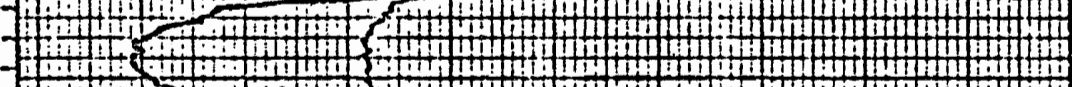

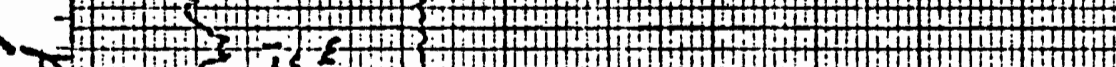

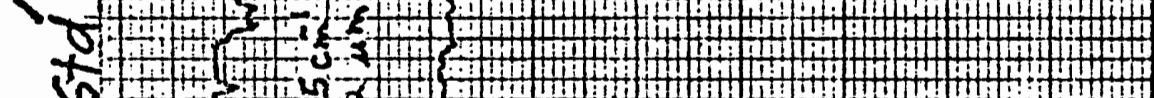

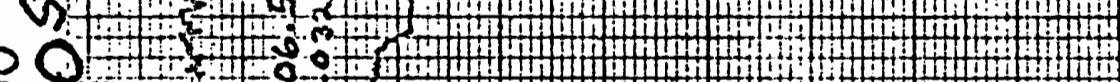

80

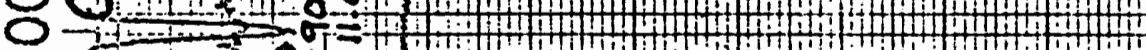
O $\mathrm{s}$. S.

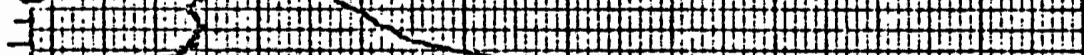

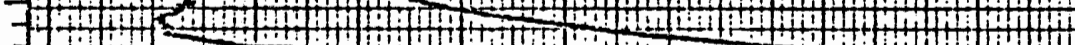

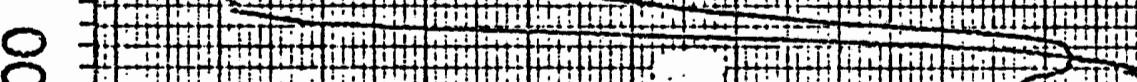

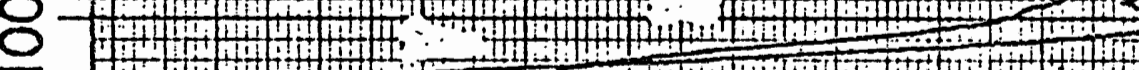

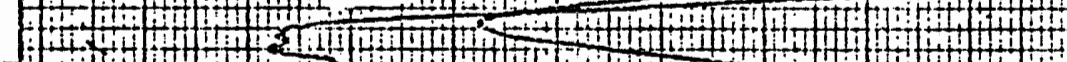
for

(1)

N

$=$

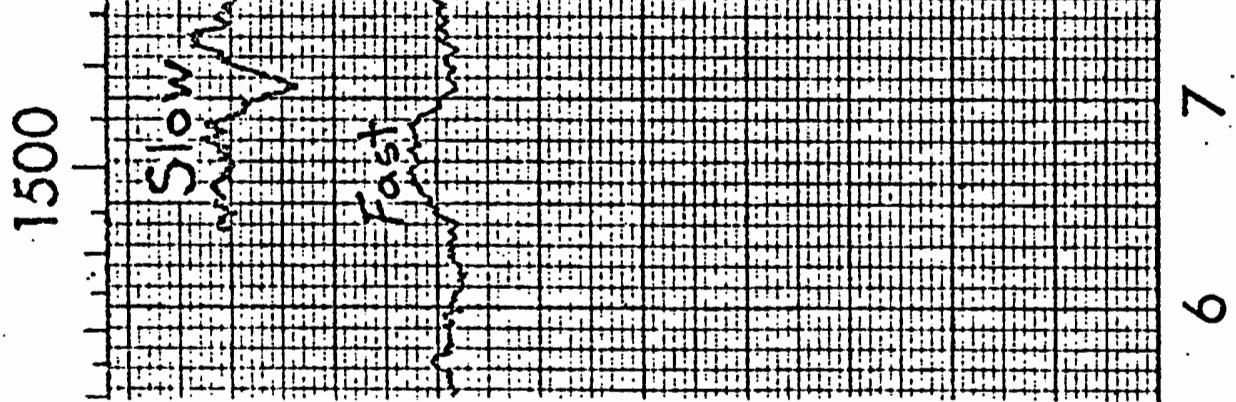

Infrared spectrum of the chromyl fluoride

fluorination products, (gas phase). 


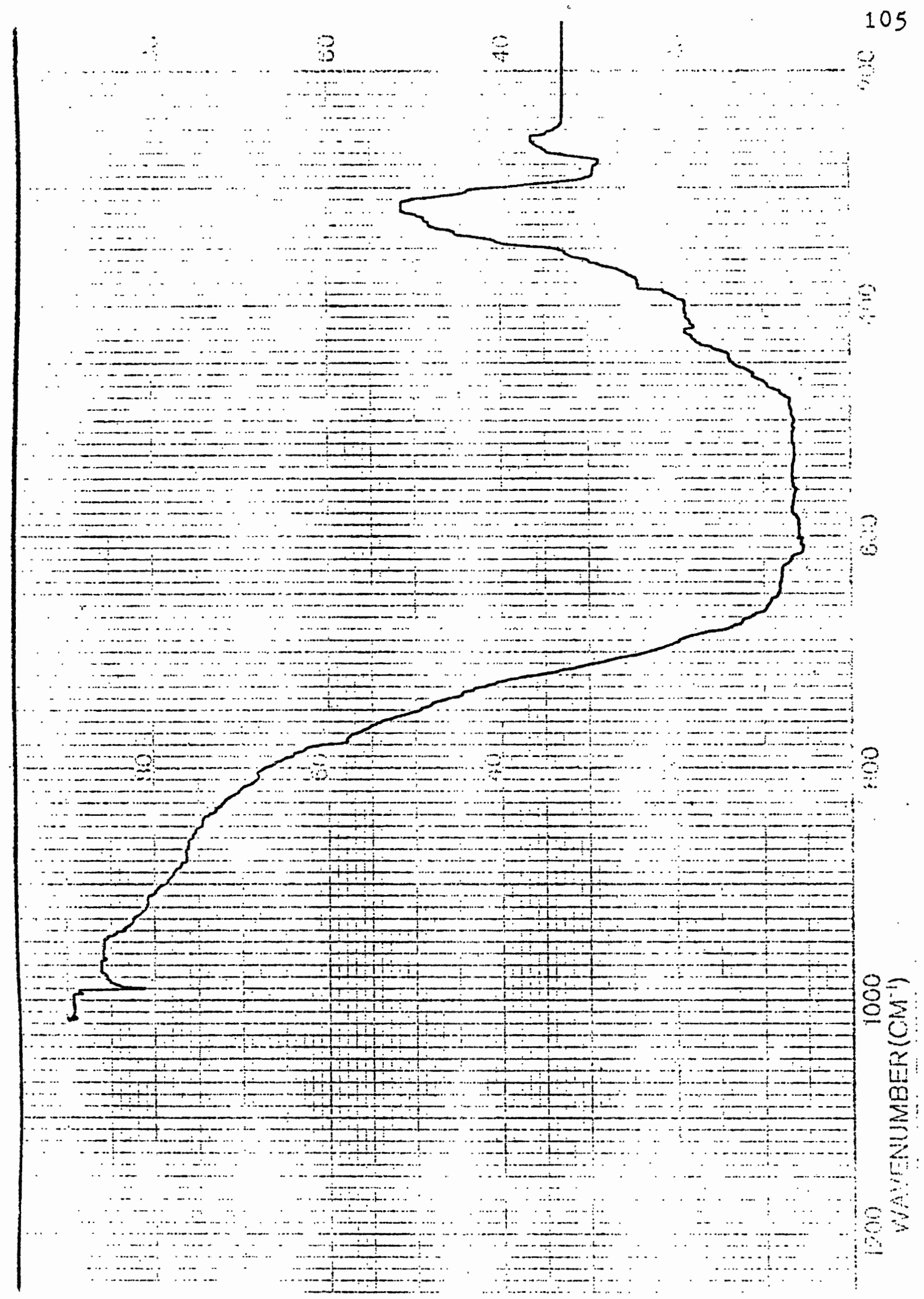

Infrared spectrum of $\mathrm{CrF}_{3}$, (KBr pellet). 


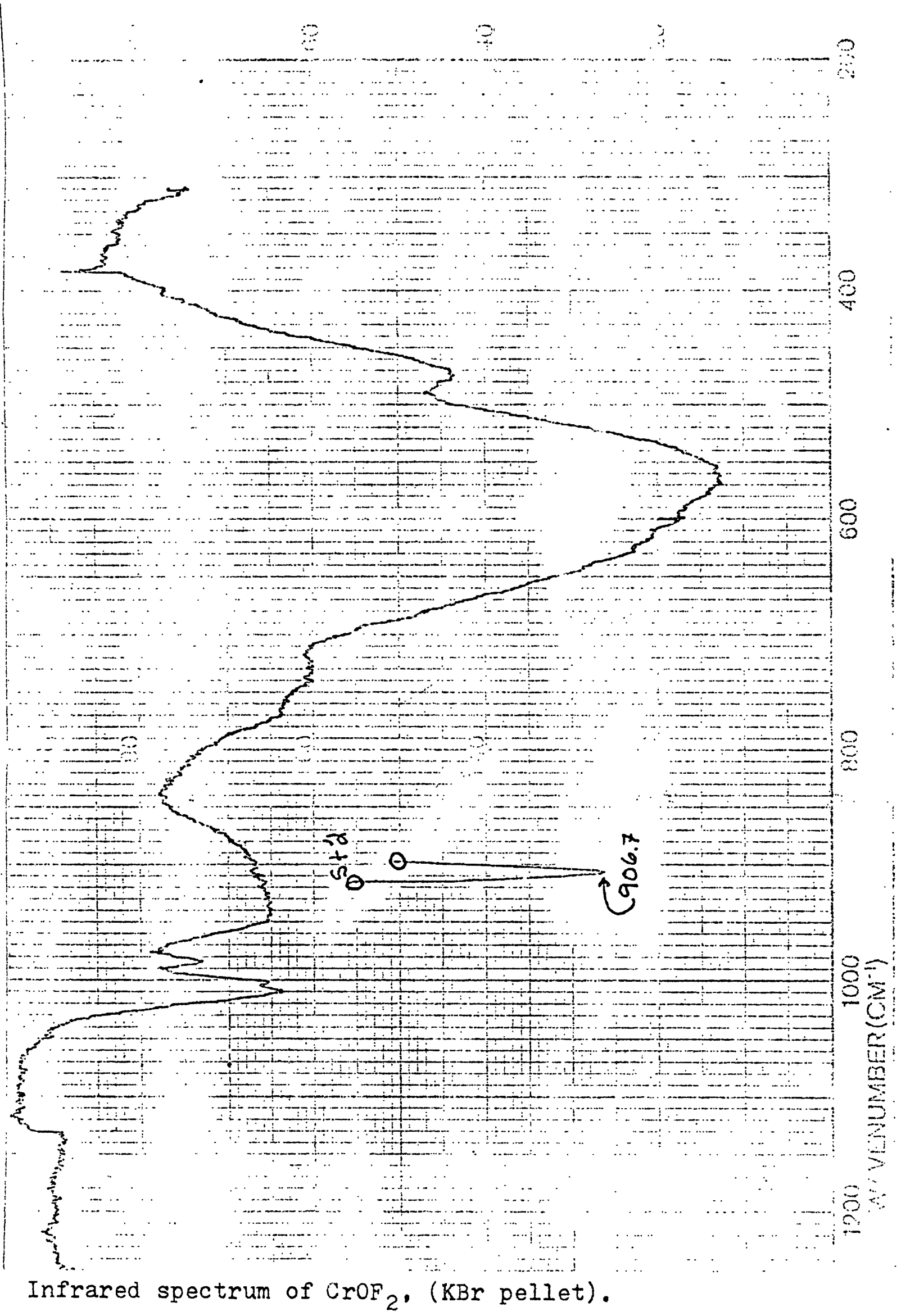




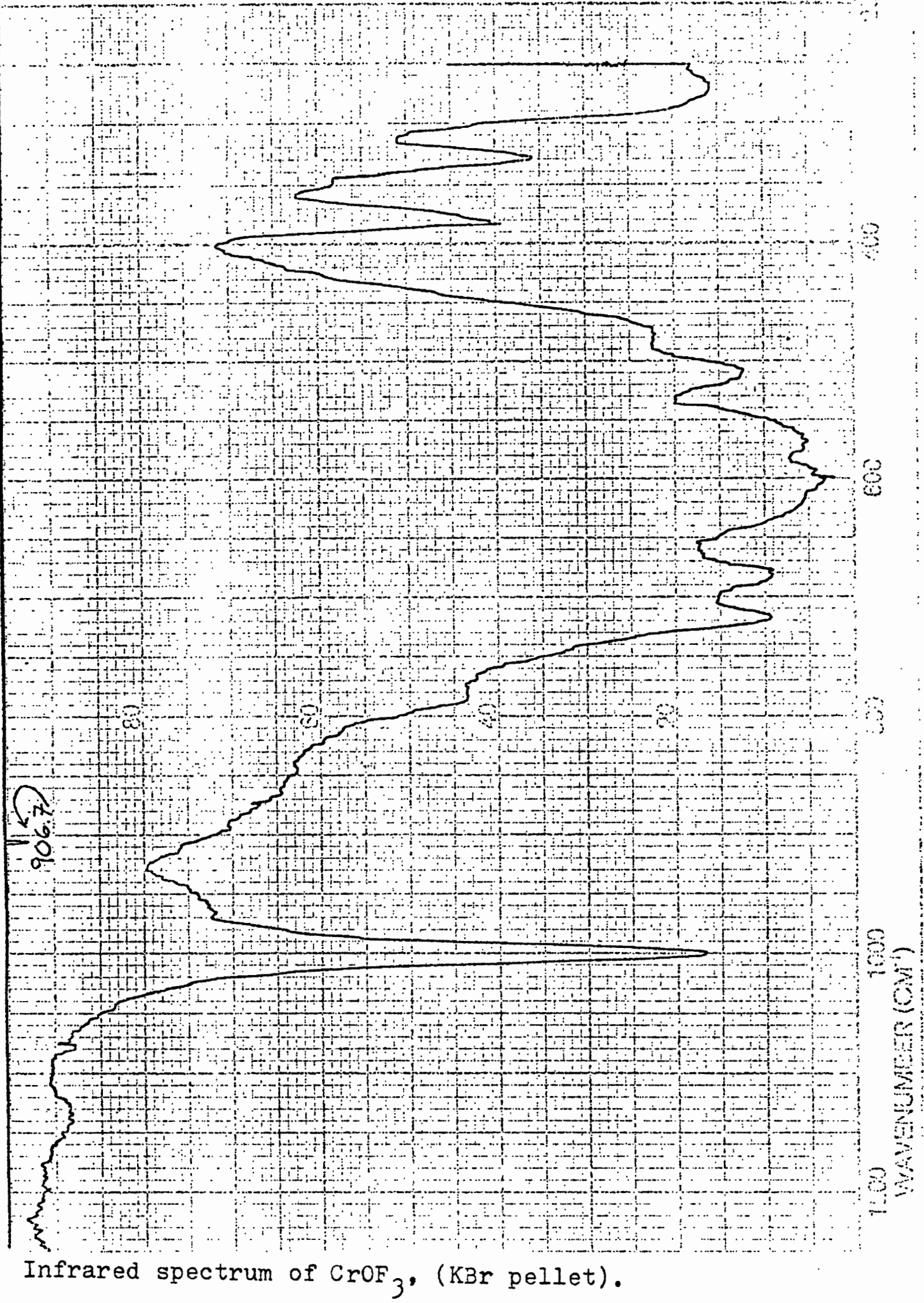




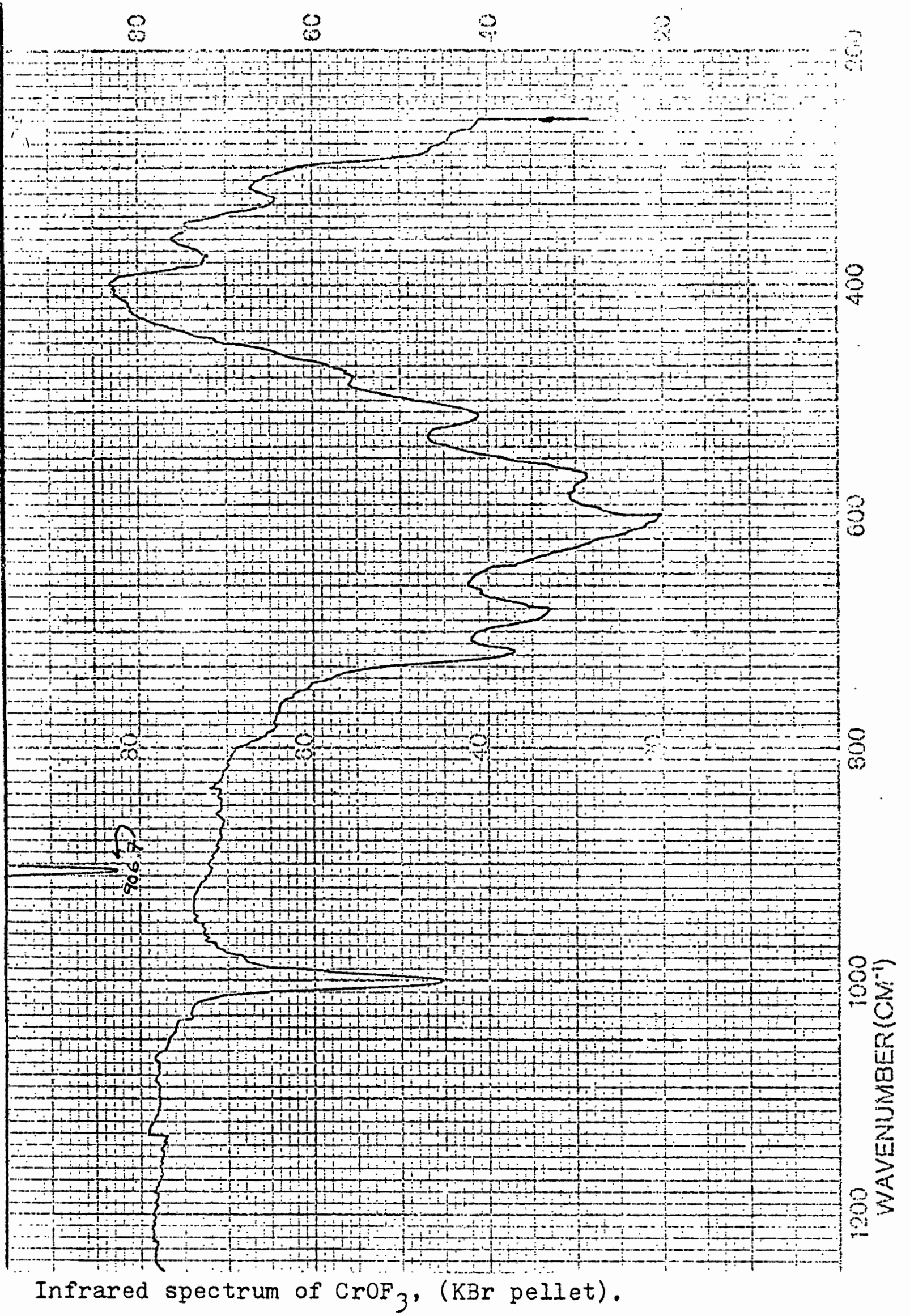




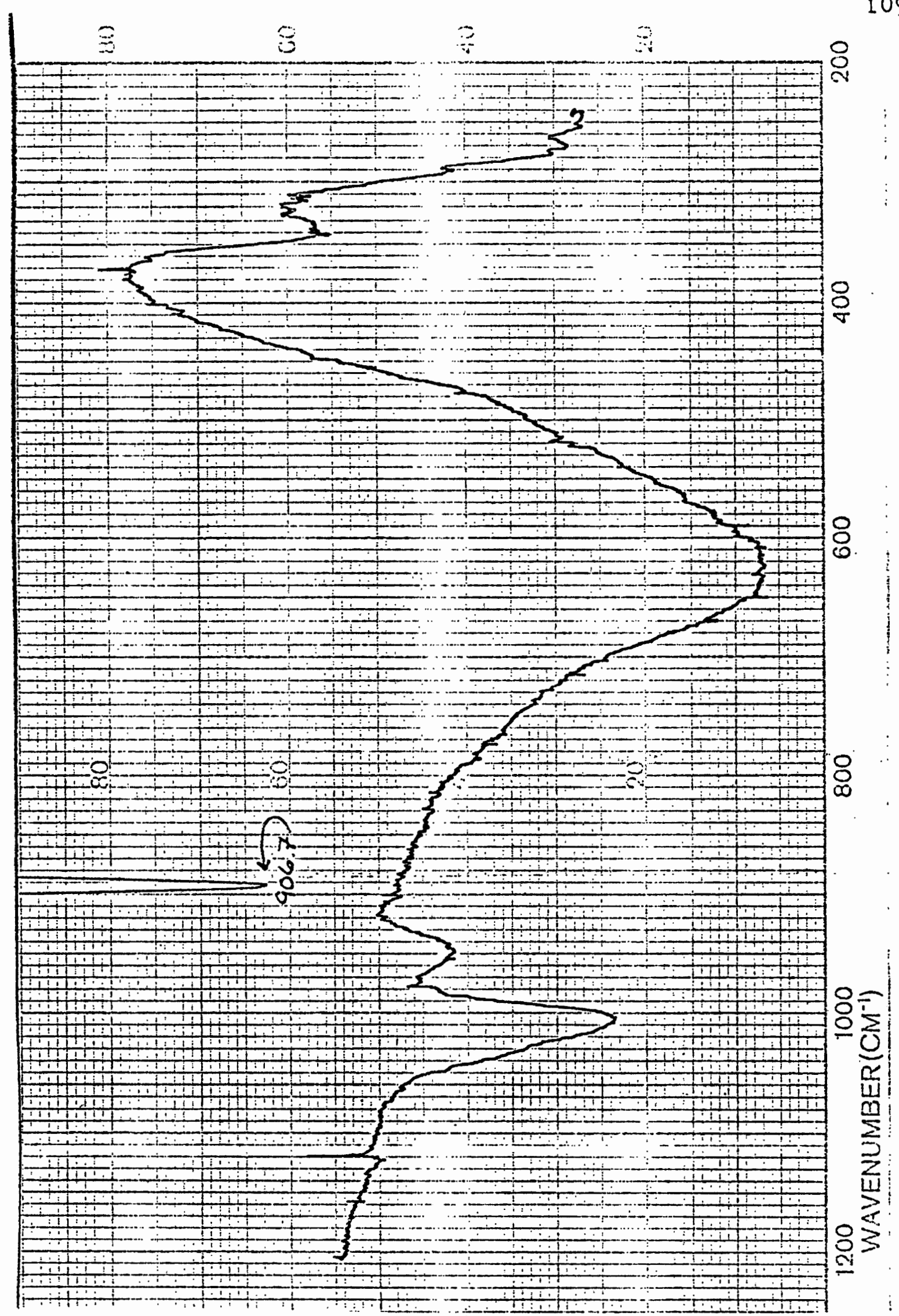

Infrared spectrum of $\mathrm{KCrOF}_{4},(\mathrm{KBr}$ pellet $)$. 


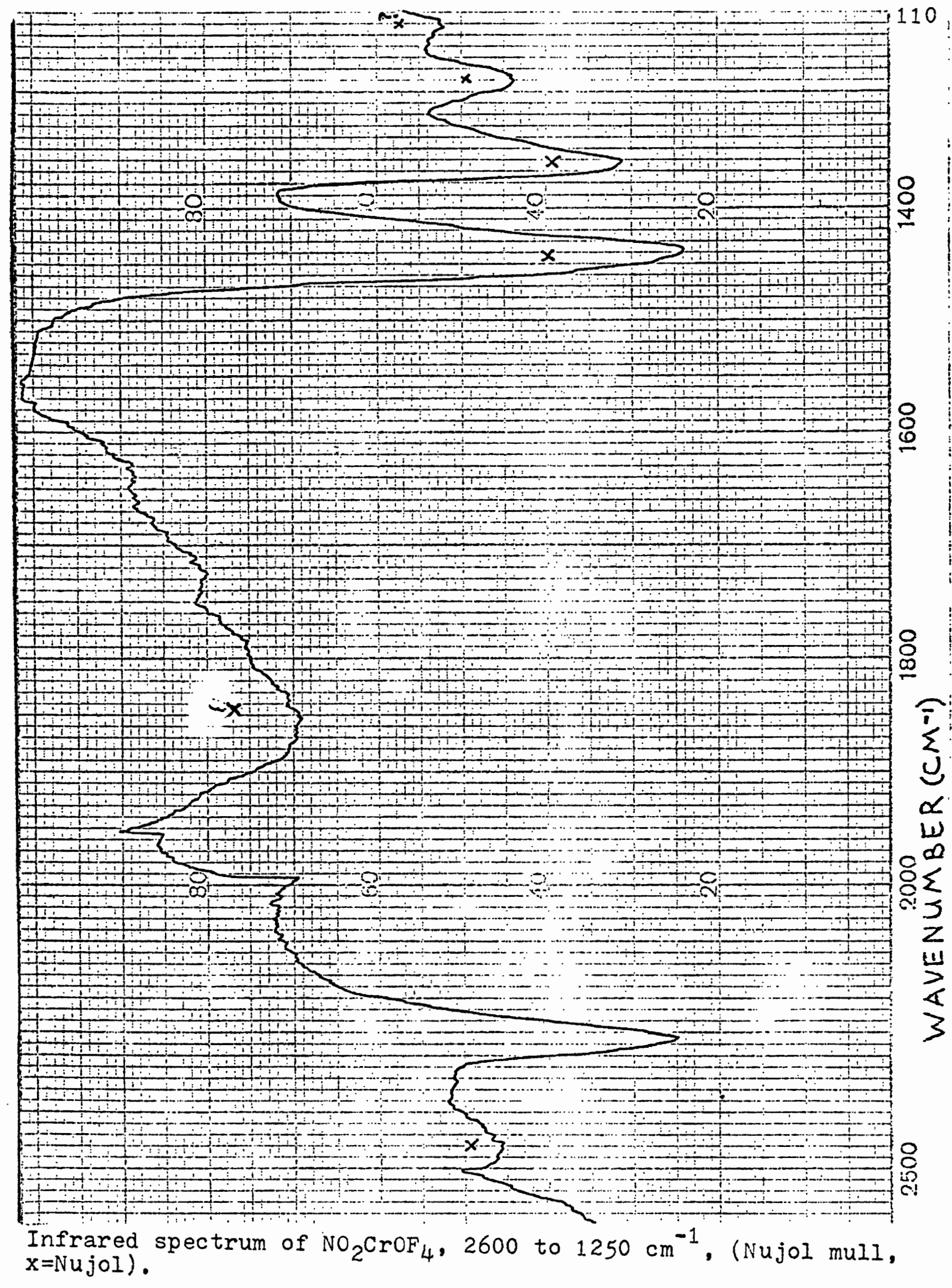




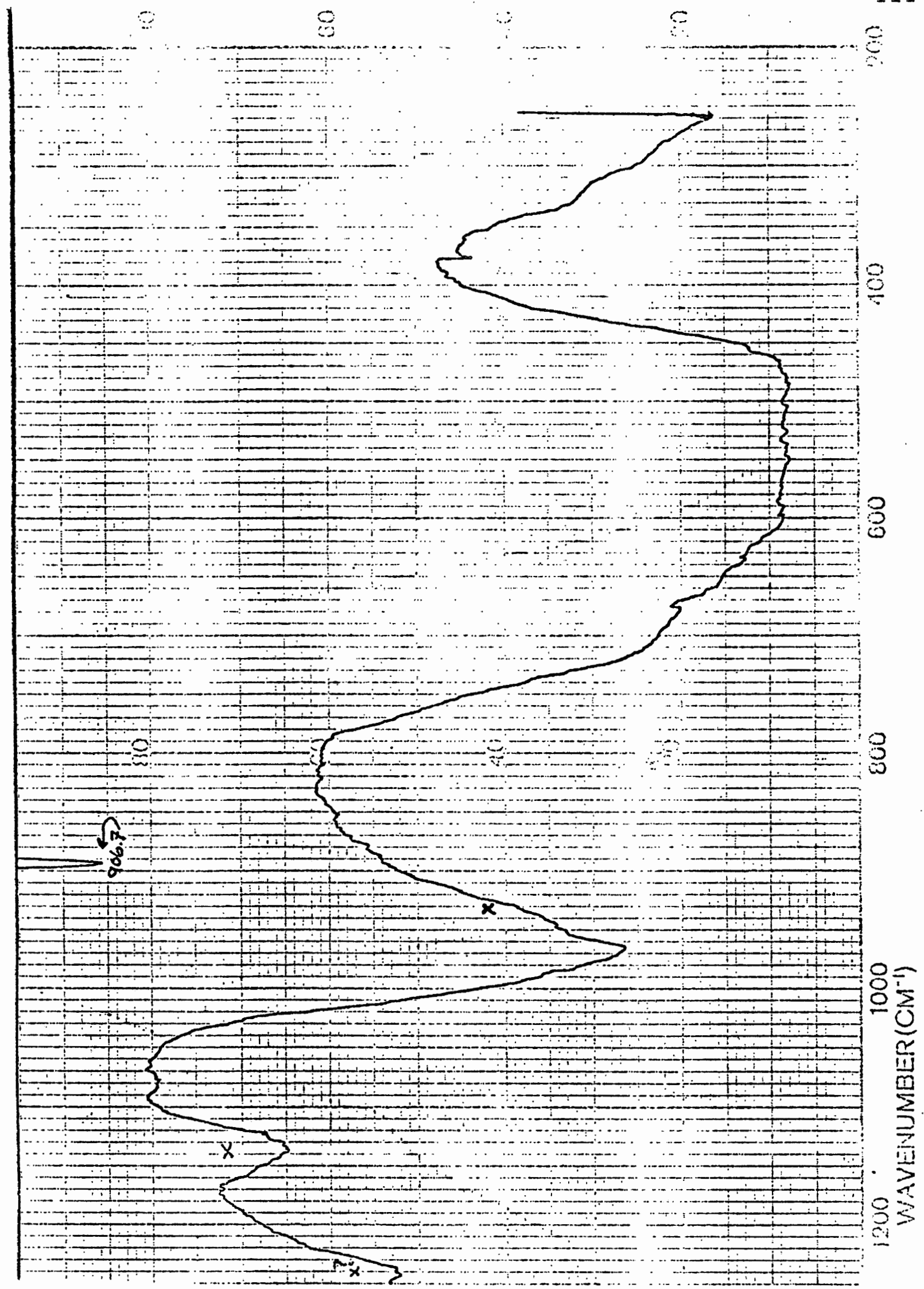

Infrared spectrum of $\mathrm{NO}_{2} \mathrm{CrOF}_{4}, 1250$ to $250 \mathrm{~cm}^{-1}$, (Nujol mull, $x=N u j 01$ ). 


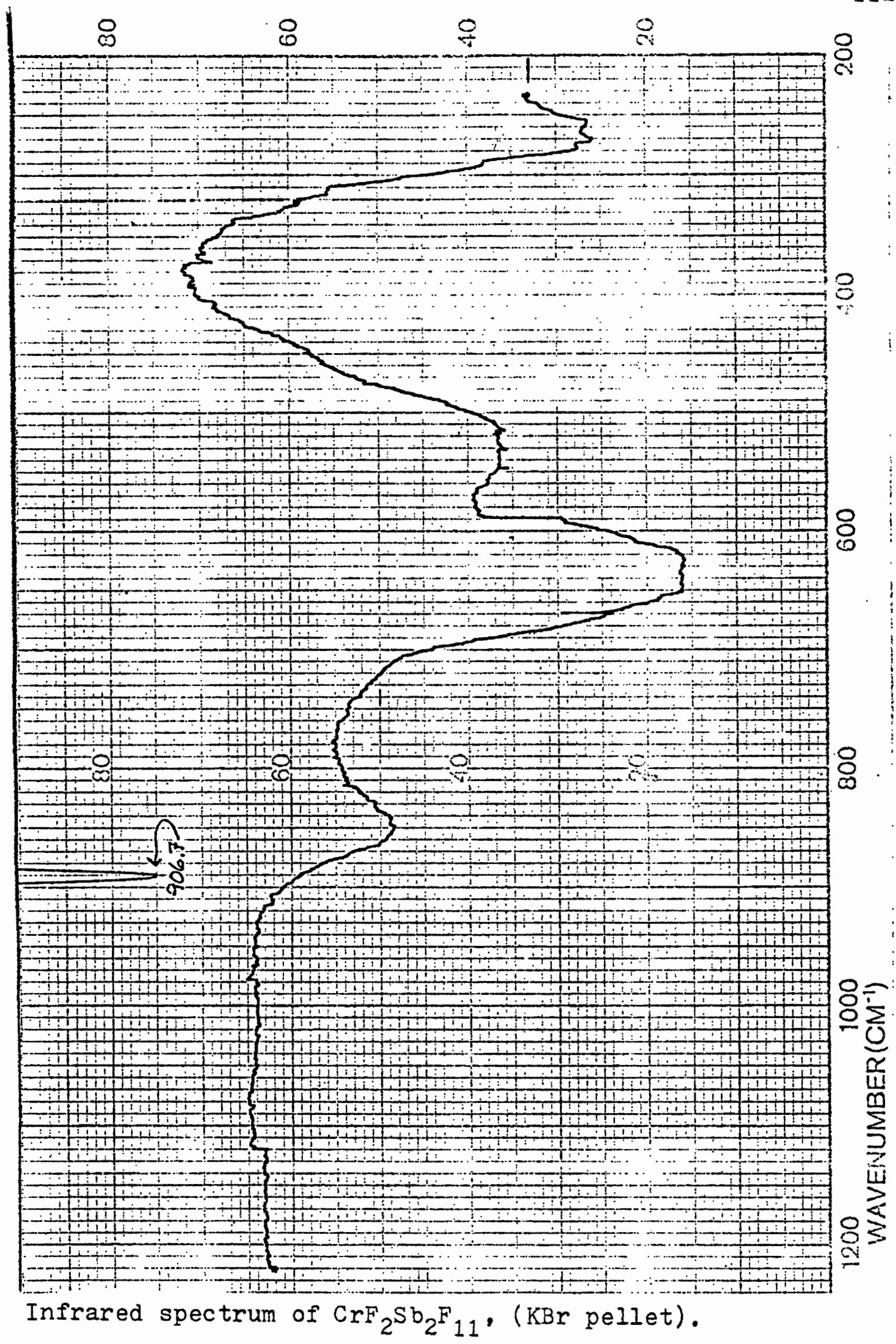

